Portland State University

PDXScholar

Spring 5-21-2013

\title{
Global Learning Outcomes of a Domestic Foreign Language Immersion Program
}

Kathleen Ann Godfrey
Portland State University

Follow this and additional works at: https://pdxscholar.library.pdx.edu/open_access_etds

Part of the First and Second Language Acquisition Commons, Higher Education Commons, and the Language and Literacy Education Commons

Let us know how access to this document benefits you.

\section{Recommended Citation}

Godfrey, Kathleen Ann, "Global Learning Outcomes of a Domestic Foreign Language Immersion Program" (2013). Dissertations and Theses. Paper 1034.

https://doi.org/10.15760/etd.1034

This Dissertation is brought to you for free and open access. It has been accepted for inclusion in Dissertations and Theses by an authorized administrator of PDXScholar. Please contact us if we can make this document more accessible: pdxscholar@pdx.edu. 
Global Learning Outcomes of a Domestic Foreign Language Immersion Program

\title{
by
}

\section{Kathleen Ann Godfrey}

A dissertation submitted in partial fulfillment of the requirements for the degree of

\section{Doctor of Education}

in

\section{Educational Leadership: Postsecondary Education}

\author{
Dissertation Committee: \\ Janine M. Allen, Chair \\ Christine Chaille \\ Emily de la Cruz \\ Sandra Freels \\ Martha Hickey
}

Portland State University

2013 
(C) 2013 Kathleen Ann Godfrey 


\begin{abstract}
There is a critical need for college students to receive an education that fosters global learning in preparation for life in an increasingly interdependent and interconnected world. Universities recognize this need and endeavor to provide a range of programs that target global knowledge and skills, and meet the needs of traditional and non-traditional students. Domestic foreign language immersion programs can contribute to student global learning and development by providing students with an opportunity to participate in a rich global learning experience in the U.S. While some researchers have investigated impacts of domestic foreign language immersion on language proficiency, few studies of other kinds of global learning outcomes are available, and research is needed to gain an understanding of program impacts and make improvements.

The purpose of this study was to determine the extent to which participation in a domestic foreign language immersion program was perceived to influence global learning and development. The study used a mixed-methods design that incorporated as a key instrument a retrospective survey of former participants in a university-level domestic foreign language immersion program. Perspectives from short-term study abroad, foreign languages, transformative learning, and global citizenship informed the research.
\end{abstract}

The study found that participants in a domestic foreign language immersion program perceived influence in all three domains of global development. The degree of perceived influence was similar in the three domains except in the area of social 
responsibility, which received a significantly lower rating. Finally, student

characteristics, including age, language level, prior international or other intercultural experience, and on/off-campus residence were not associated with perceived program influence. A qualitative analysis helped explain these findings. 


\section{Acknowledgments}

I would like to thank the following people for their support along this educational path. First of all, I would like to thank the members of my committee. My sincere gratitude goes to my adviser, Dr. Janine Allen, for her helpful suggestions and guidance during the dissertation writing process. I would also like to express my appreciation to Dr. Christine Chaille, Dr. Emily de la Cruz, and Dr. Martha Hickey for inspiring me, helping me expand my ideas about the world, and giving me exhaustive feedback on my topic. I want to especially thank Dr. Sandra Freels for her encouragement to pursue this educational journey many years ago and for her valuable suggestions regarding foreign language perspectives on my topic.

I also want to thank the cohort study group, my cohort, and Patricia Branstad, for sharing their viewpoints with me on my topic, and also for their helpful feedback and unwavering encouragement during the dissertation development process as I struggled to find my voice.

My greatest appreciation goes to my husband, Rudolf Godfrey, for his patience and ability to keep me on an even keel during this endeavor, and also for his complete confidence in me and understanding of the importance of achieving this dream.

Without all of you, this dissertation would not have been possible. My deep appreciation to you all! 


\section{Table of Contents}

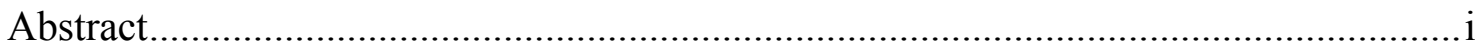

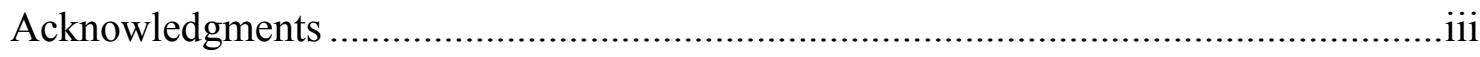

List of Tables ..................................................................................................... vii

List of Figures..................................................................................................

CHAPTER ONE: INTRODUCTION ….......................................................... 1

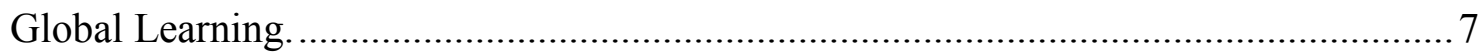

The Role of Foreign Language Departments. ................................................... 8

Domestic Foreign Language Immersion .......................................................... 10

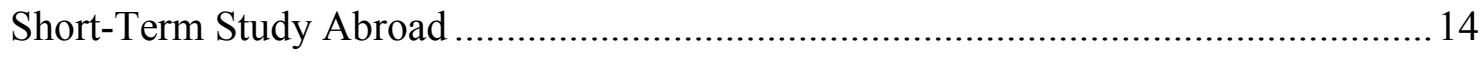

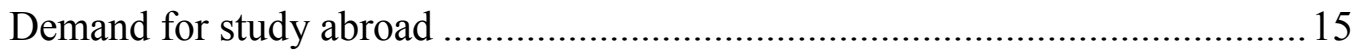

Types of short-term study abroad programs .............................................. 16

Features of study abroad programs......................................................... 17

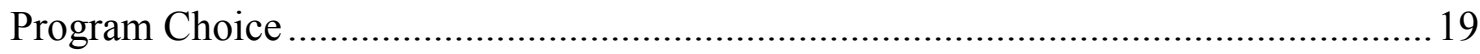

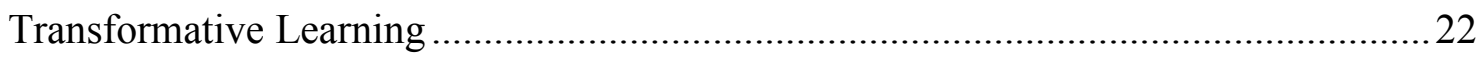

Conceptual Framework and Research Questions ............................................ 28

The theory of global learning and development .........................................29

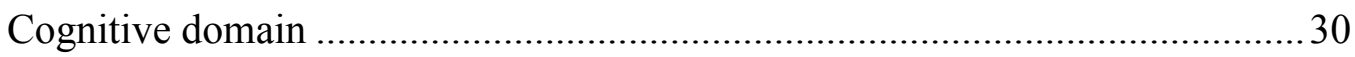

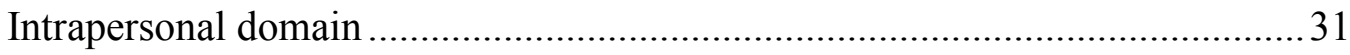

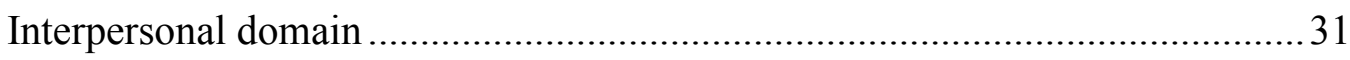

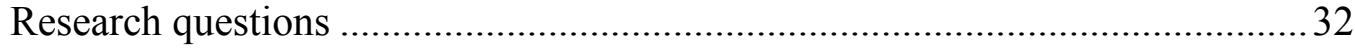

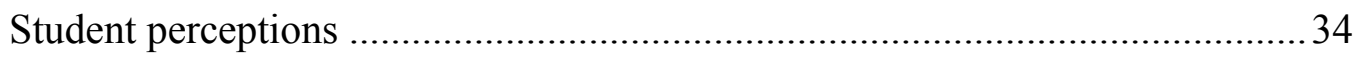




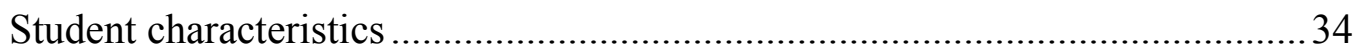

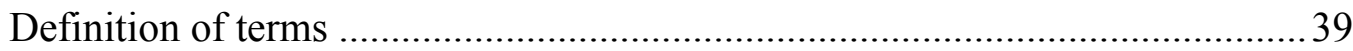

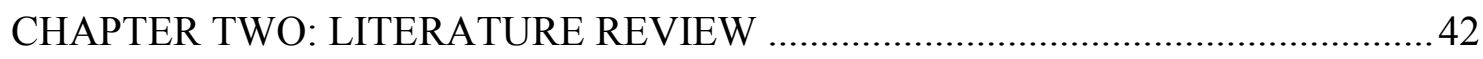

Transformative Learning in the Language Classroom ....................................................4 43

Domestic Foreign Language Immersion and Short-Term Study Abroad ......................49

Studies related to cognitive development......................................................... 49

Studies related to intrapersonal and interpersonal development ..........................58

Other Research Related to Global Learning.................................................................64

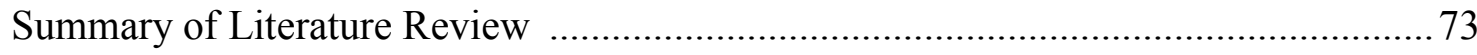

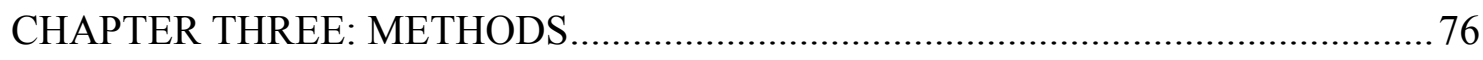

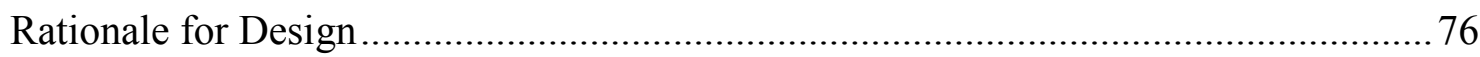

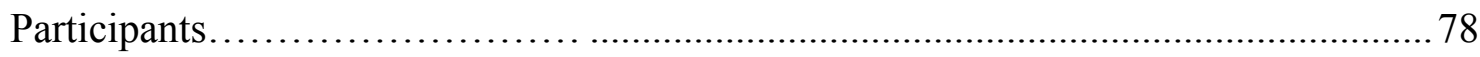

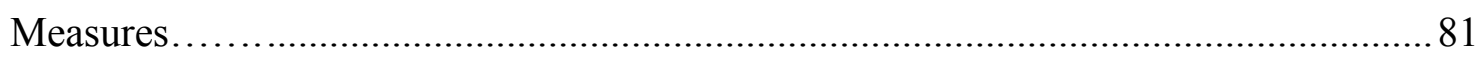

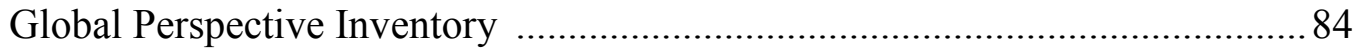

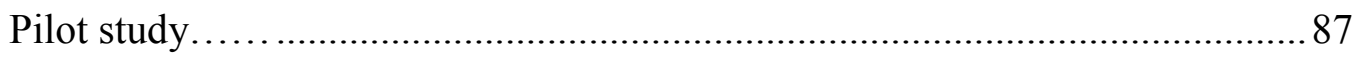

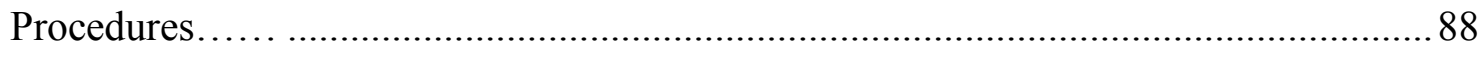

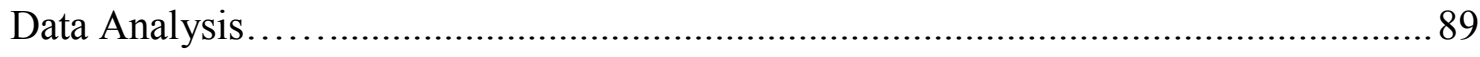

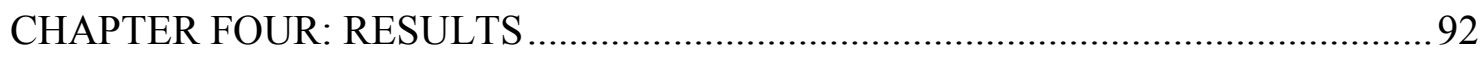

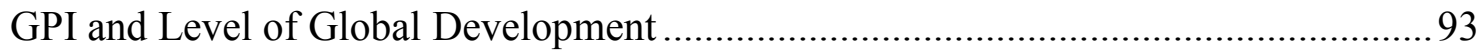

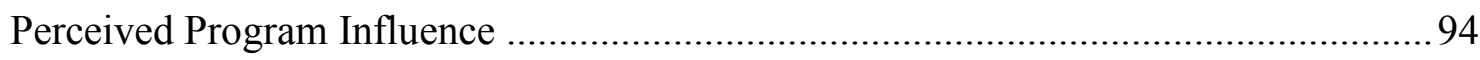

Program Influence Across Global Development Domains ………………………........ 95

Student Characteristics and Extent of Program Influence.............................................. 96 


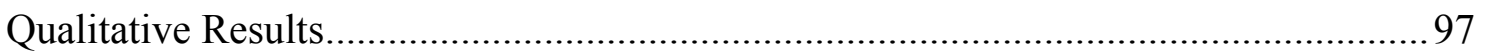

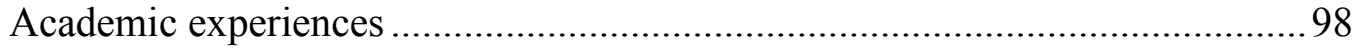

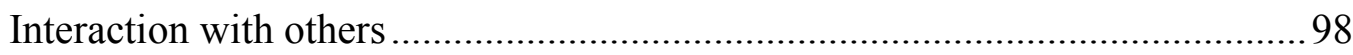

Shared activities outside of class ......................................................................99

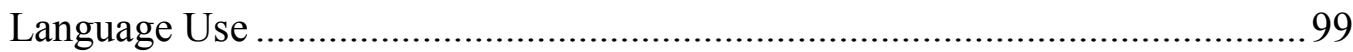

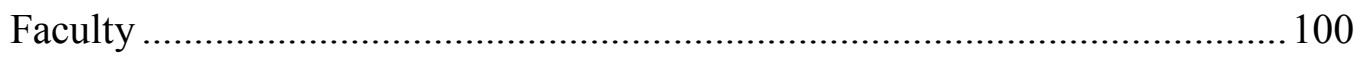

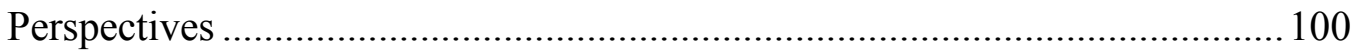

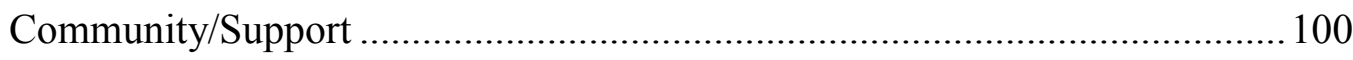

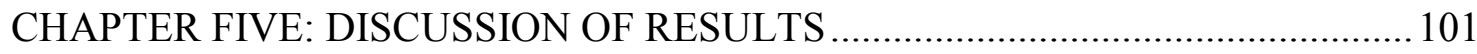

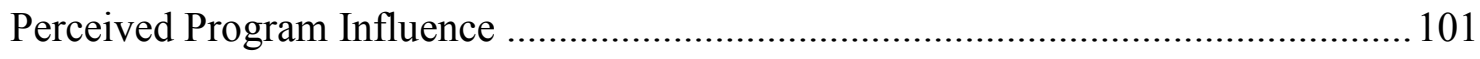

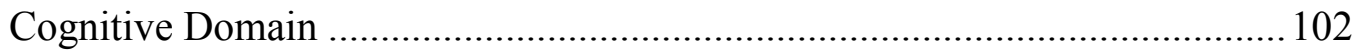

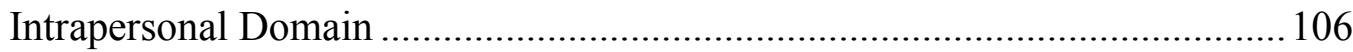

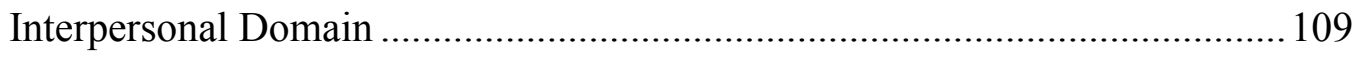

Program Influence Across Global Development Domains ..........................................110

Student Characteristics and Extent of Program Influence.......................................... 115

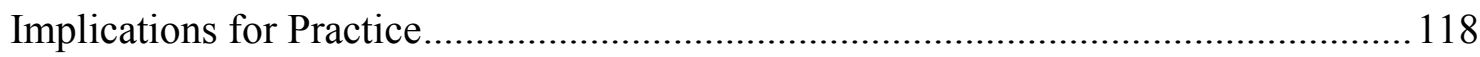

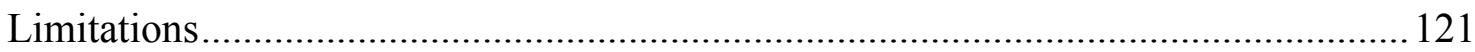

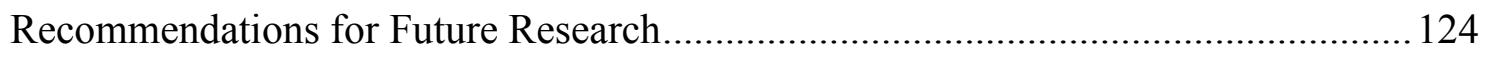

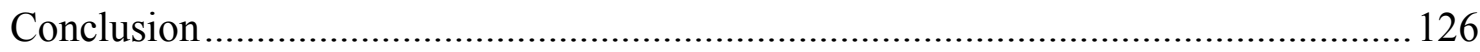

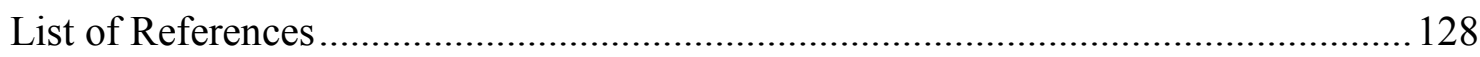

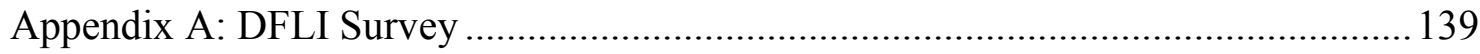

Appendix B: Advance Email, Email Invitation, Follow-up Reminder ......................... 155 


\section{List of Tables}

Table 1: Comparison of Short-Term Study Abroad and Foreign Language Domestic

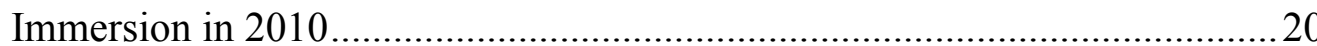

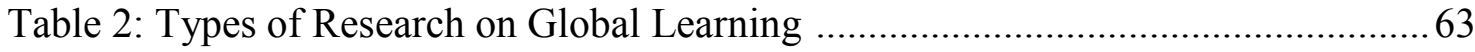

Table 3: Comparison of Global Citizenship and Global Learning and Development ...65

Table 4: Characteristics of Survey Participants Relative to all Program Participants

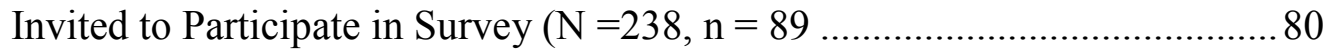

Table 5: Means and Standard Deviation of Influence of Participation in DFLI on

Global Development on the Six GPI Scales; Post Hoc Analyses of One-Way

Within-Subjects ANOVAs of the Six GPI Scales ..................................... 94

Table 6: Summary of Multiple Regression Analyses of the Relationship Between

Student Characteristics and Scores on the Six GPI Scales ..........................96

Table 7: Themes From Qualitative Data and Frequency of Occurrences ...................98

Table 8: Program Features, Participant Values, and Global Development .................112 


\section{List of Figures}

Figure 1. Overlap of three domains of global development (Braskamp et al., 2009) ...32

Figure 2. Input-Environment-Outcome Model (Astin, 1993) .......................................35 


\section{Chapter One}

\section{Introduction}

There is a critical need for college students to understand global issues and learn skills that will enable them to lead successful and useful lives in today's world. Not only do students need an education that will help them achieve personal success; they must also be able to recognize the effects of their own choices to be able to act with the best interests of the environment and other human beings in mind. The world is evolving, becoming more interconnected and interdependent, and the need for graduates who can respond to these changes in an informed way is more urgent than ever. Recent global developments are both rapid and far-reaching, and are transforming modern life for all. Concretely, these global developments include

1. technological advances that have facilitated communication worldwide and revolutionized trade, such as the advent of the internet, or wide-scale use of containerization in shipping (Postrel, NY Times, 2006);

2. the increasing role of supranational organizations that have removed impediments to trade between countries and dismantled national borders, such as the World Trade Organization or the European Community (Steger, 2009);

3. the growth of enormous transnational corporations that have the power and wealth to influence domestic and foreign policy in many countries (Bhanji, 2008); and 
4. shifts in global migration from less developed to more developed countries (United Nations Department of Economic and Social Affairs/Population Division, 2004) for economic or other reasons.

These developments have helped spread American and other types of Western influences to other countries, but have also made perspectives of other countries more prevalent in the U.S. In general, borders between countries have become more permeable than ever before as exchanges of cultural viewpoints, and new as well as old technologies in the broadest sense have swelled. Steger (2005) characterizes these recent global developments as "a multidimensional set of social processes that create, multiply, stretch, and intensify worldwide social interdependencies and exchanges while at the same time fostering in people a growing awareness of deepening connections between the local and the distant" (p.13). As Smallman and Brown (2010) point out, this characterization of global developments not only encompasses processes at the state level but also emphasizes processes that affect the individual in terms of identity or culture. It is virtually impossible today to ignore these processes, whether they result in more multiculturality in our neighborhoods, increase international investments, goods and services, or raise awareness of the world beyond our national borders. Giddens (1991) describes globalization as a force that homogenizes the world by bringing together people, objects, and ideas, and at the same time heterogenizes the world by making differences in the world more visible in our own localities and abroad. This seemingly contradictory characterization of the 
effects of globalization only underscores the breadth of this phenomenon and the need for a globally responsive education.

At the same time as many global developments lead to improvements in people's lives, there are any number of pressing global issues that give rise for concern. A brief glance at a newspaper virtually any day of the week is sufficient to recognize that a range of international problems, such as global warming, the collapse of markets worldwide, and the influx of refugees into a number of countries, abound. These problems require solutions that can only result from educational practices that (a) make graduates aware of the global effects of their professional, civic, and personal actions and (b) enable them to take a well-informed stance when international issues are at stake. The popular phrase "act local, think global" underscores the need for global solutions as it reminds us of the dual nature of globalization and calls on us to work towards improving life in the broadest sense for those in our own community while at the same time being considerate of the health of the planet as a whole.

It is critical that graduates from our colleges and universities possess a feeling of responsibility for the world as a whole that can lead to lifestyle decisions that promote the betterment of the global community. However, the ability to feel responsibility towards the global community requires the development of yet another set of skills. In order to be able to feel empathy and solidarity with the rest of the world, graduates need to possess knowledge of the globe, a curiosity to learn more, and the ability to communicate with people from other cultures. Acquisition of these 
skills in turn requires self-knowledge and self-acceptance to be able to understand and accept others and recognize the value of others' perspectives.

Universities acknowledge the need for such an education and have come to embrace concepts of learning that give students a global perspective on human affairs and the environment, and equip them to act intentionally and responsibly. In addition, universities recognize that educating undergraduates requires multiple types of programs that enable all students, regardless of their developmental level or other individual characteristics, to participate in a range of rich and engaging global learning experiences (Hovland, 2009). According to the American Council on Education (1998), these programs should

1. give students basic tools they need to access international perspectives, especially foreign language skills and intercultural training;

2. provide exchanges with significant numbers of students and faculty from a range of other countries on campus;

3. provide opportunities to interact firsthand with citizens of other countries through study abroad experiences, internships, or other programs;

4. explore international dimensions of course content in any academic discipline; and

5. explore the effects of U.S. policies and activities on other countries as well as on citizens of other countries residing in the U.S.

An example of such a program that provides many of these global learning experiences is domestic foreign language immersion (DFLI). DFLI programs place 
students together for a period of time in an environment intended to expose students to practices that emulate the target language country linguistically and culturally. In an immersion environment, students have contact to international faculty and must communicate solely in the target language while taking classes designed to improve language ability and provide cultural content. These programs provide an opportunity for students to gain valuable global experience and present a viable means by which universities can make global learning available to students at home.

DFLI programs, available at only a few colleges and universities in this country, are sometimes compared to short-term study abroad programs that offer immersion experiences in other countries. Short-term study abroad programs are ever more popular among universities interested in global learning as they give students access to significant global learning experiences without requiring long-term commitments. For this reason, the last decade has seen dramatic growth in short-term study abroad (Dwyer, 2004; Donnelly-Smith, 2009; Chieffo \& Griffiths, 2009).

However, participation in short-time study abroad programs may not be a good fit for all college students (Olson, Green, \& Hill, 2006). Short-term study abroad programs are often unaffordable, especially because of the travel costs involved. In addition, some students have family, work, or other obligations that make it difficult to spend time far away from home. Finally, some students find the idea of spending a period of time in an unfamiliar environment overwhelming and do not feel prepared to undertake a program of study in another country. DFLI offers a good solution for such students to gain valuable global experience without going abroad, and, at the same 
time, provides students with a more controlled foreign language environment than is usually found in study abroad.

Our understanding of the global impacts of DFLI programs is imprecise. Whereas a few recent studies have been conducted on global learning outcomes associated with participation in short-term study abroad programs (Chieffo \& Griffiths, 2009), my search for global learning studies has uncovered virtually no research on global learning outcomes of DFLI programs. The few studies that exist have focused narrowly on language proficiency. These studies have shown that DFLI programs compare favorably to short-term study abroad in terms of language proficiency gains (Rifkin, 2005a; Cowles \& Wiedemann, 2008). However, research on DFLI programs has not addressed other types of global learning outcomes such as knowledge of global issues, ability to relate to others from other cultures, or global social responsibility.

Universities strive to reach more students as they align their palette of educational offerings designed to prepare students to participate actively and intentionally in an increasingly interconnected world. However, it is only possible to coordinate programs and courses if universities undertake efforts to illuminate global learning opportunities. Broader research on global learning outcomes of DFLI programs can contribute to these efforts. For this reason, the study described here focused on the global learning effects of a DFLI program located in an urban area in the Northwest. My intention in undertaking the study was to address a gap in research 
by investigating the character and extent of global learning that takes place in this program.

\section{Global Learning}

Definitions of global learning are continually evolving and differ from university to university, as cultural, organizational, and demographic characteristics of universities vary widely and universities seek to adapt global learning concepts and implementation strategies to fit their own unique situations (Hovland, 2009). For this reason, there is no one widely recognized approach to global learning. For example, as part of a global learning initiative, a small private liberal arts college might require foreign language students to study abroad for a semester, whereas this requirement that may not be feasible at a state university because of student demographics or funding opportunities.

A decision whether or not to require foreign language majors to study abroad can be only one small part in a multifaceted university-wide curricular plan. According to Hovland (2009), the task of educating undergraduates globally is complex, as global learning goals and outcomes must be coordinated across the curriculum and throughout the entire university. Hovland argues that this task is facilitated greatly by the fact that global learning overlaps generally with liberal education learning outcomes, such as content knowledge in a variety of disciplines, development of intellectual skills, and civic knowledge and engagement. This overlap provides a key for universities interested in strengthening global learning initiatives. As Hovland claims, universities are increasingly defining global learning as a vehicle 
to integrate multiple disciplinary perspectives, explore diversity, build capacity for civic engagement and prepare students to take responsibility for common global problems.

\section{The Role of Foreign Language Departments}

Global learning must not be left to any one individual or program or department. While university departments can play a significant role in facilitating global learning, there are limits to the contributions any single department can make. In particular, university foreign language departments are often relegated the task of providing a global education because of their international focus and active support of study abroad. In my experience, university foreign language instruction can provide some of the global learning experiences students need to live in a modern global society. University foreign language courses help students develop language skills, understand cultural perspectives as well as gain knowledge of foreign geography, literature, history, and political and environmental issues. Modern approaches to foreign language instruction are designed to make learning meaningful. For example, students learn others' perspectives through readings of authentic texts on personally relevant topics and, to a limited extent, through contact with native speakers. Students have the opportunity to enhance their learning experience by linking course content to personal or discipline-based knowledge and collaborating with other students on research projects.

Current thought on foreign language instruction is not only centered on a narrowly defined objective of promoting language learning but includes broader 
global learning goals that reflect the shift in higher education towards an education that emphasizes global perspectives (Modern Language Association, 2007). Whereas the traditional goal for the advanced language learner was achievement of nativespeaker competence, there has been a move towards a foreign language education that highlights learners' relationships to others and focuses on the ability of learners to operate between languages as informants of both one's own culture and the target culture. The Modern Language Association describes this ability as translingual and transcultural competence and argues for a shift in foreign language education practice:

Students are educated to function as informed and capable interlocutors with educated native speakers in the target language. They are also trained to reflect on the world and themselves through the lens of another language and culture. They learn to comprehend speakers of the target language as members of foreign societies and to grasp themselves as Americans--that is, as members of a society that is foreign to others. They also learn to relate to fellow members of their own society who speak languages other than English. (Transforming Academic Programs, para. 1)

This goal shift recognizes the need for students to understand that communication between speakers from different cultures is not only impacted by language ability but also by the cultural group one represents. This shift also recognizes the need for students to understand and appreciate viewpoints of another culture. Awareness of 
oneself and others' perspectives in a global context is a key outcome of global learning.

However, university foreign language classroom instruction is not enough to achieve this goal for a number of reasons. First of all, university foreign language instruction may not enable students to reach advanced levels of language proficiency (Rifkin, 2005a) that would enrich awareness of other cultural perspectives because the amount of sustained language practice students receive in foreign language courses is simply too small. Second of all, opportunities to interact with native speakers and get to know the culture first-hand are limited by the availability of international students and other native speakers living in the local community. This lack of opportunity for interaction with native speakers dilutes any gains in cultural understanding that are made in the classroom, and also makes it difficult for students to form friendships with those from other countries. Finally, opportunities for personal development are limited because the familiarity of a university foreign language classroom setting does not allow students to explore new strengths and abilities that would be called on in an unfamiliar target language environment. For this reason, students interested in deeper global learning experiences may turn to study abroad or, if available, DFLI programs that allow them to remain closer to home and still experience significant learning.

\section{Domestic Foreign Language Immersion}

While there are currently some 260 immersion programs of various types at the K-12 level in the U.S. (Center for Applied Linguistics, 2006), at the university level, there are only a handful of immersion programs in existence, with the most well 
known programs operated by Middlebury College in Vermont. These programs share a number of characteristics:

1. The goal is to become proficient in the target language and culture while earning academic credits. Some programs enroll students with any level of language proficiency, and others require three or four semesters of prior language coursework.

2. Students pledge to use only the target language during the program.

3. Faculty are largely native speakers, and the student-faculty ratio is usually lower than in on-campus foreign language programs.

4. Extracurricular activities, for example, sports, lectures, or film showings, are offered as a means to enrich the learning experience.

5. Programs are held during the summer break, and duration ranges between three and six weeks.

6. Programs are generally held in relatively isolated settings away from town centers.

The DFLI program that was the subject of this study was founded in 1956 with the idea to give students of German the opportunity to be immersed in the German language and culture, while taking academic coursework in German. For many years, this program has been held on the campus of a small liberal arts college located in a residential area outside a large city. In the 1980 s, up to 80 students participated in the program each summer. Numbers dwindled in the 1990s to around 40 students per year with a steady rise again in enrollment in the 2000s that peaked in 2010 with 70 
participants. Two-thirds of program participants come from the West Coast and onethird from other locations in the U.S. Approximately one-third of the students come directly from the host university. Most participants are college students, both undergraduate and graduate, from different types of public and private institutions. In addition, there are a smaller number of participants who are not enrolled at a college but want to work on their German proficiency for work or other purposes. Finally, there are always one or two senior guest auditors and occasionally a high school student.

There is a minimum language requirement of two years of college German, and during the five-week program, most participants enroll full time in three upperdivision German courses. Students complete a language course and two other content courses in literature, film, theater, and the like. The courses are taught by mostly native-speaker faculty who come either from German-speaking countries or other American universities.

The location and facilities support the immersion experience. Significantly, there are few other students on this quiet campus in the summer, so there are few encounters with English speakers beyond college dining and post office staff. This solitude helps reduce participants' inhibitions about speaking German in public and helps create a German community. Participants have access to college facilities such as the library, computer labs, and the recreation center. Access to these facilities helps create the feeling of living normal everyday life while speaking German and participating in German cultural activities. The campus is surrounded by a large state 
park that participants use for walks and jogging in their free time. There is very little public transportation available, thus countering any desire that arises to go into town in the evenings or on the two days off, Wednesday and Sunday.

There is close contact to faculty outside of class. Most participants and faculty reside together in a residence hall, with a smaller number of local students commuting to campus. Two of the faculty serve as resident assistants who are responsible for the welfare of the participants and also take charge of extracurricular activities. The faculty devote a lot of energy to making the program a rewarding experience for the participants as they share a wide range of activities, such as lectures, poetry recitals, hikes and beach trips on the days off, and dance and sporting events. A major goal is to promote language learning by giving participants every opportunity possible in and outside of class to use German in a wide range of situations, as they get to know each other and the faculty. Because of the close contact, the resident assistants are able to effectively watch for and respond to student needs that arise.

A significant and memorable part of the experience for participants is the German-only requirement. This requirement is a novel experience for most participants since very few have had the opportunity to participate in a German-only community in the U.S. or in Europe. Meeting this requirement is one of the most challenging aspects of DFLI for many participants. Depending on personal traits, prior language learning experiences, and level of proficiency, participants welcome the challenge but feel ill at ease at the same time. Participants may become easily frustrated because their level of proficiency feels like an obstacle when they do not 
find ways to express themselves satisfactorily. In addition, there may be a lot of anxiety among participants who do not want to expose their self-perceived language deficiencies. It is the task of faculty and resident assistants to help students feel comfortable with their language abilities by being respectful of participants' efforts and encouraging them to communicate, while at the same time backing off when they observe that participants are overwhelmed. For this reason, being able to participate in non-language-intensive activities such as sports and music, or sharing meals together gives students an important break and helps them unwind. Faculty are not only called upon to calm students' frayed nerves, but at the same time sensitively help students correct errors, especially in speaking, to the fullest extent possible. This level of language support is rarely possible in a college classroom setting in which instructors need to cover an ambitious amount of material in a short time and give grades to frequently large classes of students. DFLI participants quickly catch on to faculty attitudes towards participants' efforts to use German and become less critical and more supportive of their peers. It is because of this feeling of support that many participants have fond memories of their participation in the program.

\section{Short-Term Study Abroad}

Unfortunately, there is a lack of research on DFLI programs at the college level. For this reason, I turned to research on short-term study abroad, a type of program similar to DFLI in several ways. I decided to examine studies of the global learning impacts of short-term study abroad programs that include a foreign language component to see if these studies provided evidence of global impacts that might be 
relevant to my study. Similarities between DFLI and short-term study abroad are as follows:

1. DFLI and short-term study abroad programs are both commonly touted as effective ways for students to boost foreign language skills and learn about other countries and cultures (Freedman, 1998; "Die Deutsche Sommerschule am Pazifik," n.d.).

2. Both programs seek to enhance formal instruction through experiential learning outside the classroom.

3. The two programs are of similar duration. Short-term study abroad programs are defined as lasting less than one semester or one quarter (Institute of International Education, 2006) and the DFLI program in this study had a duration of five weeks.

\section{Demand for short-term study abroad.}

There is a demand for programs that provide more intense learning experiences

than can be found in the classroom. Study abroad programs, both short-term and longer-term, have experienced steady growth over the years. In the last 15 years, the percentage of students going abroad to study has increased dramatically with 99,448 participants in 1996-1997 as opposed to 241,791,791 in 2006-2007 (Institute of International Education, 2008).

However, as encouraging as this increase is, the total number of students who study abroad remains relatively small, accounting for no more than $1 \%$ of all undergraduate students (Lewis \& Niesenbaum, 2005). In addition to financial 
difficulties and family or other obligations that prevent students from participating in longer-term study abroad, the increasing numbers of older students enrolling in undergraduate degree programs has confounded the problem of accommodating students who may not be able to go abroad for an extended time. Older students are even less likely than younger students to take time away from family or work to participate in a traditional study abroad program lasting one to two semesters (Chieffo \& Griffiths, 2009).

Recently, however, the introduction of short-term study abroad programs has provided a partial solution to the problem of students' inability to study abroad due to financial or other reasons. According to the Institute of International Education (2008), currently more than $50 \%$ of students who go abroad do so for less than a standard academic semester or quarter, compared to $38 \%$ in 1993.

\section{Types of short-term study abroad programs.}

Short-term study abroad programs differ in a variety of ways, and there is more variation among them than there is among the small number of college DFLI programs. According to Engle and Engle (2003), the nature and focus of most study abroad programs can be determined by eight components: length of sojourn, entrylevel language ability, required language use (in class and out), faculty (local or USbased), type of coursework, provision for mentoring/guided cultural reflection, opportunity for cultural/experiential learning, and housing arrangements. In some cases, students enroll solely in courses provided through the program, while other programs arrange for students to enroll in local university courses on site. 
There are three widespread types of short-term study abroad programs (Donnelly-Smith, 2009). One common model is the January or winter-term course. Many colleges and universities have a winter term of approximately one month between two traditional-length semesters and offer short-term study abroad programs during this term. A second common model is summer short-term study abroad with programs lasting between one week and six weeks. A third type of program is a weeklong study abroad trip that is integrated into a semester-long academic course.

Beyond these three widespread types of programs, short-term study abroad increasingly encompasses a broader range of curricular models and locations. Several nontraditional types of study abroad models, including service learning and international internships, are becoming more common. In terms of location, study abroad programs have traditionally targeted European countries. While many shortterm programs today are still held at European locations, a growing number of programs are located in places on other continents (Chieffo \& Griffiths, 2009).

\section{Features of study abroad programs.}

There is debate about the impacts of certain features of study abroad programs. Whereas some study abroad experts support homestay arrangements that place students with local host families on site, arguing that these homestays give students particular insight into native culture and opportunities to use language skills outside the classroom, other experts argue that homestay environments do not always provide positive learning experiences. In some homestay situations, for example, hosts may speak very little with their guest students because of the effort involved in 
communicating with a nonproficient speaker in the target language. In addition, some students have difficulty adapting to host family routines and diets.

Another debated feature of study abroad programs is the importance of enrolling students in local university programs. Advocates for enrolling students in local programs argue that students gain tremendously from being immersed in classrooms together with native speakers, and that taking classes solely with other Americans limits students' opportunities for meaningful exchanges. However, others point out that students may not be ready emotionally or socially, or may not have the language ability, to participate in local university classes.

Wang (2010) points out that study abroad students may become isolated and have little access to native speakers. Program design can also hinder access to native speakers. Study abroad programs that take students to too many locations within a short period of time may create a situation in which students do not have adequate time to get to know individual settings and people, but have more of an American experience abroad akin to tourism. In an international learning assessment of students at a state university, Carter, Latz, and Thornton (2010) found that participation in short tourist trips abroad appeared to have a negative impact on tolerance for cultural diversity and interest in cross-cultural topics. This result points to the importance of providing a solid educational foundation for students studying abroad. It is generally recognized by reputable study abroad providers that students need the opportunity to interact socially with local native speakers in order to improve intercultural skills as well as language ability and self-confidence. 
While short-term programs vary in quality (Chieffo \& Griffiths, 2009), research suggests that, in general, these programs can have a significant impact on students' world views (Fry \& Jon, 2009; Dwyer, 2004, Chieffo \& Griffiths, 2004). In addition to gains in language proficiency, students may see gains in intercultural awareness, increases in self-confidence, and expanded global awareness. Finally, participation in short-term study abroad frequently results in decisions to study abroad for an extended period and a greater likelihood that students will pursue interdisciplinary studies focusing on international topics (Lewis \& Niesenbaum, 2005).

\section{Program Choice}

Students interested in language learning enroll in both short-term study abroad and DFLI programs for many reasons. The predominant reason for most students is simply to improve language abilities. Some students do not have the opportunity at their home institutions to take language courses, are not satisfied with the courses that are offered, or want to have more opportunity to practice speaking than is possible in a classroom. Other students attend to fulfill degree requirements at their home institutions.

While short-term study abroad programs are well known, many students are unfamiliar with DFLI or do not understand how DFLI programs differ from regular foreign language courses offered during the summer break. Students who opt for DFLI often do so because the programs are recommended to them by instructors or by other students who previously participated in a DFLI program. 
There are several reasons students attend DFLI programs rather than study abroad. Some seek an immersion experience but are unable or unwilling to study abroad. Still others enroll in DFLI as preparation for study abroad or to build on previous study abroad experiences. In terms of costs, DFLI is a viable alternative for some to short-term study abroad. Short-term study abroad programs cost between $\$ 3,000$ and $\$ 8,000$ depending on the location and other factors (Ron Witczak, personal communication, February 5, 2010), whereas DFLI is more affordable, in part because of reduced travel expenses. A further consideration is that students enrolled in DFLI programs can earn more academic credits within a shorter time span than in study abroad programs. Table 1 shows a sample comparison of a short-term study abroad program for German at the University of Arizona ("University of Arizona International Affairs," n.d.) and the Deutsche Sommerschule am Pazifik ("Deutsche Sommerschule am Pazifik," n.d.).

\section{Table 1}

Comparison of Short-Term Study Abroad and Foreign Language Domestic Immersion in 2010

\begin{tabular}{llllc}
\hline $\begin{array}{l}\text { Program } \\
\text { Type }\end{array}$ & Name of Program & Duration & $\begin{array}{l}\text { No. Quarter } \\
\text { Credits }\end{array}$ & $\begin{array}{l}\text { Cost (including } \\
\text { tuition/housing) }\end{array}$ \\
\hline $\begin{array}{l}\text { Short-term } \\
\text { study abroad }\end{array}$ & $\begin{array}{l}\text { University of Arizona: Study } \\
\text { Abroad in Leipzig }\end{array}$ & 30 days & 9 & $\$ 4,800$ \\
DFLI & $\begin{array}{l}\text { Portland State University: } \\
\text { Deutsche Sommerschule am } \\
\text { Pazifik }\end{array}$ & 36 days & 12 & $\$ 3,870$ \\
\hline
\end{tabular}


This sample comparison illustrates the comparative advantages of a particular DFLI program over a short-term study abroad program in terms of cost and number of credits awarded within a similar time period.

While students can easily see the cost and credit benefits of attending a DFLI program, other less tangible benefits are not as apparent, for example benefits that derive from the living arrangements and types of activities. The residence hall accommodations and the shared activities in a DFLI program help create a feeling of togetherness and community that promotes respect and acceptance of others, effects that positively influence the learning experience. Small and Supple (2001, p.3) describe community in terms of "social relationships that individuals have based on group consensus, shared norms and values, common goals, and feelings of identification, belonging and trust." Hamilton, Crane, and Bortoshesky (2007), in a description of Concordia Language Villages, a language immersion summer camp for elementary and secondary school students, argue that building community is a key factor in the success of the immersion experience in that it enhances motivation and reduces anxiety. The close quarters and extended period of time spent together at a DFLI program are conducive to creating a safe environment that helps counter students' natural inhibitions about making embarrassing blunders in a foreign language. The faculty encourages students to speak and creates a real need among students to interact verbally with others. Students get to know each other quickly and learn to positively support fellow students in their attempts to speak and write in another language. 
As noted by Rifkin (2005b), and Cowles and Wiedemann (2008), students in collegelevel DFLI programs (Rifkin, 2005b; Cowles, 2008), form close bonds to each other and tend to seek each other out long after the immersion experience has passed to recreate that feeling of togetherness and community. This is evidenced by a number of Facebook pages and other forums that allow alumni to maintain contact with others.

\section{Transformative Learning}

DFLI programs have been shown to be an effective means for students to boost foreign language skills and learn about other countries and cultures (e.g.,Rifkin, 2005a; Cowles \& Wiedemann, 2008). However, I maintain that the DFLI approach as practiced in the program that is the focus of this study is conducive to a deeper, more integral type of learning that goes beyond mastering verb tenses, oral skills, and cultural concepts. The DFLI approach as practiced in this program can offer opportunities for transformative growth, as students get to know themselves and others better and become more open to others' ideas about the world.

Mezirow (2000) states that the urgent need to understand and make meaning of experience is a part of human nature and that learning becomes transformative when we shape and reshape our ways of making sense of the world. The tools we use to make meaning of experience are what Mezirow calls our "frames of reference." A frame of reference is a "structure of assumptions and expectations through which we filter sense impressions" (p. 16) as we seek to interpret events and situations we encounter. Frames of reference arise and solidify as a result of previous experience 
and are shaped by our cultural background. They form the basis of our sense of identity as they help us understand who we are and what are values are.

Mezirow (2000) draws contrasts between transformative and informative learning. Informative learning involves the assimilation of new information that is compatible with our current frames of reference. In terms of foreign language learning, this could mean the acquisition of new vocabulary or cultural facts about a country. It is impossible to imagine a person becoming fluent in a language without this type of skill building, and informative learning is certainly crucial to language acquisition, as it is to other disciplines. Transformative learning, on the other hand, is a process that is triggered by a disorienting dilemma that occurs when we encounter a situation or event that cannot be interpreted adequately using our frame of reference. Disorienting dilemmas are often caused by a major life crisis or major milestone in life. These dilemmas may also result from an accumulation of these two types of events. Mezirow states that transformation occurs when the disorienting dilemma is followed by critical reflection and discourse, and culminates in a revamping of the learner's frame of reference so that he or she is better able to accommodate and interpret experience. Mezirow calls this process a perspective transformation.

According to Mezirow (2000), transformative learning is an emotionally charged and sometimes painful process. While other scholars (e.g., Cranton, 2006, Taylor, 2006) concede that transformative learning is often uncomfortable, they claim that other less dramatic types of experiences, such as encounters with persons from other cultures, may lead to a perspective transformation. Thus, a transformation may 
be triggered by a realization that a seemingly harmless habitual behavior may not garner the same reaction in another culture as it does at home. For example, an American might discover through trial and error that refusal to drink an alcoholic beverage is considered an affront to the host in some European countries. This realization alone may lead to a perspective transformation and result in an expansion of the person's understanding of the variety of cultural perspectives that exist.

Several scholars have focused on transformative learning in the context of adult foreign language learning. According to Johnson and Nelson (2010), foreign language learners may experience transformative learning as they grapple with new behaviors and cultural perspectives entwined in a new foreign language and compare these behaviors and perspectives to those of their native language. Goulah (2006) takes the idea of grappling with unfamiliar cultural perspectives a step further and claims that as learners study a new language, this learning process connects them to the global community and causes learners to reflect on their role in the global community and eventually begin to expand their sense of membership in that community.

According to Foster (1997), transformative learning may occur through the process of foreign language skill acquisition. Foster states that foreign language learning is an uncomfortable process that requires learners to leave behind familiar habits of communication and struggle to articulate thoughts in a language they have not yet mastered. This uncomfortable process is unsettling as it threatens the learners' view of themselves as reasonably intelligent, socially competent individuals, 
especially since practicing the new language requires learners to demonstrate their emerging language skills in front of peers. Such an unsettling experience may trigger a disorienting dilemma that then results in a perspective transformation as learners break through to a level of language proficiency at which they are able to communicate with relative ease and perhaps begin to identify with the new language and culture.

Mezirow (2000) claims the true goal of adult education is to help learners realize their potential to become "more liberated, socially responsible, and autonomous" (p. 30). This goal can be accomplished only through a learning process that helps learners reshape their frames of reference to be more inclusive, open to other points of view, and emotionally capable of change. There are many means by which teachers can foster transformative learning. According to Cranton (2006), teachers should establish meaningful and authentic relationships with students to provide fertile ground for transformative learning. Establishing such relationships enables teachers to sensitively engage students in consciousness-raising activities that foster personal development. However, there is no clear-cut recipe for facilitating these consciousness raising activities; Cranton points out that the transformative learning process is different from person to person. Establishing authentic relationships with students allows instructors to discover what individual students find motivating, and also helps instructors ease students through the uncomfortable process of transformation by providing a safe environment. 
Other factors conducive to transformative learning are

1. collaborative learning activities that give students the opportunity to critically reflect and share ideas with others (Pilling-Cormick,1997);

2. practices that tap into imaginational and creative ways of knowing, including music, drama and other arts (Davis-Manigaulte, Yorks, \& Kasl, 2006); and

3. careful choices of texts and topics that help students explore issues that are of interest to students (Taylor, 2006).

These are features that can be found in DFLI programs. One course offering in the DFLI program in this study that combines all of these features is the theater workshop, a course that culminates in a student performance of a play at the end of the program. While official enrollment in the workshop is not greater than for any other course, the workshop tends to involve virtually all of the program participants in some way, be it in creating and setting up props, practicing roles with the student actors, watching rehearsals, or sharing anecdotes and emotional experiences with others. The students enrolled in the workshop write parts of the script for a performance that is usually a combination of scenes from different plays in addition to the student-written portions. These workshop participants collaborate on ideas for the theater piece, problem-solve staging issues, find or create props and costumes, and learn their roles as they work towards the end result, all in less than five weeks' time. The theater piece invariably incorporates events from students' lives. For example, one year, an incident on a field trip that involved breaking up with a partner via cell phone was developed into a theater piece about human relationships and the role of technology. The use of 
collaborative learning in a theater performance that incorporates students' own themes and texts is a rich opportunity for transformative learning.

In a DFLI environment, many opportunities for transformative learning arise as students and faculty reside together and interact in and outside of class. Faculty engage students in a variety of situations, and students often report learning most in countless informal discussions with instructors. Through shared experiences, students become aware of new ways of behaving and viewing the world, and have opportunity to critically reflect on and discuss experiences with other students and faculty. The feeling of togetherness and community helps students cope with the intense learning experience and the discomfort and vulnerability they feel communicating in the target language.

In addition, the choice of rich content supports critical reflection and discourse among students and faculty, and aids the transformative effect. For example, one of the courses offered at the DFLI program in this study in 2011 was titled "Accommodation and Reformation" and had as content the difficult transition between youth and adulthood. This theme was chosen for its relevance to undergraduate students. The overall theme of the program in 2011 was "Transformation and Revolution" a theme that was intended to promote reflection on transformation.

There is one more feature of DFLI programs that fosters transformative learning. Daloz (2000) argues that constructive engagement with those different from oneself can also be transformative. The prerequisite for this transformative effect is the existence of an empathic connection with the other person rather than a mere 
encounter. This engagement with others in the program, be it with faculty or also other participants from other parts of the country and backgrounds, is a key feature of DFLI.

\section{Conceptual Framework and Research Questions}

According to O'Sullivan (1999), transformative learning and global learning are intertwined. If the transformative learning approach is the means by which a program can promote global learning, the question arises as to specifically what types of global learning occur in a DFLI program. The DFLI program in this study touts language and cultural learning as the main learning goals, but we know, at least anecdotally, that the program also provides other types of global learning. As one student recently claimed:

If it were possible to separate life into a few landmark moments, then I would have to mark my experience at the [DFLI Program]... as the most awesome, life-changing experience of my young adult life...Putting academics aside, the [DFLI Program] gave me a new outlook on life, a new unwavering drive to see more of the world, a prolific amount of amusement, and several new lifelong friendships. (Anonymous, December 18, 2008)

In this quotation, the participant expresses the transformative impact DFLI can have. Several of the students' comments point to outcomes that align with university global learning goals: knowledge gains, personal growth, awareness of and curiosity about the world, and growth in ability to relate to others. These comments indicate that it is possible to work towards global learning goals at home. Educators are beginning 
to realize that students can have rich global learning experiences that facilitate global learning outcomes through domestic programs that have carefully designed educational objectives.

The development that occurs in a DFLI program affects not only a student's knowledge of language and culture, but many other aspects of a student's life. Through this experience, a student undergoes changes in self-awareness and selfacceptance as well as changes in perceptions of his or her own culture and environment. This change extends to an increased awareness and acceptance of those from different backgrounds and results in a thirst for knowledge about other persons and places. Further, the student may begin to feel more connected to and responsible for the world as a whole. An important characteristic of this development is that change in one aspect of a student's life influences other aspects. Any meaningful examination of one aspect of growth invariably requires a comprehensive examination of the student's growth as a whole.

\section{The theory of global learning and development.}

Braskamp, Braskamp, and Merrill (2009) have developed a theoretical framework of global learning and development that is applicable to many kinds of programs and incorporates many of the global learning outcomes I believe occur in a DFLI program. This framework was developed to explain human development, especially during the traditional college ages of 18 to 24 . The framework is based on two general assumptions:

1. Human development is a holistic process that comprises simultaneous growth 
along intellectual, social, civic, physical, moral, spiritual, and religious dimensions.

2. In order for students in today's pluralistic society to thrive, they need to develop a global perspective to make sense of the multiple and distinct perspectives of people from different backgrounds and understand how these perspectives influence our society.

Braskamp et al.’s framework (2009) encompasses two perspectives:

1. a model of human development that describes human development as a journey through life in which people engage in meaning making through thinking, feelings, and relating to others; and

2. theories of intercultural communication that recognize the involvement of cognitive, affirmative, and behavioral domains in intercultural growth.

Braskamp et al.'s framework describes how a person thinks, forms a sense of identity, and relates to others. The framework envisions three domains of human development that are each divided into two scales. These domains and the corresponding scales are:

1. Cognitive Domain (Knowing and Knowledge)

2. Intrapersonal Domain (Identity and Affect)

3. Interpersonal Domain (Social Interactions and Social Responsibility)

\section{Cognitive domain.}

This domain is focused on knowing and knowledge. Knowing is considered to be a person's view of what is true and important to know based on cultural context. Knowledge is a person's understanding and awareness of different cultural lenses and 
how these impact our global society. Included in the Knowledge category is also knowledge of a foreign language. Growth in the cognitive domain is characterized by a lessening of reliance on external authorities and recognition of the relativism of truth as well as greater complexity in one's understanding of knowing and knowledge

\section{Intrapersonal domain.}

This domain is focused on identity and affect. Identity refers to one's level of self-awareness and acceptance of the ethnic, racial, and gender dimensions of one's identity as well as one's strengths and values. Affect refers to the level of awareness and acceptance of other cultural perspectives and includes the level of emotional confidence one has in complex situations involving those from another culture.

\section{Interpersonal domain.}

This domain is centered on social interaction and social responsibility. Social interaction refers to one's willingness to interact with others who are different from oneself and also cultural sensitivity in dealings with those from other cultures. Social responsibility refers to one's ability to recognize and commit to interdependence in one's dealings with others, and also social concern for others.

Braskamp et al. (2009) see human development as a journey in which change and growth in one domain impacts the other domains. Thus, development of cognitive skills interacts with and influences one's sense of identity and how one relates to others. The three domains are envisioned as three overlapping circles that represent the interrelationships and integration of these three aspects of human development. 


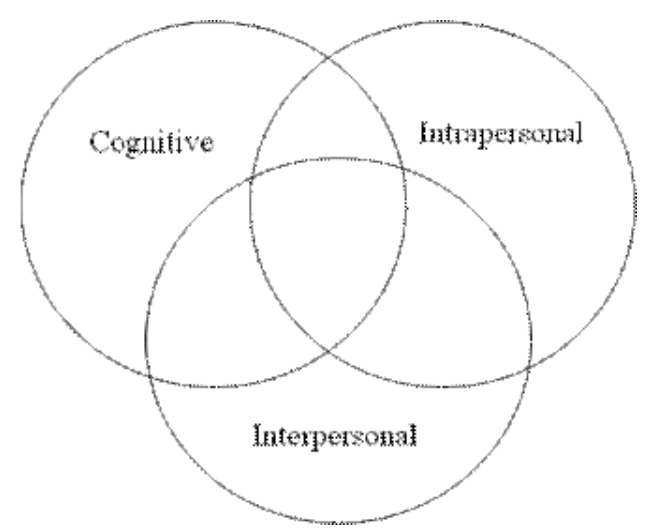

Figure 1. Overlap of three domains of global development (Braskamp et al., 2009)

This study looked for evidence that can shed light on the impact of a DFLI program on global learning. This evidence should (a) help program planners better understand the types of global learning that can most appropriately be provided through DFLI and (b) more generally improve the ability of this type of program to promote desirable global learning outcomes such as global awareness and social responsibility. According to Chickering and Braskamp (2009), an intentional effort is required on the part of educators to develop students' global perspectives. Without an understanding of program outcomes, programs miss opportunities to make program improvements that benefit students and support global learning efforts of universities in a more focused way.

\section{Research questions.}

The research questions for this study were:

1. To what extent do students perceive their participation in a DFLI program to have influenced their global development in the cognitive, intrapersonal, and interpersonal domains? 
2. Does students' perceived influence of participation in a DFLI program differ among the cognitive, intrapersonal, and interpersonal domains of global development?

3. Does the perceived influence of a domestic foreign language immersion program on cognitive, intrapersonal, and interpersonal development differ by the student characteristics of age, gender, language level, degree level, on- or off-campus residence, full-time or part-time enrollment, number of times attended, or prior international or other intercultural experience?

4. If students perceive their participation in a DFLI program to have influenced their global development in the cognitive, intrapersonal, and interpersonal domains, what might explain these findings?

There are many examples of participant attitudes and behaviors that can provide evidence of cognitive, intrapersonal, and interpersonal development. Students who have developed an interest in learning more about the world and others may, for example, report seeking knowledge of other cultures. Students with greater selfawareness and self-acceptance may demonstrate more self-confidence or more concrete ideas about their own goals in life. Students with greater awareness and acceptance of others may be more patient when they encounter non-native speakers who do not speak English well, or more understanding of those with differing beliefs. Students with more willingness to interact with those different from themselves may seek out venues where they can have contact or develop friendships with people from 
different countries. Finally, students with a greater degree of social responsibility may show more interest in volunteerism or other forms of civic engagement.

\section{Student perceptions.}

Students' perceptions of the extent of development that occurs as a result of participation in a DFLI program are important because they are indicative of the value of a program. Universities invest a lot of effort into the development and implementation of many types of programs and hope that participation in such programs will make a difference in students' lives. A statement by students that participation in a DFLI program led to a change in their world view or increased interest in other cultures is in itself a confirmation of the value of the program. In addition, students' confirmation that the program impacted their lives is an indirect indication that the impact will be lasting. After all, it is the experiences a person values that tend to endure.

In order to identify these perceptions, I asked participants in the DFLI program in this study to reflect on their experience in the program, identify attitudes and behaviors that indicated levels of global development, and then had participants report on the degree to which the program influenced their growth in the three domains. This allowed me to determine which dimensions of global development were impacted by the program and to what degree.

\section{Student characteristics.}

In addition, I investigated whether the degree to which students reported the program impacted them was associated with student characteristics, including age, 
degree level, gender, language level, on-campus or off-campus residence, full-time or part-time status, prior international or intercultural experience, and post-program international or intercultural experience. Astin (1993) states that collecting information on inputs, that is, the characteristics students bring with them when they enroll in a university program, is critical to any effective assessment. Inputs shape the outcomes of a program directly. In addition, inputs indirectly shape the program environment through the way students engage with the program. In order to determine program impact, it is necessary to control for inputs using statistical tests to be able to distinguish between program impact and characteristics students already possess when they enter a program. Figure 2 depicts the relationships between inputs, environment and outcomes:

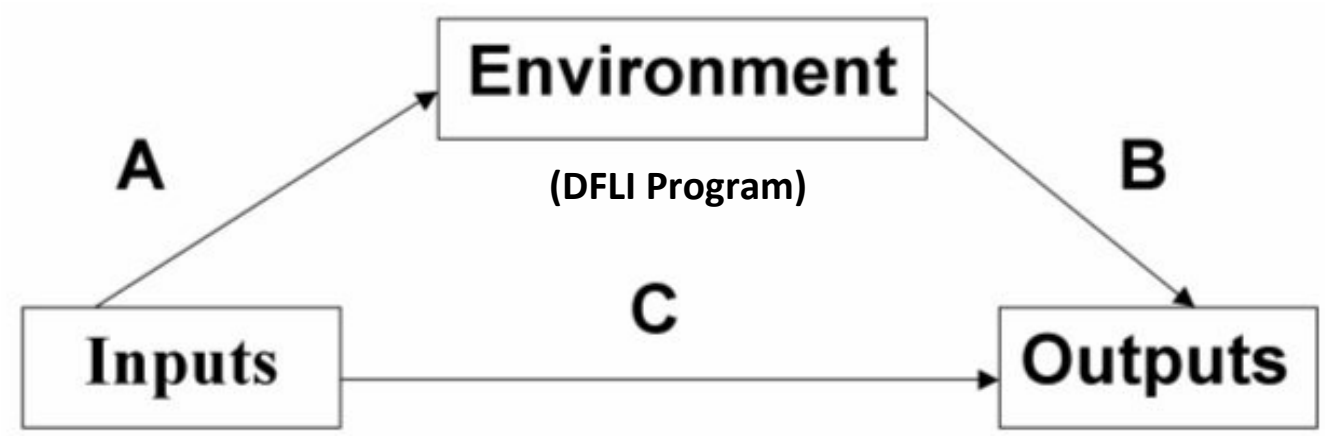

(Student Characteristics\}

(Global Learning Outcomes)

Figure 2. Input-Environment-Outcome Model (Astin, 1993)

In this study, the inclusion of student characteristics allowed me to determine whether individual differences among program participants had a bearing on the perceived impact of the DFLI program on global learning outcomes. In order to find out whether the program was a good fit for all students, it was important to ascertain 
whether the program fostered global development among all students to a similar degree or whether the program impacted development for some students more than for others.

For Merriam and Caffarella (1999), experience plays a critical role in learning. They state that the accumulation of experience over time as we grow older is a rich resource that adults utilize in the process of learning. As the DFLI program in my study draws students from a wide range of ages, it was important to find out if participation influenced global learning and development for all ages similarly or if some of the impact could be attributed to maturation, that is, the personal and behavioral changes that occur as a person lives longer. For this reason, I included age as one of the student characteristics I investigated.

The program enrolls students with differing levels of exposure to college programs, both undergraduates with little college experience and graduates who have attended college for many years. Similar to the rationale for examining the impact of the program on different age groups, it was critical to examine whether the perceived influence of the program was similar for students with differing levels of educational experience, a characteristic that could also be indicative of maturation.

Gender was also included in the investigation, as research has shown that there are gender-related differences in educational impacts. For example, Baxter Magolda (1992) found that women tend to prefer to learn by gathering ideas as they interact with others, while men tend to seek debate and resolve uncertainty through logic and research. Similarly, Gilligan (1982) demonstrated that in the area of identity 
development, women's conceptions of self are rooted in connection and relatedness to others, whereas men define themselves in terms of separation and autonomy. In addition, women tend to have moral perspectives that are focused on responsibility and care while men are likely to emphasize justice and rights in their moral judgments. Given the fact that development of identity and increased interest in social interaction were two of the focal points of this study, it was possible that these gender-based developmental differences might play a role in perceived program impact.

In addition, on- or off-campus residence and full-time or part-time status were included in the study because I surmised that students who did not live on campus or did not attend on a full-time basis and thus did not receive the "full" immersion experience might perceive less program influence on global development.

There are a number of students who participated in the program more than once. I theorized that (a) repeat participation could mean either a high degree of satisfaction with the program and thus distort overall survey responses, or (b) these students might report more program influence on global learning because of the multiple exposures to the program. For these reasons, I incorporated this student characteristic in the study.

Language level was also one of the characteristics I included. Two studies (Hokanson, 2000; Rifkin, 2005a) found that students with higher proficiency have more access to other cultural perspectives because of their greater ability to comprehend meaning and interact in the foreign language. It was possible that students 
with higher proficiency who attended the DFLI program also had higher levels of global development and therefore did not learn as much during the program itself.

I also examined program impact on participants with prior international or other intercultural experience. The environment in a DFLI program is designed to mirror facets of life abroad while at the same time offer some familiar features from home such as housing arrangements or American university-style advising. This is one reason the experience is touted as a bridge program for those wishing to go abroad for the first time. However, the program also attracts participants with prior international or other intercultural experience, and this study sought to illuminate how these participants benefit in terms of global learning.

Finally, I included post-program international or intercultural experience as a characteristic in the data set. DFLI is designed to emulate an international environment, and I surmised that students who had a significant international or intercultural experience after DFLI program participation might have better appreciation of the impact of the DFLI program on global learning.

In addition to the above data, I accessed program applications and other background documentation that allowed me to track ages and other characteristics of program participants who did not respond to the survey. This information was important in determining self-selection bias, that is, whether certain student characteristics influenced program participants' decision to participate in the survey. 


\section{Definition of terms.}

The following terms are defined here with reference to their specific use in this study:

Domestic foreign language immersion (DFLI): A foreign language program, located in the U.S, in which students take courses, live together, usually in a student residence hall, for a period of three to six weeks, and pledge to communicate solely in the language they are learning.

The cognitive domain: A dimension of global development concerned with knowing and knowledge. Knowing refers to a person's view of what is true and important to know based on cultural context. Knowledge is a person's understanding and awareness of different cultural lenses and how these impact our global society. This category also includes knowledge of a foreign language. This term is based on Braskamp et al.’s (2009) theoretical framework of global learning and development.

The intrapersonal domain: A dimension of global development concerned with identity and affect. Identity refers to one's self-awareness and acceptance of all dimensions of one's identity, as well as one's strengths and values. Affect refers to the level of awareness and acceptance of other cultural perspectives as well as a person's level of emotional confidence in complex situations involving those from another culture. This term is based on Braskamp et al.’s (2009) theoretical framework of global learning and development.

The interpersonal domain: A dimension of global development concerned with one's willingness to interact socially with those from another culture and one's feeling 
of social responsibility for others. It includes a person's level of cultural sensitivity in dealings with others. This term is based on Braskamp et al.'s (2009) theoretical framework of global learning and development.

International experience: Refers to knowledge gained from living abroad for study, work, or family reasons for a period of time longer than six weeks.

Intercultural experience: Refers to knowledge gained from interacting frequently with those from another culture, either in the U.S. or abroad, for a period of time longer than least six weeks.

\section{Summary}

While the DFLI program that was the subject of this study focuses on language and cultural learning as the main learning goals, many of the programmatic features also support global learning and development. First of all, this program provides many of the rich learning experiences that, as stated by the American Council on Education (1998), are needed to promote global competence. For example, this program supports the development of language and intercultural skills, provides the opportunity for students to interact with students and faculty from another country, and incorporates non-English resources from other countries in the exploration of course content,

Second of all, this DFLI program is comparable in several ways to short-term study abroad, a type of program that has been associated with global learning and development. Third of all, program practices provide opportunities for transformative growth, a deeper type of learning that encourages identity development and awareness, and understanding of others. This type of learning aligns closely with global 
development. Finally, anecdotal evidence in the form of program participants' letters and e-mails suggests that this DFLI program can promote global learning and development. 


\section{Chapter Two}

\section{Literature Review}

Overall, the literature related to global outcomes in the context of undergraduate education is sparse. In addition to a small number of linguistic studies of DFLI programs, there are a variety of studies that relate indirectly to DFLI and inform approaches to global learning and global learning research. This literature review covers studies of

1. transformative learning in foreign language classrooms, 2. linguistic impacts of DFLI programs,

3. global learning outcomes of short-term study abroad, and 4. global citizenship in undergraduate education.

The review begins with an overview of the research on transformative learning in language classrooms. O'Sullivan (1999) claims that transformative learning is an approach through which education can foster global learning, and his perspective provides a context through which to interpret the other studies reviewed in this chapter. The sections following the literature on transformative learning provide an overview of the literature available on college-level DFLI programs. The third group of studies on short-term study abroad programs are most similar to my study in terms of program type and research topic, that is, program influence on global learning outcomes. In this select set of studies on short-term study abroad, I chose not to include literature on foreign language acquisition because it was only peripherally related to my study. The last section in this literature review provides an overview of 
other types of research on global citizenship in undergraduate education that were related thematically to this study and informed my research design.

\section{Transformative Learning in the Language Classroom}

As Johnson and Nelson (2010) point out, the topic of transformative learning in the language classroom has not been fully explored. A number of scholars (e.g., Byram \& Kramsch, 2008) have focused broadly on the transformative effect of language learning from the perspective of culture without explicitly discussing perspective transformation. Still other scholars discuss transformative learning associated with language learning from a theoretical perspective, and a smaller third group of scholars focuses on empirical research on transformative learning in language classrooms.

This review includes four empirical research studies on transformative learning. The first three examined the perspective transformation experiences that occurred in language learning situations that did not specifically target transformative learning. These studies also investigated the educational factors that contributed to perspective transformation. The fourth study varied from the first three in that it examined the impact of an explicit transformative learning approach in a foreign language classroom.

King (2000) conducted a mixed-methods study of 208 adult learners enrolled in English as a Second Language (ESL) courses to investigate the nature of perspective transformation experiences that occurred and the educational factors that contributed to these experiences. Data was collected by means of a survey that was 
followed by interviews with 24 survey participants. Results of the survey indicated that $67 \%$ of respondents had experienced perspective transformation related to their classroom study of ESL. This result was in stark contrast to a previous study in a nonESL college setting using the same instrument in that only $33 \%$ of the respondents in the earlier survey reported a perspective transformation. This difference between the two studies points to a possibility that language learning is a powerful vehicle for transformation and gives credence to Johnson and Nelson's claim (2009) that language learning has a powerful transformative effect.

The findings of King's (2000) survey demonstrated transformative learning in three areas: language learning, culture, and personal change. With reference to language learning, the most common responses were that learning English was easier or more enjoyable than anticipated. Other respondents commented on the similarities between English and their native language. In terms of culture, participants reported increased acculturation or development of intercultural awareness. With regard to personal change, participants reported gains in self-esteem or empowerment through learning to cope with the new language and culture. These gains in self-esteem and empowerment affected participants' actions and their relationships to others.

During the interviews conducted as part of this study, the classroom activity that emerged as the greatest contributor to the participants' perspective transformations was class discussion, with writing mentioned as the second most important classroom activity. In addition to classroom activities, $47 \%$ of survey participants indicated teachers' encouragement and support as a prominent contributor 
to their perspective transformations. King acknowledged the fact that external factors influenced the transformative learning experience for these students, and found that life changes outside of the classroom, especially immigration, moving, and job changes, combined with classroom ESL study, played a significant role in the perspective transformations that occurred. Neither age, marital status, nor prior education were significant moderating variables in the findings, but length of ESL study correlated significantly with perspective transformation. The researchers recommended that ESL instructors participate in training in transformative learning, and also that instructors modify classroom practices to strengthen opportunities for transformative learning.

Buttaro and King (2001) conducted a case study of the transformative impact of an adult Hispanic ESL class on eight adult female Hispanic students. The researchers' intention was to discover the themes that contributed to the students' linguistic, cultural, and educational development. The findings were as follows:

1. The encouraging and motivating environment in the classroom supported students' language learning and gave them more self-esteem that in turn led some of the students to seek better-paying jobs.

2. Students became aware of the positive impact that Hispanic culture had on their development, especially Hispanic cultural aspects related to family and friends. In writing samples and interviews, the students reported, for example, that they tended to spend time with other Hispanics, including family members, while they studied English. The students also stated that being 
bilingual and bicultural helped them overcome shyness and adjust to American culture. Finally, students expressed beliefs that being immigrants in New York City was advantageous because of the many opportunities provided by the city to bilingual individuals.

3. Students came to recognize the importance of education for themselves and for their children, and also for the need for teachers to be supportive in times of academic difficulty and create an environment that fosters self-esteem and interest in learning.

The researchers concluded that ESL courses must take into account individual histories, cultures, needs, and goals for students to learn successfully. In addition, when the goals of the course are made clear to students, the content does not need to be as relevant to students' personal interests but can be tied more closely to community, national, or international themes. Finally, learning is best achieved in an ESL setting when students are able to set their own goals with the help of advising. In a case study similar to King's (2000) research on adult ESL learners, Johnson and Nelson (2010) investigated the transformative impact of a beginning Spanish class on three adult learners. Prior to this study, Johnson and Nelson had observed that students in beginning Spanish classes experienced types of learning that went beyond the content explicitly stated in the syllabus, for example, verb tense conjugation; oral, reading, and writing skills; and cultural concepts. The researchers' purpose was to gain a better understanding of the learning experiences of students in beginning Spanish, and the degree to which classroom activities contributed to 
perspective transformation for students not majoring in Spanish. Johnson and Nelson selected three students for the study by means of a survey designed to identify which respondents had undergone a perspective transformation as a result of participation in a Spanish class. These three students then participated in semi-structured, face-to-face interviews roughly based on questions from the original survey.

The types of perspective transformation all three students reported were in the areas of cross-cultural awareness and tolerance. The three students indicated that as a result of their classroom study of Spanish, they developed a sense of solidarity with the Hispanic community and a desire to participate in that community. In addition, the students experienced a shift in their awareness of diversity, particularly of diversity within the Hispanic community. Finally, the students all expressed a change in awareness of the ethnocentric nature of their own culture.

The three students identified three types of activities that contributed to their perspective transformation: (a) the opportunity to gain contact to native speakers of Spanish, (b) the collaborative learning environment that allowed the three students to learn other students' perspectives during discussions and other collaborative activities, and (c) watching and analyzing films from the target culture. The three students all reported the film activities to have had the greatest influence on their transformation. One student reported that watching and discussing these films made her critically aware of culture, especially since she did not herself participate in the events shown in the films but was an outside witness to the events. 
In a critical instrumental case study of six high school learners of Japanese, Goulah (2007) examined the impact of a transformative learning approach to culture using a popular Japanese pop culture anime film. The themes of the class that were chosen to enhance perspective transformation were cosmology and ecospirituality. The researcher collected notes on participants' discussions of the film as well as student work samples and data from audio-taped interviews with each participant. The researcher noted that participants initially had difficulty engaging in a classroom discussion, but gradually began to participate more frequently, and finally began to guide the discussions themselves. Results of the study suggest that a transformative learning approach can help high school students engage in high-level critical crosscultural comparison. The study also demonstrated that a transformative approach can be used successfully both in a foreign language context and with adolescents, a finding that contradicts the common view that transformative learning is only effective with adults.

These four studies on transformative learning in the language classroom all provide evidence that language study can provide opportunities for transformative learning. In the four studies, recurring themes were awareness of culture or diversity and the development of self-esteem. The features of the classroom that contributed to transformative learning were class discussion, collaboration with classmates, and opportunities to have contact with native speakers. Three of the four studies also emphasized the pivotal role of the teacher in providing encouragement and other kinds of support. 


\section{Domestic Foreign Language Immersion and Short-Term Study Abroad}

In order to provide a meaningful overview of the literature on DFLI and study abroad programs, Braskamp et al.’s (2009) theoretical framework of global development in the cognitive, intrapersonal and interpersonal domains was used to categorize the literature and show research trends. Unfortunately, there is a dearth of research on short-term study abroad (Chieffo \& Griffiths, 2009), especially quantitative research. However, the growing demand for short-term study abroad programs has fueled a demand for data on global learning outcomes of these programs, and a small number of studies have appeared.

\section{Studies related to cognitive development.}

The following studies of cognitive impacts of DFLI and study abroad programs on language acquisition all focused on language acquisition. The first three studies were concerned with the extent to which participation in DFLI resulted in language proficiency gains. The remaining four studies focused on specific features of DFLI programs that contribute to language acquisition. All of these studies reported a positive impact on foreign language acquisition.

Braskamp et al. (2009) include knowledge of a foreign language as an aspect of global cognitive human development. This knowledge is indeed important as it enables students to recognize and accept cultural perspectives of others. The language proficiency guidelines of the American Council of Teachers of Foreign Languages (ACTFL, 1985), a set of guidelines widely used in U.S. foreign language programs, state that students need to have achieved an advanced level of proficiency to be able to 
participate fully in informal and some formal conversations, and handle situations that are unpredictable. The ability to participate fully in conversations in a foreign language is vital for students who endeavor to understand others' perspectives. According to Rifkin (2005a), it is only at the advanced level of proficiency or above that students are able to "engage in serious discussion of sophisticated topics with native speaker interlocutors, gaining not only in linguistic but also cultural proficiency as they do so" (p. 15). At least one study has provided research evidence of the significance of the advanced level of language proficiency with regard to access of cultural perspectives. Hokanson (2000) studied cognitive learning style preferences of a group of 29 students who traveled to Guatemala to learn Spanish and noted that students who began the trip with advanced-level language skills were able to make the greatest progress in terms of sensitivity to the culture they encountered in Guatemala.

In a study comparing students of Russian in traditional classroom and immersion learning environments, Rifkin (2005a) conducted a series of tests over three years to determine the relationship between type of learning environment, hours of instruction, and language acquisition. The tests were based on ACTFL language proficiency guidelines (ACTFL, 1985). Rifkin's findings indicated that immersionbased instruction led to greater acquisition in listening, reading, speaking, writing, and grammar than traditional classroom-based instruction. His findings also showed that students who take part in a traditional four-year language program are unlikely to reach the ACTFL advanced level of proficiency but complete their language studies with intermediate-level proficiency, a level that allows only rudimentary language use 
in informal and predictable interactions. For students who wish to "break through" to the advanced level of proficiency, Rifkin (2005b) recommends students begin language study in a traditional classroom and then participate in an immersion program in the U.S. or study abroad.

Rifkin (2005a) states that college students who study abroad do not make as significant a gain in language proficiency as those who participate in DFLI. He notes that without adequate preparation and language skills, social and cultural patterns encountered abroad may be overwhelming to students. Students may need to talk about these encounters with other Americans in English, which prevents them from meeting language goals. For this reason, he recommends that students first participate in a DFLI program to improve their language skills before studying abroad.

Rifkin's findings (2005a) confirm the results from a widely cited older study of college students learning Russian (Brecht, Davidson, \& Ginsberg, 1993) that also found intermediate-level proficiency to be the average level for students completing four years of college Russian. Brecht et al. additionally found that only $40 \%$ of intermediate-level students who studied abroad were able to reach the advanced level of proficiency, the level at which students are able to take advantage of the opportunities to interact meaningfully with native speakers. Rifkin's findings as well as those of Brecht et al. make apparent a role for DFLI programs in enabling students to make significant language proficiency gains.

Cowles and Wiedemann (2008) also compared the impact of short-term study abroad with that of DFLI on language acquisition. They used ACTFL's oral language 
proficiency interview protocol (“ACTFL," n.d.) to examine oral language proficiency of college students learning Brazilian Portuguese. Similar to Rifkin's results (2005a), she found that students who participated in DFLI demonstrated more language proficiency gains generally than those who studied abroad in Brazil. They note that students who participated in foreign language domestic immersion had a broader repertoire of language production and used less repetition than students who studied abroad. However, students who studied abroad used more colloquialisms than those who participated in a DFLI program.

Cowles and Wiedemann (2008) asked students participating in their study about the merits and missed opportunities of the programs the students participated in. The students who studied abroad in Brazil found the experience of staying with local host families, the opportunity to talk to native speakers and watch TV in Portuguese, and also formal instruction to be valuable. The missed opportunity for these students was that they spoke English with peers, host family members and other Brazilians. The DFLI students found the language pledge, the meals and activities with instructors, the explicit error correction by instructors and peers, and the exposure to a variety of native speakers to be valuable. However, these students missed the opportunity to be able to practice speaking the language in an in-country environment.

The next four studies investigated impacts of specific programmatic features of DFLI programs on language proficiency. The first three studies focused on pedagogical aspects that contribute to language acquisition, and the fourth study attempted to explain the students' experience of language learning through immersion. 
Spielmann and Radnofsky (2001) conducted an ethnographic study of the role of euphoric and dysphoric tension in language acquisition for beginning learners of French. Euphoric tension was defined as a stressful event that was pleasurable and stimulating whereas dysphoric tension was deemed to be a stressful event that caused anxiety or apprehension. Spielmann and Radnofsky conducted student interviews in French with beginning students and observed student interactions. During the course of their research, they discovered that it was more important to focus on students' interpretations of situations and activities rather than on the situations and activities themselves. They found that students reacted more positively to both euphoric and dysphoric tension if they perceived the situation or activity to be productive in terms of advancing their language proficiency. They distinguished between tension caused by the classroom environment or teaching style, and tension caused by curricular activities and materials. Spielmann and Radnofsky found faculty attempts to reduce dysphoric tension by choosing less challenging curricular activities and materials in addition to providing a comfortable classroom environment counter-productive. The comfortable, student-friendly teaching style led to euphoric tension, but the less challenging curricular activities and materials caused dysphoric tension. The activities and materials that were most dysphoric were simplistic tasks such as decontextualized and self-referential grammar lessons and exercises. These activities were meant to be more accessible to beginning students but created dysphoric tension for students who already felt painfully infantilized by their inability to communicate in French at their normal level of sophistication. Spielmann and Radnofsky found the student-friendly 
teaching style did not compensate for the dysphoria-producing activities. It was noted that the overall environment outside the classroom was comfortable and predictably American, and that if students felt particularly stressed, they could take comfort within the familiar surroundings. However, the students often commented that the struggle they experienced trying to express themselves in French made them feel they were not their real selves and that this feeling caused dysphoric tension. Recommendations of the researchers were to optimize euphoric tension within the instructional curriculum by providing diverse and challenging activities that do not overtax students' abilities.

Russo (1997) studied metaphorical competence of students of Italian by eliciting and examining writing samples of students for frequency of metaphors. Using an observational approach, he first examined essays written as classroom assignments and then conducted a speech analysis in which he asked students to identify Italian metaphors in spoken speech. He concluded that metaphorical competence increased in relation to exposure to metaphors in initial stages of learning, but this competence did not increase as rapidly as linguistic competence. After the initial stages of language study, exposure to metaphors had little effect, however, and students tended to rely on metaphors from their native language when using Italian. Further, students at higher levels of proficiency tended to avoid metaphors, which in turn led to a paucity of figurative language. Russo asserted that students need to acquire tools to recognize, understand, and generate appropriate target language metaphors. Whereas the ability to use appropriate metaphors may not seem essential to language learning and use, 
Russo argues that metaphorical competence is an integral part of human communication and perhaps of cognition itself.

Jiang (1999) studied the vocabulary development of participants in an immersion program for Chinese. His research was based on memory studies that showed a distinction between first language and foreign language learners in the way vocabulary is mentally stored. In first language acquisition, a child learns, for example, both the word for and concept of "chair" simultaneously. The concept of "chair" and the word "chair" are then stored together in the child's mental lexicon. For nonnative language learners, however, who have already learned the concept "chair" and merely have to acquire the foreign word for "chair," the mental lexicon stores the word and the concept separately. Jiang found evidence that learners who participated in DFLI acquired vocabulary in a fashion similar to first language acquisition. He theorized that the intensity of language exposure in this unique program in which students were surrounded by spoken Chinese contributed to this development. A study by Liskin-Gasparro (1998) focused on how learners perceived their linguistic development and how contextual factors in the learning environment as well as individual issues, such as goals, self-confidence, and friendship interacted with their progress and performance in Spanish. The seven participants in this study were all graduate students enrolled in a language immersion program for Spanish. LiskinGasparro interviewed students weekly and also collected students' daily written reflections. One of the findings of her study was that students felt a high degree of uncertainty regarding language use. This uncertainty tended to spark crises of 
confidence. This finding was particularly striking given the fact that the participants all had extensive language learning backgrounds including study abroad and therefore had a large amount of experience communicating in a foreign language. This uncertainty seemed to depend on many variables including the task, the formality of the context, tension related to academic deadlines, and general energy levels. LiskinGasparro hypothesized that the linguistic limitations these students perceived were related to the fact that these were all successful college graduates used to being able to express themselves well in college settings. This observation seems to corroborate Foster's (1997) description of a disorienting dilemma triggered by the unsettling effect language learning can cause when students are not able to communicate adequately in the target language.

A further finding of the Liskin-Gasparro study (1998) was that students wavered in their perception of the role of formal instruction in becoming more fluent and accurate speakers. Some students stated at times that constant error correction was helpful, but at other times claimed that error correction and constant focus on language forms hindered development of fluency. Liskin-Gasparro attributed this contradiction to two pervasive beliefs about language learning amongst the participants: (a) language learning is something that happens exclusively in the classroom and (b) only through immersion outside the classroom can a person become fluent in the language. However, all participants in the study agreed that the requirement of the program that students communicate in Spanish all of the time was crucial to their development of fluency. Liskin-Gasparro surmised that later in the program the participants were able 
to reconcile these contradictions by constructing for themselves a view of the program as a kind of "immersion super-classroom" in which elements of the formal language classroom such as error correction and examples of appropriate language use were present in the immersion setting outside the classroom. She recommended that more thought be given to integrating in-class and out-of-class experiences when designing immersion programs.

These studies on the language proficiency impacts of DFLI and short-term study abroad programs provide evidence that participation in DFLI compared favorably in terms of language proficiency gains to short-term study abroad. There are likely several reasons for this effect. First, the requirement that participants use the target language at all times gives students abundant language practice, also in challenging situations in which students might otherwise be tempted to revert to English. The provision of extracurricular activities adds additional opportunities for practice. Second, the familiar American living arrangements allow students to focus on language studies rather than try to make sense of unfamiliar aspects of everyday life in another country. Third, close contact to native speaker faculty gives students additional opportunity to practice speaking and allows the faculty to help students monitor progress. All of these features are possible within the controlled immersion setting and difficult to provide in a study abroad situation in which students are on their own outside of the language classroom. 


\section{Studies related to intrapersonal and interpersonal development.}

There have been no studies of DFLI programs on global learning impacts other than language proficiency, and most scholarly research on short-term study abroad has also focused on issues of language proficiency. However, there are a few recent studies that investigated other aspects of global learning that fit within the intrapersonal and interpersonal domains described by Braskamp et al. (2009). The studies reviewed below are of two different types. The first type examined the impacts of short-term study abroad on student learning and development. The second type of study compared the impacts of longer-term and short-term study abroad programs.

Shames and Alden (2005) examined identity changes in 13 students who participated in short-term study abroad in England, Ireland, Greece, Italy, and Spain. These students all had learning disabilities and/or attention deficit hyperactivity disorder and struggled historically with learning. In this qualitative study, Shames and Alden collected data by means of interviews and sorting activities that asked students to group learning and programmatic characteristics according to perceived significance of impact. The results of the study showed an increase in intellectual and social curiosity, improved knowledge of language and other skills, and increased normalization, independence and self-confidence. The students attributed these impacts largely to the novelty and intensity of the program. Based on the findings of this study, Shames and Alden recommended that programs provide diverse opportunities for student interaction with learning materials, develop holistic admissions criteria that look at more than students' GPA, and also require post-study 
abroad student debriefing. This study demonstrated not only the types of global impact a short-term study abroad program can have, but also how investigation of learning outcomes can potentially lead to changes in program design.

Lewis and Niesenbaum (2005) studied the impact of a spring course that included a short-term study abroad experience in Costa Rica as well as service learning and student research components. In this survey study, Lewis and Niesenbaum found that students who participated in the program expressed increased interest in interdisciplinary studies, and underwent a shift in their perceptions of the effects of globalization. A further impact attributed to the program was that half of the students who participated in the program enrolled in further study abroad programs, both short term and longer term. Lewis and Niesenbaum concluded that students who feel daunted by the prospect of participation in a semester-long study abroad program can gain real benefit from short-term study abroad.

However, not all scholars agree with Lewis and Niesenbaum's (2005) claim that students who participate in short-term study abroad can gain real benefit. Some studies comparing short-term and longer-term study abroad concluded that short-term programs are inferior to longer-term study abroad programs in terms of global learning outcomes.

Kehl and Morris (2007) investigated differences in global mindedness among 520 short-term and semester-long study abroad participants at private universities. In this study, global mindedness was defined as a "worldview in which an individual perceives his or herself as connected to the world community and is aware of his or 
her responsibility for its members" (p. 69). Kehl and Morris determined via an online survey that there was a significant difference in global mindedness between the two groups of students, with longer-term program participants exhibiting more global mindedness than participants in short-term programs. A discouraging finding of their study was that there was no significant difference in global mindedness between shortterm study abroad students and students on campus who intended to study abroad but had not yet enrolled in such a program.

Medina-Lopez-Portillo (2004) looked at the correlation between intercultural sensitivity and program duration and determined via qualitative and quantitative methods that 18 students who participated in a long-term program in Mexico showed significantly more intercultural sensitivity than 10 students who participated in a similar short-term study abroad program in Mexico.

In addition to the mostly small studies mentioned so far, there were three larger studies of global learning in study abroad. In a study on the impacts of short-term study abroad programs, Chieffo and Griffiths (2004) surveyed 2,336 students at the University of Delaware. They included both students who had never studied abroad as well as those who had participated in a study abroad program. In the survey, students who had studied abroad indicated that they were more comfortable speaking a foreign language as a result of their study abroad experience. In addition, they considered themselves to be more patient with people who did not speak English well than their on-campus peers. Further, when asked about the most important thing they had learned, short-term study abroad participants mentioned knowledge/appreciation of 
another country or culture, and tolerance/patience/understanding of differences. In contrast, the on-campus group of students was largely focused on classroom knowledge in their responses to the same question. Chieffo and Griffiths concluded that even a month-long study abroad experience can show meaningful and measurable global impacts.

Dwyer (2004) reported on a retrospective longitudinal study conducted by the Institute of International Education of Students (IES) of 3,700 alumni of study abroad programs to determine program impacts. Of the 3,700 alumni, $32 \%$ of respondents had participated in full-year programs, $62 \%$ in semester-long programs and $6 \%$ in 6 -week, short-term programs. Using the IES Model Assessment Practice, a set of guidelines established for developing and assessing study abroad programs, this study investigated the student learning environment, academic attainment, intercultural development, career impact, and personal growth. Results of this study showed that regardless of program duration, all programs had a significant impact on students. The study also showed that year-long study abroad programs had more significant and enduring impact on students than semester or short-term programs, and that this impact could be sustained for over as many as 50 years. Curiously, the study further found that short-term students were as likely as or more likely than students in semester-long programs to gain sustainable benefit from studying abroad. The author of this study surmised that this result was due to the careful planning, expert implementation and significant resources needed to make efficient use of time in a short-term program. An important conclusion of the study was that programs lasting at 
least six weeks can have a significant impact on student growth in a number of important outcomes.

The University of Minnesota Study Abroad for Global Engagement (SAGE, 2006) group conducted a large-scale study of 6,000 former study abroad participants. These participants had taken part in a wide range of study abroad programs, both long and short-term, spanning 50 years. The global engagement variables defined by SAGE were philanthropic donations, volunteerism, social justice, international political civic engagement, domestic political civic engagement, global leadership, and global values. They concluded that while there was a positive and statistically significant relationship between duration and three of the six global engagement factors (philanthropic donations, international political civic engagement, and domestic political civic engagement), the level of variance explained by duration was so minimal that for all intents and purposes, duration of study abroad did not matter in terms of global engagement.

An examination of the focus of the literature reviewed using Braskamp et al.'s framework (2009) gives a clear picture of the types of research that have been conducted as well as the gaps that remain. Table 2 summarizes the types of outcomes targeted in the literature in this review and shows that research on DFLI has focused solely on knowledge of foreign language whereas some research on short-term study abroad has focused on intrapersonal or interpersonal growth. 
Table 2

Types of Research on Global Learning

\begin{tabular}{|c|c|c|c|c|}
\hline $\begin{array}{l}\text { Prog. } \\
\text { Type }\end{array}$ & Study/Year & Cognitive Domain & Intrapersonal Domain & $\begin{array}{l}\text { Interpersonal } \\
\text { Domain }\end{array}$ \\
\hline $\begin{array}{l}\mathrm{I} / \mathrm{T} / \\
\mathrm{SA}\end{array}$ & Rifkin/2005a & Knowledge (language) & & \\
\hline $\mathrm{I} / \mathrm{T}$ & $\begin{array}{l}\text { Brecht, Davidson, } \\
\& \text { Ginsberg/1993 }\end{array}$ & Knowledge (language) & & \\
\hline $\mathrm{I} / \mathrm{SA}$ & $\begin{array}{l}\text { Cowles \& } \\
\text { Wiedemann/2008 }\end{array}$ & Knowledge (language) & & \\
\hline I & $\begin{array}{l}\text { Spielmann \& } \\
\text { Radnofsky/2001 }\end{array}$ & Knowledge (language) & & \\
\hline I & Russo/1997 & Knowledge (language) & & \\
\hline I & Jiang/1999 & Knowledge (language) & & \\
\hline I & $\begin{array}{l}\text { Liskin-Gasparro/ } \\
1998\end{array}$ & Knowledge (language) & & \\
\hline SA & $\begin{array}{l}\text { Shames \& Alden/ } \\
2005\end{array}$ & $\begin{array}{l}\text { Knowing (intellectual } \\
\text { curiosity) } \\
\text { Knowledge (language, } \\
\text { other skills) }\end{array}$ & $\begin{array}{l}\text { Identity (normalization, } \\
\text { independence) Affect } \\
\text { (self-confidence) }\end{array}$ & $\begin{array}{l}\text { Social Interaction } \\
\text { (social curiosity) }\end{array}$ \\
\hline SA & $\begin{array}{l}\text { Lewis \& } \\
\text { Niesenbaum/ } 2005\end{array}$ & & & $\begin{array}{l}\text { Social Responsibility } \\
\text { (globalization) }\end{array}$ \\
\hline SA & $\begin{array}{l}\text { Kehl \& Morris/ } \\
2007\end{array}$ & & & $\begin{array}{l}\text { Social Responsibility } \\
\text { (connectedness, } \\
\text { responsibility for } \\
\text { others) }\end{array}$ \\
\hline SA & $\begin{array}{l}\text { Medina-Lopez- } \\
\text { Portillo/2004 }\end{array}$ & & $\begin{array}{l}\text { Affect (intercultural } \\
\text { sensitivity) }\end{array}$ & \\
\hline SA & $\begin{array}{l}\text { Chieffo \& } \\
\text { Griffiths/2004 }\end{array}$ & $\begin{array}{l}\text { Knowledge (language, } \\
\text { ulture, country) }\end{array}$ & $\begin{array}{l}\text { Affect (understanding of } \\
\text { difference) }\end{array}$ & \\
\hline SA & Dwyer/2004 & & $\begin{array}{l}\text { Identity (personal } \\
\text { growth) } \\
\text { Affect (intercultural) }\end{array}$ & \\
\hline SA & SAGE/2006 & & & $\begin{array}{l}\text { Social } \\
\text { Responsibility (civic } \\
\text { engagement, } \\
\text { philanthropy, etc.) }\end{array}$ \\
\hline
\end{tabular}

Note. I=immersion, $\mathrm{T}=$ traditional foreign language program, $\mathrm{SA}=$ study abroad

The table makes apparent two gaps in research:

1. There were no studies of global learning outcomes of DFLI programs in the intrapersonal and interpersonal domains. The only studies of DFLI programs were in the cognitive domain and were studies of program effects on language proficiency. 
2. None of the researchers, with the exception of Shames and Alden (2005), have conducted comprehensive, holistic studies of all three domains of human development.

Almost all of the research reviewed found significant global learning outcomes for students who studied abroad for short periods of time. These multiple findings are an indication that meaningful learning can occur in programs of short duration.

\section{Other Research Related to Global Citizenship}

Because there were only a small number of studies related to global learning in DFLI and study abroad programs, this literature review was expanded to include other studies related to global citizenship. Global citizenship is a term that closely overlaps with Braskamp et al.'s definition of global learning and development (2009). None of the studies in this section were of programs with a foreign-language component, nevertheless, these studies were of interest because they provided information on research methods commonly used to investigate global learning and informed this investigation of a DFLI program.

Deardorff (2009) notes several challenges in researching global citizenship, such as defining terms and setting realistic expectations for program outcomes. There are numerous definitions of global citizenship, and Deardorff states that the most common themes underlying these definitions are: “(1) knowledge; (2) understanding the interconnectedness of the world in which we live; (3) intercultural competence, or the ability to relate successfully with those from other cultures; and (4) engagement on the local and global levels around issues that impact humanity" (p. 348). All of these 
themes are included in Braskamp et al.'s (2009) definition of global learning and development:

Table 3

Comparison of Global Citizenship and Global Learning and Development

\begin{tabular}{ll}
\hline Global Citizenship & Global Learning and Development \\
\hline Knowledge & Cognitive domain (knowledge) \\
Understanding interconnectedness of world & $\begin{array}{l}\text { Cognitive domain (knowledge and knowing) } \\
\text { Intercultural competence }\end{array}$ \\
& $\begin{array}{l}\text { Intrapersonal domain (affect) } \\
\text { Interpersonal domain (social interaction) }\end{array}$ \\
Engagement on the local and global levels & Interpersonal domain (social responsibility) \\
\hline
\end{tabular}

According to Deardorff (2009), of all the themes included in the definition of global citizenship, the concept "intercultural competence" is the most ambiguous and therefore the most problematic. There is no consensus among intercultural experts on terminology used to describe this concept, and Deardorff advises those who wish to conduct research on global citizenship to be mindful of the ways in which this concept is described in the literature and select the description that most closely fits the research design.

In addition, researchers also need to take a close look at the duration and features of the program to be investigated and set realistic learning outcomes (Deardorff, 2009). Without careful examination, investigators of short-term study abroad programs may, for example, easily overestimate the amount of contact to native speakers that program participants will have during their stay abroad and thus overestimate the potential impact of the program.

Deardorff (2009) looked specifically at assessment that has been conducted on global citizenship outcomes related to study abroad and stated that the most commonly 
used instruments were e-portfolios, self-report surveys, embedded course assessment, focus groups, interviews and observations. The studies reviewed here used a number of different types of instruments together with a variety of research methods to investigate a range of topics. The studies were all related to global citizenship within the context of undergraduate education.

In a mixed methods study, Hendershot (2010) examined student perceptions of identity with regard to global citizenship as well as student perceptions of perceived progress towards global citizenship. These 65 students were members of four cohorts enrolled in a global citizenship college program. Hendershot conducted her research using a survey designed for the study based on Mezirow's (2000) theory of transformative learning to measure students' beliefs and perceptions of opportunities for transformative learning in the college program. She also collected students' application essays as well as data from two of the cohorts using self-reflection interviews or focus groups. The study found evidence that students' conceptions of global citizenship shifted as students progressed in the program. Initially, the students perceived global citizenship to be the acquisition of knowledge and skills in the short term, but as students advanced, they recognized that global citizenship is an ongoing process of learning and growth. This shift is reflective of students' recognition of a transformative learning experience in which attainment of global citizenship is dependent on changes in frames of reference rather than the acquisition of facts or other information. The students identified several factors as the main contributors towards their global citizenship development. These factors were: constructive 
engagement with those who are different, opportunities to pursue social activism, engaging discussions with peers and faculty, and membership in a mentoring community. All of the students indicated that they had made progress towards global citizenship, and $61 \%$ stated they needed to continue to do more to facilitate their growth in this area.

Anderson, Levis-Fitzgerald, and Rhoads (2003) studied the implementation of one-unit seminars that were intended to challenge and motivate undergraduate students by providing practice in democratic learning and global citizenship through dialogue. The seminars were all related to the events of September 11 and were limited to 15 students each. The researchers collected data via an email survey of 236 students. The survey consisted of closed-ended items as well as a number of openended questions. In addition to surveying students, 93 faculty who had led the seminars were asked to participate in an email evaluation at the end of the seminars. The students participating in the study reported an increase in global awareness through the insights gained into the events of September 11. Some students commented that the seminars presented multiple perspectives not often found in U.S. media. Students also indicated that the dialogue format used in the seminars contributed to their growth in global awareness. The faculty surveyed noted increased student understanding of the global environment. Other themes that emerged as results of the study were the notion of students as sources of knowledge, empowerment of students, the importance of self-reflection, and the recognition that students' opinions mattered to faculty. 
In a preliminary mixed methods study of the impact of international learning, Carter et al. (2010) used a demographic survey and e-portfolios to assess international learning of 101 students. Learning outcomes as well as the data collection instruments were developed by a group of six colleges and universities through a grant from the U.S. Department of Education. The learning outcomes were centered on the development of knowledge, abilities, and attitudes in international learning. Analysis of the data suggested several general trends, including the following:

1. Attainment of learning outcomes improved as students advanced through the four-year college program, especially in the knowledge and attitudes categories, with the greatest improvement occurring after the sophomore year.

2. Study abroad had a positive impact in all areas of development.

3. Heritage/bilingual students showed more development in the areas of knowledge and foreign language skills, but monolingual native English speakers scored higher in skills related to using differing cultural frames of reference to think critically. The monolingual native English speakers also had higher scores in the attitudinal category with regard to ability to recognize their own biases or perceptions of the impact of cross-cultural experiences on their own development.

4. Attitudinal scores were the lowest for monolingual native English speakers who had traveled abroad as tourists for less than one month, and for bilingual/heritage students whose parents immigrated to the U.S. Most of the 
bilingual/heritage students participating in the assessment had spent longer periods of time living abroad.

Carter et al. (2010) concluded that carefully planned and executed short-term study abroad experiences can have a significant impact on students' development, and that short-term programs are especially important for older students who cannot easily spend longer periods of time abroad. Carter et al. also concluded that students with diverse ethnic, cultural, and linguistic backgrounds are not necessarily more tolerant of cultural differences or cultural ambiguity than other students. Finally, they called for more emphasis on integrating foreign language abilities across the university curriculum.

Dolby's qualitative study (2008) followed 46 American and Australian students prior to, during, and after a longer-term study abroad experience. Her purpose was to investigate how the students negotiated national and global identities, and also to demonstrate the nuances in the meaning of the word "global citizenship." Her intention was to show that any conceptualization of global citizenship needs to take into account factors that vary from nation to nation. The students were all interviewed prior to and following their study abroad experiences, and contacted via email during their stay abroad. The study abroad experiences students described occurred prior to the events of September 11. In the interviews, students were asked to reflect on their experiences from a national and global perspective. Dolby used a grounded theory approach to analyze and code for patterns and themes. She found that whereas the American students in the study were obsessed with trying to understand their own 
national identity and the role of the U.S. in the world, the Australians had a weaker sense of national identity, but a stronger sense of global identity that allowed them to feel more at ease abroad. Dolby, in examining American and Australian historical factors, concluded that the students' attitudes towards their national and global identity aligned well with the particular historical backgrounds of the two nations. The results of this study confirmed Dolby's initial assumption that global citizenship has to be defined in terms of contrasting national contexts. She noted that whereas the American students constantly engaged in critical self-reflection, the Australian students, coming from a country that is not considered to be a prominent player in global politics, did not engage in such reflection. In spite of this, the Australian students demonstrated more global awareness and political knowledge of the world. They did not exhibit an "Australian-centric" view of the world but seemed to feel more connected to the world than the American students.

In another study of American and Australian students at two universities in the U.S. and one university in Australia, Parsons (2010) conducted survey research via email to determine whether students' participation in a number of key components of university internationalization influenced the levels of a number of skills, attitudes, and behaviors associated with global citizenship. There were 1,302 participants in the study. Parsons developed the survey herself, using several well known instruments for measuring global learning as well as literature on topics such as internationalization, worldmindedness, and intercultural communication. She developed survey scales to measure foreign language proficiency, knowledge of a specific region or country, 
international knowledge, international attitudes and perceptions, cross-cultural skills, and international behaviors, all categories associated with global citizenship. Her results showed that high scores on the survey correlated significantly with a number of key components of an internationalized university. These components were: study abroad, contact with international students, an internationalized curriculum, and frequent attendance at international events. There was no apparent difference in the results for American and Australian students. This suggests that national context did not play a significant role in the impact of internationalization on global citizenship.

In a large-scale quantitative study of 17,000 former study abroad participants between 1950 and 1999, Mohajeri Norris and Gillespie (2009) investigated the impact of study abroad on the career paths of these students. They collected data using a retrospective longitudinal survey consisting of 28 questions and numerous subquestions that was developed and administered by the IES Abroad. The response rate was $25 \%$. The results of the study showed that (a) the study abroad experience had a significant impact on nearly two-thirds of the respondents, (b) half of the respondents later found careers that had a global aspect, and (c) sustained foreign language use was much greater for respondents who worked internationally. Study abroad for a full year, enrollment in university courses in the host country, homestay, and participation in internships all correlated positively with international work. Mohajeri Norris and Gillespie did not administer the survey to a control group, and it is unclear how high the percentage of careers with a global aspect was for persons who did not study abroad. Mohajeri Norris and Gillespie compared the results for alumni 
from the 1990s to the results from previous decades and found that recent alumni pursued careers with a global aspect more than alumni from any previous decade.

The research on global citizenship in undergraduate education spans a range of topics. Four of the studies reviewed examined the effects of college international programs on the development of global citizenship. Hendershot (2009) examined the effect of a college global citizenship program; Anderson et al. (2003) studied the effects of one-unit seminars around a global theme; and Parsons (2010) as well as Carter et al. (2010) investigated the impact of university international programs. All four studies found evidence of global citizenship development that underscored the value of university programs focusing on global learning. The topics chosen in the other two studies were somewhat different. Dolby (2008) studied the significance of national context in definitions of global citizenship, and Mohajeri Norris and Gillespie's study (2009) investigated the impact of study abroad on career choice.

My purpose in including this last group of other studies was to examine the research methods these scholars used to investigate global citizenship, a construct similar to Braskamp et al.'s (2009) concept of global learning and development. These studies employed a range of quantitative, mixed-methods, and qualitative designs. However, the studies had several commonalities.

First of all, all of the studies with the exception of Dolby's investigation (2008) used email questionnaires that were designed by the researchers. Hendershot's (2009) mixed-methods design incorporated focus groups and interviews in addition to the questionnaire, and Carter et al.'s (2010) mixed-methods design used a questionnaire 
and e-portfolios. The other three quantitative studies relied solely on questionnaires with mostly closed-ended questions. Only Dolby (2008) did not use a questionnaire but collected data in her qualitative study by means of pre- and poststudy abroad interviews and by email during the study abroad period. None of the researchers apart from Carter et al. discussed a rationale for the use of their methods. These instruments are among those Deardorff (2009) mentioned as typical for assessment of global citizenship outcomes related to study abroad.

Additionally, what is striking is the fact that all of the researchers relied on self-report data. As Wang (2010) states, global learning outcomes are only available to the researcher through direct query of participants. Any investigation of this topic needs to take into account students' perceptions of learning as these perceptions provide valuable data that cannot be obtained otherwise. The types of global learning outcomes that emerge, perhaps with the exception of language learning outcomes, are not quantifiable in terms of the amount of knowledge learned, because the learning itself is not accessible to students in terms of knowledge or information. Global learning is only accessible through shifts in frames of reference that inform students' learning.

\section{Summary of Literature Review}

A review of the literature related to DFLI and global learning outcomes revealed a lack of research on both DFLI and short-term study abroad. All of the scant research into impacts of college-level DFLI programs thus far has either been on language proficiency (Rifkin, 2005a; Cowles \& Wiedemann, 2008) or has probed the 
ways in which specific pedagogical approaches or content influence second language acquisition (Russo, 1997; Liskin-Gasparro (1998); Jiang, 1999; Spielmann \& Radnofsky, 2001). In a review of this literature, several findings emerged:

1. DFLI programs can provide an effective means to increase language proficiency in a short time.

2. Pedagogical approaches that were investigated in a DFLI environment, including provision of diverse and challenging activities, a target-languageonly requirement, and exposure to the use of metaphors, can have positive effects on language learning.

3. The intense immersion experience can lead to more native-like acquisition of the target language.

However, there has been no research conducted on global learning impacts of these programs, a gap in the research on DFLI that I addressed in this study.

Given the absence of research on DFLI and global learning, I turned to literature on the impact of short-term study abroad programs in order to gain a better understanding of possible program impacts. Short-term study abroad programs are similar to DFLI in a number of ways, and while the research into global learning and development of short-term study abroad is also limited, this limited research gave some indication of the influence a DFLI program might have on students' global development. Most of the short-term study abroad literature reviewed for this study provided evidence of significant global learning outcomes for students who studied 
abroad for a short period of time and offered an additional argument for the investigation of impacts of equally short-term DFLI programs.

Several studies of transformative learning in language classrooms investigated both the nature of transformative learning that occurred and the specific classroom features that students identified as significant transformative learning experiences. Students reported on language classroom experiences that gave them self-esteem or self-awareness, or made them more aware of their own culture and the target culture. In addition, they reported changes in perspectives on learning and knowledge. These are all characteristics of an increased global perspective. Factors that students mentioned as contributing to transformative learning were class discussions, collaborative learning experiences, opportunities for contact with native speakers, watching films, and teacher encouragement and support. All of these factors paralleled features found in DFLI programs and informed this study.

Finally, a review of research on global citizenship in non-language-related undergraduate programs indicated ways in which other researchers have investigated program impacts. Most of the research incorporated email questionnaires, and all of the research relied on self-support data. I used the information from these studies of non-language-related undergraduate programs to inform my choice of research design and selection of research tools. 


\section{Chapter Three}

\section{Methods}

Similar to several studies of global learning impacts of short-term study abroad programs, this research study used a mixed-methods design incorporating as a key instrument a retrospective survey of former participants in a DFLI program. This chapter explains the rationale for this approach, as well as instrumentation and strategies used for data collection and analysis.

\section{Rationale for Design}

The premise of this study was that participation in a DFLI program fosters a range of global learning outcomes. This premise was based on evidence from studies of short-term study abroad and other international learning programs as well as anecdotal evidence from former participants and on my own experience with DFLI. I conducted this study to help fill the gap in research on the global impacts of DFLI, and also to address the current demand for assessment of learning outcomes in the academic community (Steinberg, 2007) by illuminating the types of learning outcomes one might expect such a program to foster in students.

For this research, I chose a concurrent nested mixed-methods design in which both quantitative and qualitative methods were used with one nondominant method embedded in another predominant method (Creswell \& Plano Clark, 2007). The premises for this type of design are insufficiency of a single data set and the need for different types of data in response to different types of research questions. 
In this study, a predominant quantitative design was selected to collect data to be used to ascertain students' perceived program influence based on a numerical scale. According to Teddlie and Tashakkori (2003), such an approach is appropriate when the research objective is to explain relationships between variables. In this case, the quantitative approach was used to determine whether participants perceived the program to have had an influence on their global development as well as to determine the extent to which this influence was associated with participant characteristics.

However, while it was possible to investigate whether the program was perceived to have had an influence using a quantitative method, this method could not address the question of how the program had an influence. In addition, there was little research evidence I could draw on to explain the quantitative findings of this study. It was for this reason that I chose a mixed-methods approach with a qualitative instrument that could provide more detailed information than could be gained from a statistical analysis of quantitative data alone (Teddlie \& Tashakkori, 2003).

Teddlie and Tashakkori (2003) state that mixed-methods research achieves better results when studying complex social phenomena by offsetting strengths and weaknesses of a one-method approach. The combination of a quantitative and qualitative design used in this study is based on the concept of complementarity, a design type in which results derived from one method are used to explain or illustrate results collected through a second method (Green, Caracelli, \& Graham, 1989). This design allowed for a more complex description of the perceived influence of the DFLI program, thus providing a more complete picture of the role of such a program in 
university efforts to promote global learning and the specific program features that facilitated this learning.

\section{Participants}

Participants in the study had all attended the DFLI program between 1999 and 2011 and completed an online survey. Participants' ages at the time of the study varied between 20 and 76 . With regard to degree level, $68.5 \%$ were undergraduates, $28.1 \%$ were graduates, and $3.4 \%$ were senior guest auditors. The only program requirement was that students have at least two years of German, and participant language levels, based on ACTFL proficiency guidelines, ranged between intermediate and advanced high (ACTFL, 1985). All program participants were encouraged to live on campus to gain a fuller immersion experience, and $57.3 \%$ of survey participants took advantage of this. About $43 \%$ of mostly local-area participants commuted from home. Twothirds of participants were from the West Coast and one-third came from colleges in the Midwest or on the East Coast. One-third of the participants were regularly enrolled as students at the host university. Approximately $30 \%$ of the participants participated in the program more than one time.

An attempt was made to find email addresses for as many former students as possible to take part in the study. There were email addresses for most students on file, although many of these were no longer accurate. It was possible to trace a number of former students through former faculty or through Facebook forums that were created for alumni. I was able to find valid email addresses for 238 former students and invited them to participate in the study. Of these 238 students invited to participate, 89 
did so. The overall response rate was $37.4 \%$. This response rate compares favorably to Hadis' (2005) response rate of $20 \%$ in an online survey of 536 study abroad alumni as well as to the response rates for three large-sample surveys of study abroad alumni (Dwyer, 2004; Mohajeri Norris \& Gillespie, 2009; University of Minnesota Study Abroad for Global Engagement, 2009) with response rates between 25\% and 29.6\%.

Table 4 shows a comparison of characteristics for survey participants and the program participants invited to take part in the survey. There were several differences between the survey participants and the program participants invited to take part in the survey:

1. The average age for those who participated in the study was 37.7 as opposed to 33.5 for all program participants invited.

2. Sixty-four percent of survey participants were female as opposed to $59.2 \%$ in the group of all participants invited.

3. With regard to on- or off-campus residence, $42.7 \%$ of survey participants lived off campus as opposed to $20.2 \%$ of invited program participants.

4. Sixty-five percent of the survey participants were undergraduates in contrast to $78.6 \%$ of invited program participants.

Although no statistical analysis was conducted to determine significant differences, the descriptive statistics indicate similarity between those who chose to participate and those who did not with regard to age, gender, and degree level but less similarity with reference to on-campus or off-campus residence. 
Table 4

Characteristics of Survey Participants Relative to all Program Participants Invited to Participate in Survey $(N=238, n=89)$

\begin{tabular}{|c|c|c|c|c|c|}
\hline \multirow[b]{2}{*}{ Characteristic } & & \multicolumn{2}{|c|}{ Invited to Participate } & \multicolumn{2}{|c|}{ Participants } \\
\hline & & $\mathbf{N}$ & $\%$ & $\mathbf{n}$ & $\%$ \\
\hline \multirow{5}{*}{$\begin{array}{l}\text { Age at Time of Survey } \\
\text { (M for } \mathrm{N}=33.45, \mathrm{M} \text { for } \mathrm{n}=37.7 \text { ) }\end{array}$} & $18-25$ & 138 & 58.0 & 21 & 23.6 \\
\hline & $26-29$ & 38 & 16.0 & 12 & 13.5 \\
\hline & $30-39$ & 29 & 12.2 & 26 & 29.2 \\
\hline & $40-49$ & 13 & 5.5 & 15 & 16.9 \\
\hline & $50-76$ & 20 & 8.4 & 15 & 16.8 \\
\hline \multirow{5}{*}{$\begin{array}{l}\text { Age at Time of Program Participation } \\
\text { ( } \mathrm{M} \text { for } \mathrm{N}=28.5, \mathrm{M} \text { for } \mathrm{n}=32.5 \text { ) }\end{array}$} & $18-25$ & 70 & 29.4 & 20 & 22.5 \\
\hline & $26-29$ & 49 & 20.6 & 12 & 13.5 \\
\hline & $30-39$ & 75 & 31.5 & 26 & 29.2 \\
\hline & $40-49$ & 20 & 8.4 & 15 & 16.9 \\
\hline & $50-76$ & 24 & 10.1 & 16 & 18.0 \\
\hline \multirow[t]{2}{*}{ Gender } & Female & 141 & 59.2 & 57 & 64.0 \\
\hline & Male & 97 & 40.8 & 32 & 36.0 \\
\hline \multirow[t]{2}{*}{ On-Off-Campus Residence } & On & 190 & 79.8 & 51 & 57.3 \\
\hline & Off & 48 & 20.2 & 38 & 42.7 \\
\hline \multirow[t]{2}{*}{ Times Attended } & Once & 190 & 79.8 & 61 & 68.5 \\
\hline & 2-6 Times & 48 & 20.2 & 27 & 30.3 \\
\hline \multirow{5}{*}{$\begin{array}{l}\text { Degree Level/Full- or Part-Time } \\
\text { Status }\end{array}$} & Undergrad Full-Time & 172 & 72.3 & 56 & 62.9 \\
\hline & Grad Full-Time & 43 & 18.1 & 24 & 27.0 \\
\hline & Undergrad Part-Time & 15 & 6.3 & 5 & 5.6 \\
\hline & Grad Part-Time & 3 & 1.3 & 1 & 1.11 \\
\hline & Senior Guest Auditor & 5 & 2.1 & 3 & 3.4 \\
\hline \multirow[t]{3}{*}{ Language Level (Placement Testing) } & Intermediate $^{a}$ & unknown & unknown & 20 & 22.5 \\
\hline & Advanced Low ${ }^{\mathrm{a}}$ & unknown & unknown & 23 & 25.8 \\
\hline & Advanced Mid/High ${ }^{\mathrm{a}}$ & unknown & unknown & 46 & 51.7 \\
\hline \multirow[t]{2}{*}{ Significant International Experience } & Prior to Program & unknown & unknown & 84 & 95.5 \\
\hline & After Program & unknown & unknown & 84 & 84.5 \\
\hline
\end{tabular}

${ }^{\mathrm{a}}$ Based on ACTFL Proficiency Guidelines (ACTFL, 1985).

A possible explanation for the difference was that off-campus participants identified more strongly with the DFLI program because they attended the local university that sponsored the program. The off-campus participants were likely more 
aware of the DFLI program than participants from other parts of the country and also took pride in the fact that this nationally known program was affiliated with their home institution. It was not possible to compare the participants to non-participants in terms of language level, prior international or other intercultural experience, or postprogram international or other intercultural experience because I was unable to collect information on these characteristics from the non-participant group.

\section{Measures}

Data for this study were collected using a retrospective survey that asked participants to rate their agreement with a number of statements related to personal global development and then indicate the extent to which the DFLI program influenced their responses. I chose survey methodology as the means of data collection for several reasons. One reason was my relationship to the participants. My involvement with the DFLI program began in 2001 and, as the assistant director of the program, invariably almost all of the participants in this study had had contact with me either through the application and enrollment process or because of my work on site at the program location for four summers. Since this study investigated participant attitudes and behaviors, rather sensitive issues, I was concerned that any direct contact during the data collection process, for example, by means of a telephone interview, might cause participants to distort responses for reasons of social desirability, that is, to overreport what was perceived as positive and underreport negatively perceived attitudes or behaviors (Dörnyei, 2003). As Fowler (1995) states, a research instrument that can be self-administered helps to reduce response distortion, and it is in part for 
this reason that I decided to use an online survey that participants could fill out in privacy.

An advantage to using a retrospective survey was that it could be used in lieu of a quasi-experimental design with pre- and posttesting (Hadis, 2005). In place of a pretest in this study, the participants recalled attitudes and behaviors at an earlier time in their lives that corresponded to the responses they would have given on a pretest at the time of program participation. This recall then allowed them to gauge program influence and respond to the survey items. With this single-measure survey, data could be collected quickly at one time without the need to track respondents over a long period of time (Beckett, Da Vanzo, Sastry, Panis, \& Peterson, 2001).

A further advantage to this means of data collection was that it allowed for collection of data over many years of the program and thus provided a larger population and sample size suitable for the statistical measures used in the analysis. This design made it possible to draw on the experiences of program participants over many years rather than participants in any single year. This served to improve construct validity, since a study of multiple program sessions captured a more accurate picture than any single session's iteration of the program. Although the overall concept of the program has not changed for many years, changes in the make-up of applicants, faculty and programmatic features result in a somewhat different atmosphere and impact every year. For example, several years ago, the program was forced to relocate to a much smaller residence hall that lacked adequate living space. The overcrowding in rooms, lounges, and instructional spaces in combination with a 
week of severe hot weather caused a lot of stress among students and faculty and impacted the learning experience as participants were unable to sleep or concentrate fully on their studies. Had the research been conducted solely during that year's session, results might have been affected by these circumstances and not reflected the overall character of the program.

It could be argued that students who participated in the program as long as ten years ago might not be able to accurately remember their attitudes and behavior at an earlier time in their lives. However, Hadis (2005) and Becket et al. (2001) argue that a method that relies on memory is appropriate for situations in which an important experience leaves a lasting impression on a person's life, as recall of salient occurrences tends to remain intact. I argue that the experience of participation in DFLI is such an experience. As the assistant director of such a program, I often hear students describe the impact the program has had on their lives. The process of self-reflection that survey completion required was intended to help students recall their state of mind at the time this meaningful episode in their lives occurred.

In fact, allowing time between program participation and data collection was beneficial in another way. As Akande and Slawson (2000) point out, the impact of an educational program is often not realized by participants immediately upon completion of the program. Only when participants have returned to their normal routines and observe their attitudes and behaviors in familiar settings is it possible for them to discern changes. By allowing time to reflect on their program experience, 
participants in the study had time to process and realize the impact of the program on their lives.

Finally, the use of data collected via a survey allowed participants the opportunity to report their own perceptions of the program, unique perceptions that could not have been captured in another manner. Since program participants were the ultimate stakeholders of the DFLI program, it was important to give attention to their insights on program influence.

\section{The Global Perspective Inventory.}

Braskamp et al.'s Global Perspective Inventory (GPI, 2009) was designed to measure levels of global development at a given point in time. This questionnaire consists of about 40 statements related to development in the cognitive, intrapersonal, and interpersonal domains. Students respond to the statements using a Likert-type scale to indicate degrees of agreement. The GPI takes 15 to 20 minutes to complete. In addition to the 40 statements, the GPI asks participants for basic demographic information.

The GPI was not narrowly designed to be administered to college students, but was constructed to be used for persons of any age or cultural group. It is intended to be administered either as a pre- and posttest or at the conclusion of a program. It has been revised five times since it was piloted in 2007. The advantage of using this survey instrument for my research was that major psychometric characteristics of the GPI had been tested and revised to make them as sound as possible in terms of trustworthiness 
of self-reports, validity, and reliability. At the time of this study, the GPI had been administered by 54 institutions to 18,000 students for various purposes.

While the survey instrument developed for this study was not focused on ascertaining the level of global development per se, identification of the global development level of program participants served as a jumping-off point for determining the amount of change participants attributed to participation in the program. For this reason, the survey instrument developed for the present study incorporated all items in the GPI that pertained to the three domains of global development.

The GPI items incorporated into the survey instrument asked participants to respond to statements that indicated their level of global development across the three domains, with two scales for each domain. All responses were on a 5-point Likert-type scale where $1=$ Strongly Agree, $2=$ Agree, $3=$ Neutral, $4=$ Disagree, and $5=$ Strongly Disagree. Lower mean scores indicated a higher level of global development.

To make the GPI suitable for use as a retrospective survey, I paired each of the GPI items with the statement: "My response to the above question was influenced by my participation in the DFLI program." Participants responded to this statement for each GPI question by marking a 4-point Likert-type scale where $1=$ To a strong degree, 2 = To some degree, $3=$ Very little, and $4=$ Not at all, thus indicating to what extent their responses to the GPI items were influenced by participation in the DFLI program. This fixed-response format was selected to allow responses to be quantified for statistical analysis. In addition, this format helped reduce the time needed to 
complete the survey and thus achieve a favorable survey response rate. Participants' indications of the extent of influence of the program were used to determine whether the program had in fact influenced their global development, and whether there was differential development across the three domains. In addition to the GPI items and responses as to extent of program influence, I collected demographic data on age, gender, and prior international or other significant intercultural experience. This information, together with other demographic information collected from student applications and transcript information, was used to determine whether program influence was moderated by a number of student characteristics. I also collected information on post-program intercultural or other significant intercultural experiences to control for the effects of later experiences on survey responses.

Finally, I added an open-ended question to the questionnaire to collect qualitative data on participants' experiences in the program. The question asked: "Please describe an experience in the DFLI Program that was memorable to you." The purpose of this question was to gain insight into specific program features that might have contributed to perceived program influence. By asking an open-ended question, it was possible to obtain a more direct view of participants' ideas about the program to help explain the quantitative data. It was my hope that the responses would reflect students' global perspectives, and ideally, also shifts in perspectives, such as those revealed by the participants in Hendershot's (2010) study whose survey responses indicated a shift in perspective towards global citizenship. 


\section{Pilot study.}

This was the first time global learning outcomes of a DFLI program had been studied, and, because of this, it was unclear at the onset whether the questions asked would capture the data needed to answer my research questions. In addition, I wanted to determine the time needed to complete the survey to find out if survey length might deter participants from completing the survey. Finally, whereas the GPI has been tested psychometrically, the statements and open-ended question I added had not undergone such an analysis. For these reasons, I piloted the survey in a foreign language class prior to finalization.

The class selected for this purpose was a second-year level language class with approximately thirty students. After an in-class announcement of the survey by the instructor, I contacted the class via email, explained the purpose and provided a link to the survey. As an incentive, I offered to report results on levels of global development to those who participated. Of the thirty students invited, seven completed the survey, a completion rate commensurate to the attractiveness of the request for participation, considering the minimal incentive students had to complete a survey that had little to do with their foreign language class. The average survey completion time was 14 minutes, a time within the survey duration for Braskamp et al.'s (2009) original survey, even with the addition of items related to program influence and one openended question.

Given the fact that only seven of the 30 students in the pilot responded to the survey, it seemed unduly burdensome on the class to conduct a post-interview in-class 
debriefing. For this reason, I emailed the survey participants and asked for specific feedback on wording of survey items, ease of response, and survey length.

Unfortunately, I received no responses to this email.

Apart from the information learned from the pilot on survey duration, the results from the pilot indicated that even in a lower-division language class, students reported that the language program had influenced their global development to some degree. Based on the absence of any negative feedback or indication of faulty survey design in the pilot, I made no substantive changes to the survey apart from the addition of the items related to post-program international experiences.

\section{Procedures}

Dörnyei (2003) notes that giving advance notice to those invited to participate in a survey favorably influences participants' initial disposition towards the survey. Late in 2011, former program participants were given advance notice via email sent from the DFLI program's email address of the upcoming survey and research project. The advance email as well as the email invitation and follow-up reminder carried my signature. The advance email allowed me to determine the validity of the email addresses available. Approximately eight weeks after this advance email, program participants were sent another email inviting them to participate in the survey. This email contained an embedded link to the actual survey as well as the elements of implied consent as prescribed by the Human Subjects Research Review Committee. The survey was administered using Qualtrics, a software platform. The use of Qualtrics allowed me to track responses, send a follow-up reminder to program 
participants who did not respond initially to the survey, and also limit the possibility of participants taking the survey multiple times. The follow-up reminder was sent two weeks after the initial invitation. The advance email notice, the emailed invitation, and the follow-up reminder are included in Appendix B. All data were collected in March 2012.

\section{Data Analysis}

The quantitative data included in the analysis were survey responses and additional data on student characteristics that were collected in a spreadsheet for statistical analysis using SPSS. Responses to the items on the survey were in the form of continuous scores that were tabulated using descriptive statistics to be able to describe evidence of global learning and the extent to which participants attributed global learning outcomes to participation in the program.

In order to answer the first three research questions, I used the following statistical measures:

1. Analysis of means and standard deviation were used to answer Research Question No. 1: To what extent do students perceive their participation in a DFLI program to have influenced their global development in the cognitive, intrapersonal, and interpersonal domains?

2. A within-subjects analysis of variance (ANOVA) was applied to answer Research Question No. 2: Does students' perceived influence of participation in a DFLI program differ among the cognitive, intrapersonal, and interpersonal domains of global development? 
3. Regression analysis was used to answer Research Question No. 3: Does the perceived influence of a domestic foreign language immersion program on cognitive, intrapersonal, and interpersonal development differ by the student characteristics of age, gender, on- or off-campus residence, number of times attended, degree level, full-time or part-time enrollment, language level, or prior international or other intercultural experience?

A qualitative analysis was used to answer Research Question No. 4: If students perceive their participation in a DFLI program to have influenced their global development in the cognitive, intrapersonal, and interpersonal domains, what might explain these findings? Following the coding process described by Saldana (2009), I first read the responses and coded similar comments to obtain a general sense of common themes. I then used these preliminary codes to arrange the data into substantive categories to facilitate comparison. According to Maxwell (2005), substantive categories describe participants' beliefs or concepts concretely without regard to any particular theory. I did not preplan the categories in advance but allowed the participants' ideas to guide my analysis of the quantitative data rather than impose my own preconceived concepts of significant program features or effects on the data. After my initial categorization, I then re-compared the responses in each category and re-adjusted my first categorization. Finally, I collapsed the categories into seven separate themes.

In a second analysis, I looked at specific participant responses once more and developed a set of categories based on Braskamp et al.'s (2009) theoretical framework 
to identify ideas that could be linked to the three domains of global learning and development. The combination of the themes determined through coding and response categories based on Braskamp et al.'s framework were used to explain the quantitative findings.

In addition to the quantitative and qualitative analyses of participants' responses, I used background data available on all program participants and compared student characteristics of the 238 program participants invited to participate in the study with characteristics of the 89 participants who completed the survey. I analyzed these data descriptively to determine whether differences in age, gender, on or off campus residence, degree level, times attended, or full-time or part-time status resulted in self-selection bias. 


\section{Chapter Four}

\section{Results}

The purpose of this study was to shed light on the types and extent of global learning that are associated with participation in a DFLI program. In addition to examining overall global learning impacts, the study investigated whether there were differences in the impacts among three domains of global development as well as whether impacts were more pronounced for students with certain characteristics. Four research questions were asked:

1. To what extent do students perceive their participation in a domestic foreign language immersion program to have influenced their global development in the cognitive, intrapersonal, and interpersonal domains?

2. Does students' perceived influence of participation in a domestic foreign language immersion program differ among the cognitive, intrapersonal, and interpersonal domains of global development?

3. Does the perceived influence of a domestic foreign language immersion program on cognitive, intrapersonal, and interpersonal development differ by the student characteristics of age, gender, language level, degree level, on- or off-campus residence, full-time or part-time enrollment, number of times attended, or prior international or other intercultural experience?

4. If students perceive their participation in a domestic foreign language immersion program to have influenced their global development in the 
cognitive, intrapersonal, and interpersonal domains, what might explain these findings?

The study attempted to answer these questions by collecting data through an online survey of program alumni, and this chapter summarizes the results of quantitative and qualitative analyses of the data collected.

\section{GPI and Level of Global Development}

In addition to data on perceived DFLI program influence, Table 5 below contains GPI mean scores for both the DFLI participants and a national sample of students from Braskamp et al.’s (2009) studies. These GPI mean scores are for the readers' information. Braskamp et al.'s sample is not directly comparable to the group targeted in my research, especially in terms of age, study abroad experience, and major. However, a comparison of the two groups may help orient the reader to the global developmental levels the GPI measures as well as the global development levels of the DFLI participants in this study.

The GPI mean scores are based on survey items that were associated with the six global development scales. Survey participants were asked to indicate their level of agreement to these items on a 5-point Likert-type scale where $1=$ Strongly Agree, $2=$ Agree, $3=$ Neutral, $4=$ Disagree, and $5=$ Strongly Disagree. The responses were tallied and mean scores taken. Lower mean scores indicated a higher level of global development. 
A comparison between the two groups shows that mean scores for the DFLI group are lower on all of the scales than for Braskamp et al.'s group. This indicates a higher level of global development for the DFLI group on all scales.

\section{Table 5}

Means and Standard Deviation of Influence of Participation in DFLI on Global Development on the Six GPI Scales; Post Hoc Analyses of One-Way Within-Subjects ANOVAs of the Six GPI Scales

\begin{tabular}{lccccc}
\hline & $\begin{array}{c}\text { National Sample } \\
\text { (Braskamp et al., 2009) } \\
\text { GPI Scores, (n=42,138) }\end{array}$ & \multicolumn{5}{c}{ DFLI Participants } \\
\hline Domain & $\mathrm{M}^{1}$ & $\mathrm{M}^{1}$ & $\mathrm{SD}$ & $\mathrm{M}^{2}$ & $\mathrm{SD}$ \\
Cognitive & & & & & \\
$\quad$ Knowing & 2.38 & 1.96 & .39 & $2.61_{\mathrm{bc}}$ & .69 \\
$\quad$ Knowledge & 2.41 & 2.16 & .61 & $2.40_{\mathrm{a}}$ & .69 \\
$\quad$ Intrapersonal & & & & & .70 \\
$\quad$ Identity & 1.91 & 1.81 & .49 & $2.48_{\mathrm{ab}}$ & .70 \\
$\quad$ Affect & 2.21 & 1.92 & .40 & $2.61_{\mathrm{bc}}$ & .68 \\
Interpersonal & & & & & .69 \\
$\quad$ Social Responsibility & 2.31 & 2.26 & .57 & $2.95_{\mathrm{d}}$ & .62 \\
$\quad$ Social Interaction & 2.49 & 2.17 & .53 & $2.57_{\mathrm{abc}}$ & .72 \\
\hline
\end{tabular}

Note. Within the program influence columns, means with different subscripts differ at $\mathrm{p}<.05$ with subscript "a" signifying the highest rated subdomain influence and subscript "d" signifying the lowest rated subdomain influence.

${ }^{1}$ Means were based on a 5-point Likert-type scale where $1=$ Strongly degree, $2=$ Agree, 3 = Neutral, $4=$ Disagree, and $5=$ Strongly Disagree.

${ }^{2}$ Means were based on a 4-point Likert-type scale where 1 = To a strong degree, $2=$ To some degree, $3=$ Very Little, and $4=$ Not at all.

\section{Perceived Program Influence}

To address the first research question concerning the extent to which participants perceived participation in the program to have influenced their global development, I calculated the means and standard deviations for the participants' scores on six scales of global development. These means and standard deviations are 
shown in Table 5 above. The lower the mean scores, the more influence participants perceived the program had on their global development. Participants reported program influence in all six scales with means ranging between 2.40 on the lower end for Cognitive Knowledge and 2.95 on the higher end for Interpersonal Social Responsibility. These mean scores indicate the perceived extent of influence to be between "to some degree" and "very little" for all scales. As revealed through the standard deviations of the scores, there was more variability in the perceived influence on some scales than on others. Variability ranged very narrowly between an SD of .68 on the Affect scale and an SD of .72 on the Social Interaction scale.

\section{Program Influence Across Global Development Domains}

To answer the second research question regarding whether perceived program influence differed on the six scales of global development, I conducted one-way within-subjects analyses of variance (ANOVA). For the analyses, Mauchly's test

indicated that the assumption of sphericity had been violated, $\chi^{2}(14)=49.25, \mathrm{p}<$ $.001)$; therefore degrees of freedom were corrected using Greenhouse-Geisser estimates of sphericity $(\varepsilon=.83)$. Results of the one-way within subjects ANOVA, as shown in Table 5 above, indicated perceived program influence to have been lowest on the Social Responsibility scale, as indicated by the subscript "d." This rating was significantly different from all other ratings, $F(4.13,363.42)=34.06, \mathrm{p}<.001, \omega^{2}=$ .197. The Knowledge scale had the highest rating, as indicated by the "a" subscript, but did not differ significantly from Identity and Social Interaction. Overall, 
participants perceived similar influence on the Knowing, Knowledge, Identity, Affect, and Interaction scales.

Table 6

Summary of Multiple Regression Analyses of the Relationship Between Student Characteristics and Scores on the Six GPI Scales

\begin{tabular}{lccc}
\hline & \multicolumn{1}{c}{ ANOVA } & \multicolumn{2}{c}{ Regression Analysis } \\
\hline $\begin{array}{l}\text { Dependent Variable (6 Scales) } \\
\text { Cognitive }\end{array}$ & & R Square & Adj. R Square \\
$\quad$ Knowing & $\mathrm{F}(=9,78)=.26, \mathrm{p}=.98$ & .03 & -.082 \\
$\quad$ Knowledge & $\mathrm{F}(=9,78)=.28, \mathrm{p}=.98$ & .178 & -.080 \\
$\begin{array}{l}\text { Intrapersonal } \\
\quad \text { Identity }\end{array}$ & $\mathrm{F}(=9,78)=.90, \mathrm{p}=.58$ & .307 & .094 \\
$\quad$ Affect & $\mathrm{F}(=9,78)=.37, \mathrm{p}=.96$ & .203 & .041 \\
Interpersonal & & & \\
$\quad$ Social Responsibility & $\mathrm{F}(=9,78)=.35, \mathrm{p}=.96$ & .196 & .038 \\
$\quad$ Social Interaction & $\mathrm{F}(=9,78)=.80, \mathrm{p}=.62$ & .290 & .084 \\
\hline
\end{tabular}

\section{Student Characteristics and Extent of Program Influence}

Research Question No. 3 asked whether perceived program influence on any of the six scales, namely Knowing, Knowledge, Identity, Affect, and Social Responsibility, was associated with any of a number of student characteristics. To answer this question, I conducted multiple regression analyses. The student characteristics included in the analyses were

1. age at the time of participation,

2. gender,

3. on-campus or off-campus residence,

4. times attended,

5. degree level,

6. full-time or part-time status, 
7. language level,

8. prior international or other intercultural experience, and

9. post-program international or other intercultural experience.

The results of the six regression analyses, one for each of scale, are shown in

Table 6 . None of the multiple regression equations were significant at the $p<.05$ level.

These results indicated that none of the student characteristics included in the analyses, that is, neither age at time of participation, nor gender, on-campus or offcampus residence, times attended, degree level, full-time or part-time status, language level, prior international or other intercultural experience, or post-program international or other intercultural experience were significant predictors of perceived program influence on global development.

\section{Qualitative Results}

Research Question No. 4 asks for possible explanations of perceived program influence. To answer this question, I analyzed participant responses to an open-ended question on the survey: "If students perceive their participation in a DFLI program to have influenced their global development in the cognitive, intrapersonal, and interpersonal domains, what might explain these findings?" In the responses, participants either reported on events or situations that took place during the program, or described personal reactions to events or situations. For example, while some participants commented on interacting with other participants after class, other participants mentioned learning different perspectives through after-class interactions. My analysis of responses yielded seven salient themes. I made tallies of the number of 
comments related to each theme to ensure that only robust findings were reported (Miles \& Hubermann, 1984). Table 7 shows the themes as well as the tallies.

Table 7

\section{Themes From Qualitative Data and Frequency of Occurrences}

\begin{tabular}{lc}
\multicolumn{1}{c}{ Theme } & Number of Times Mentioned \\
Academic Experiences & 20 \\
Interaction with Others & 17 \\
Shared Activities Outside of Class & 16 \\
Language Use & 16 \\
Faculty & 15 \\
Perspectives & 11 \\
Community/Support & 7 \\
\hline
\end{tabular}

A further analysis of individual responses to the open-ended question on memorable experience is included in the discussion in Chapter Five.

\section{Academic experiences.}

The most frequently mentioned memorable experiences were related to academic occurrences. Some participants commented on what they had learned in the courses, for example, about grammar or German literature and history. Others described in-class activities, such as performing in the theater workshop, writing papers, and giving presentations. Finally, a number of participants talked about the challenging nature of the courses.

\section{Interaction with others.}

The second most frequently mentioned memorable experience was interacting with others over meals, during other activities, or "hanging out." Many of the participants reported interacting with others from different backgrounds. A smaller subtheme in this category was making new friends. 


\section{Shared activities outside of class.}

Activities outside of class were memorable for many participants. The most frequently mentioned activities were field trips, movies, cooking, and the Bergfest. Bergfest is a celebration held to mark the halfway point of the program, and during this event, every class has to give a performance, for example, of a skit or a song. Bergfest seemed to be particularly memorable to participants in this study, as this event alone was mentioned by nine different participants. Some described it as an opportunity to socialize or get to know each other better outside of class, however, two participants called it stressful, and it is probable that performing in front of a large group in German caused anxiety for some. Bergfest is a unique event because, unlike other planned activities which were all optional, Bergfest was mandatory and was attended by all participants, faculty, and also guests. This was for most participants the only time during the program that they were required to present in front of the whole group.

\section{Language use.}

Many participants reported on the novelty of using only German to communicate for five weeks. Some commented on the amount of German they were they were able to learn during the program. Four participants described speaking German all of the time as an achievement that resulted in more self-esteem, and a few others stated that being able to share their love of German with others was memorable. 


\section{Faculty.}

There were many participants who mentioned experiences with instructors as memorable. I categorized these responses separately rather than include them in the "Interaction with others" category because participants themselves seemed to distinguish between interactions with fellow participants and those with instructors. Whereas participants emphasized learning from fellow participants' perspectives, the comments on faculty tended to focus on the instructor's role as a guide or facilitator of learning. Participants recalled how knowledgeable or helpful instructors were, or remembered getting to know specific instructors closely. Some made more generic comments on instructors while others mentioned instructors by name.

\section{Perspectives.}

Participants frequently reported getting to know others' perspectives as memorable, and because of the frequency of comments this type, I decided to categorize these responses separately. Participants mentioned learning cultural differences from others, hearing memorable anecdotes that provided new insights, or, more generically, simply learning from others.

\section{Community/Support.}

Finally, a recurring memorable experience was that the community of participants and faculty at the DFLI program supported individual participants in a way that was conducive to personal growth. 


\section{Chapter Five}

\section{Discussion of Results}

In this study, the data collected provided a glimpse into learning outcomes of a program that have not been previously investigated. Given the increased interest of colleges and universities today in integrating global learning into core areas (Musil, 2006), this study has implications for many kinds of educational offerings from lecture series to specialized departmental programs to degree programs. Evidence of global learning outcomes associated with the DFLI program investigated in this study can help educators evaluate other programs in terms of features that support global education. In this chapter, I examine, interpret, and qualify the findings of the study by (a) focusing on possible explanations for perceived program influence and (b) identifying DFLI program features that may have facilitated global development. Subsequent to this discussion of findings, I present implications for practice as well as limitations of the study, and provide suggestions for further research.

\section{Perceived Program Influence}

The quantitative analysis of data showed that participants perceived participation in the DFLI program to have influenced their global development in all three domains. This analysis showed the amount of influence to be between "some" and "a little" on all scales, an indication that the program had an influence on global learning, albeit not an overwhelmingly strong influence. However, given the fact that the DFLI program targets language proficiency and cultural knowledge rather than global learning, this perceived global impact is noteworthy and important, as it 
demonstrates that DFLI can facilitate global development. This finding is consistent with results from a few other studies on multiple types of global development in shortterm study abroad programs. For example, Chieffo and Griffiths (2004) reported growth in the Cognitive and Intrapersonal domains in a large-scale investigation of study abroad. Shames and Alden (2005) found increases in all three domains in a short-term study abroad program in five European countries. In the following discussion of perceived influence in the three domains, I use the qualitative data collected on a memorable program experience to explain which program features may be associated with increased global perspectives.

\section{Cognitive domain.}

Braskamp et al. (2009) state that the central question in the cognitive domain is "How do I know?" Signs of growth in the cognitive domain are recognition of the value of other cultural perspectives as well as incorporation of others' perspectives when drawing conclusions about the world. In addition, growth in this domain includes a deepening awareness of current issues that impact the globe, knowledge of the ways in which various cultures interact socially, and an understanding of how to analyze cultural characteristics as well as the ability to discuss cultural differences in an informed manner. Another sign of development in this domain is a lessening of reliance on absolute truths.

In the qualitative analysis of student responses to a question asking participants to describe a memorable experience, two of the themes that emerged centered on others' perspectives and academic experiences. These mentioned themes suggest 
influence in the cognitive domain. Many participants described learning the perspectives of native-speaker faculty and participants "from different backgrounds" as memorable. The frequency with which participants spoke of participants from different backgrounds was surprising considering that virtually all of the participants were American college students who majored in German and appeared to share similar backgrounds. Nevertheless, this was one of the most prevalent memorable experiences reported. It is possible that regular contact with a diverse group of participants of different ages from different parts of the country was for many a significant experience with difference.

The types of exposure to others' perspectives varied. Participants mentioned listening to lectures, engaging in class discussions, or dialoguing with others informally. One participant articulated the way in which several personal nativespeaker narratives heard in a series of lectures had shaped her perspectives. One narrative the participant mentioned was an account by a speaker who told the story of growing up in East Germany and then having to cope with the loss of her country after the reunification of West and East Germany. The participant commented that hearing this and other personal stories had had a lasting experience on her life and her own perspectives.

Other participants mentioned as memorable discussions of current issues in Germany. For example, one person wrote about the assimilation process for immigrants in Germany and stated that some of her European friends expressed sentiments that were less tolerant than she had expected. She claimed that a challenge 
she faced was to identify those less inclusive perspectives and understand how they had shaped her thinking.

Another participant mentioned as memorable: "taking part in mind and language-expanding discussions during lectures, seminars, and beim Essen [at meals]." With this comment, the participant expressed how he gained knowledge through encounters that expanded his ability to recognize and reflect on others' perspectives, an indication of growth, or, at least the opportunity for growth, in the cognitive domain. The significance of discussion for this participant is consistent with a finding from a study on transformative learning (King, 2000) that class discussions contributed to perspective transformation.

Also related to cognitive development were academic experiences that many participants reported in their responses. For example, one participant stated that the classes in the DFLI program continually challenged him to "develop academically in terms of being able to research and present ideas as well as analyze literature, history and politics." Development of critical thinking skills, as suggested by this participant, is associated with cognitive growth, and such an experience may have contributed to the participant's perception of program influence. While reports of memorable academic experiences are not unique to the DFLI program but may be found in other types of college programs, these reports of DFLI participants are worth noting, especially given the large number of participants who mentioned academic experiences as memorable. Academic experiences were the most frequently mentioned theme. 
While it is important in this discussion of DFLI program influence to mention program experiences that may be associated with growth in the cognitive domain, it is also important to discuss the range of experiences mentioned. Apart from opportunities to learn others' perspectives or learn thinking skills, there was no report of other types of program features that supported cognitive global development. Participants frequently referred to opportunities to learn firsthand the perspectives of native speakers and fellow participants from different backgrounds, but there were no participant comments that described planned formal classroom instructional units about differing cultural perspectives or analysis of cultural characteristics. One summer, there was a lecture given on how to analyze observed cultural characteristics according to a model called Describe-Interpret-Evaluate (Paige, Cohen, Kappler, Chi, \& Lassegard, 2006) but the fact that there was no subsequent discussion of this particular lecture seemed to indicate the lecture may not have been well received. It is possible that the program's focus on creating a community of learners, or a "summer school family" as one participant described it, was counter-productive to discussions of differing cultural characteristics, since such discussions might have emphasized difference rather than community. While many participants mentioned conversations with others from "different backgrounds" in their responses to the question about a memorable experience, the focus of these responses appeared to be on understanding and reconciling difference rather than seeking it. Judging by the memorable experiences participants reported, it appears as if the program facilitated some aspects 
of cognitive global development, but other aspects of cognitive development occurred at best incidentally.

\section{Intrapersonal domain.}

According to Braskamp et al. (2009), the central question asked in the intrapersonal domain is "Who am I?" A more advanced global perspective in this domain is characterized by awareness and understanding one's own identity as well as possession of the confidence to act according to one's beliefs and care for one's needs when faced with a completely new situation. Other signs of development in this domain are understanding and acceptance of those different from oneself, and an absence of discomfort when presented with multiple perspectives.

Some DFLI participants' comments pointed to program influences and practices that supported growth in the intrapersonal domain. A number of participants reported that finding ways to cope with the challenging curriculum and especially with the German-only requirement led to increased development of self-esteem. Self-esteem implies self-knowledge and self-acceptance, qualities closely related to identity. One participant described the effect of the program on her self-esteem as follows:

I think the feeling of accomplishment and self-validation brought on by the sudden and intense comprehension that occurred in the second week of classes was one of the most important experiences in my adult life. I have struggled with illness most of my life and I didn't 
know how much it damaged my self-confidence until it returned along with my fiery ambition in the DFLI program.

A number of participants described as memorable the fact that the DFLI community helped them cope with the challenges of the program and overcome lack of self-esteem. For example, one participant noted that the overall feeling of the event was the strong sense of community that was created there. The mix of ages, ethnicities - not just German and American, faiths, and background in the safe environment created by the director and staff, provided a unique opportunity to open up, stretch and to grow and to learn from others, without feeling threatened or worry about being judged.

This comment describes the way in which the program may have played a role in the development on the Identity scale.

Still others described the instructors as encouraging and helpful. Buttaro and King (2001), in a study of transformative learning in an ESL class noted that the encouraging and motivating environment in the classroom gave students more self-esteem, a finding that is supported by the participant comments and the quantitative results in my study.

In terms of the Affect scale, the opportunity for interaction with others in the program in relaxed moments, as well as in situations that were challenging or stressful, may have been conducive to increased understanding of others. Participants spoke of the collaborative atmosphere and the need to solve problems with the help of other 
participants or faculty. One participant wrote the following about such a collaboration: "My most memorable experiences were the friendships I developed and the Bergfest/Theater performances. I was able to contribute my own ideas, prepare for a role, and perform both individually and in a group."

Some literature on transformative learning asserts that transformation occurs when a disorienting dilemma is followed by critical reflection and discourse that helps the learner better accommodate and interpret experience (Mezirow, 2000). However, there was no conscious effort made in the DFLI program to promote self-reflection that might have led to more personal growth. Nevertheless, it is possible that the program fosters growth in the intrapersonal domain even without an intentional effort to encourage self-reflection. As noted by Dolby (2008) in her study of American and Australian perspectives on global citizenship, Americans tend to constantly engage in critical self-reflection. Thus, critical self-reflection may well take place without any intentionality on the part of program leaders in the DFLI program. It is also possible that program leaders and faculty assume that students will engage in such selfreflection. One participant's reported memorable experience indicates just such critical reflection:

My greatest achievement at the DFLI program was obtaining a sense of humility. Having always been academically successful with math and science and music did not apply here because, well, everything was in German! Throughout these five weeks I had to endure sounding dumb or stupid to myself and in front of my peers in order 
to accomplish German proficiency, and by overcoming this I felt like I gained everything. Learning German really extended beyond the realm of knowing where to place words in a sentence or getting a high score on a vocabulary quiz- for me it was sharing the pain and suffering of an intense homework project with my peers, finding a way to fit in a jam session between classes, and having people get a sense of who I was without the comfort of my native language.

This description of a participant's memorable experience seems to be consistent with a perspective transformation that occurs when a disorienting dilemma is followed by critical reflection (Mezirow, 2000).

\section{Interpersonal domain.}

The core question in this domain is "How do I relate to others?"

Development in this domain is characterized by increased feelings of social responsibility, that is, consideration of the effects of one's behaviors on society as well as efforts to contribute to the welfare of others. Other signs of development in this domain are greater interest and curiosity in interacting with those different from oneself as well as the ability to navigate other cultures.

Studies into the effects of short-term study abroad on social responsibility show mixed results. Lewis and Niesenbaum (2003) showed growth in this area for both short-term and long-term study abroad students who participated in a program that included a service learning component. SAGE (2006) found evidence that students who participated in short-term study abroad showed as 
much social responsibility as those who studied abroad for longer periods of time. Kehl and Morris (2007) on the other hand, found significantly lower levels of global mindedness among short-term study abroad students than among students who studied abroad for a semester.

In the DFLI program in this study, a number of participants commented on the supportive atmosphere and the sense of community to be found in the program, characteristics that may be associated with the Social Responsibility scale. Other participants reported memorable experiences that were related to the Social Interaction scale, namely activities that they shared with other participants. For example, one student wrote: "There have been so many memories that I have from the DFLI program from the interactions on the stage with my fellow DFLI-ers to the times sitting out on the 'Wiese' [front lawn] watching stars and sharing about life situations." Comments on memorable experiences related to Social Interaction were frequent.

\section{Program Influence Across Global Development Domains}

The analysis of quantitative data showed that DFLI participants perceived program influence to be similar on all five scales of global development, that is, Knowing, Knowledge, Identity, Affect, and Interaction. Knowledge had the highest rating but did not differ significantly from any of the other scales except for Social Responsibility. Participants' rating of Social Responsibility was significantly lower than all other ratings. 
When one reads participants' statements on memorable experiences, one is struck by the degree to which an experience can have an influence in multiple domains of global development. For example, one participant wrote

I was somewhat shy about participating in conversations in German, but it didn't seem to make any difference as to whether or not I was accepted as part of the summer school family. In so many ways, the DFLI program has shown me what community means. At the DFLI program I was shown that everyone, regardless of ability or needs, can participate in that community and becomes part of a larger family that cares about each person's success within the whole.

In this description, the participant's comment on her initial shyness and feeling of acceptance by others point to growth in the intrapersonal domain as she felt more confident about speaking in Germans, and her comments about community and caring for others' success suggest growth in the interpersonal domain.

Similarly, another participant stated

Playing the role of the Stubenmädchen [parlor maid] in Der Soldat und das Stubenmädchen in Schnitzler's Reigen for the Dramatik [drama] course. It gave me a greater respect for German literature, and the work of analyzing and memorizing lines was so very helpful for me as a beginner. The Director was wise and patient and we all learned so much! It had such a postive impact that I am blinking back tears as I write this. 
Her comments on gaining respect for German literature align with growth in the cognitive domain as she accommodated a new perspective on literature. Her description of the helpfulness of the work involved in preparation for this play may indicate growth in the intrapersonal domain as she gained confidence in her ability to learn her role.

Table 8

Program Features, Participant Values, and Global Development

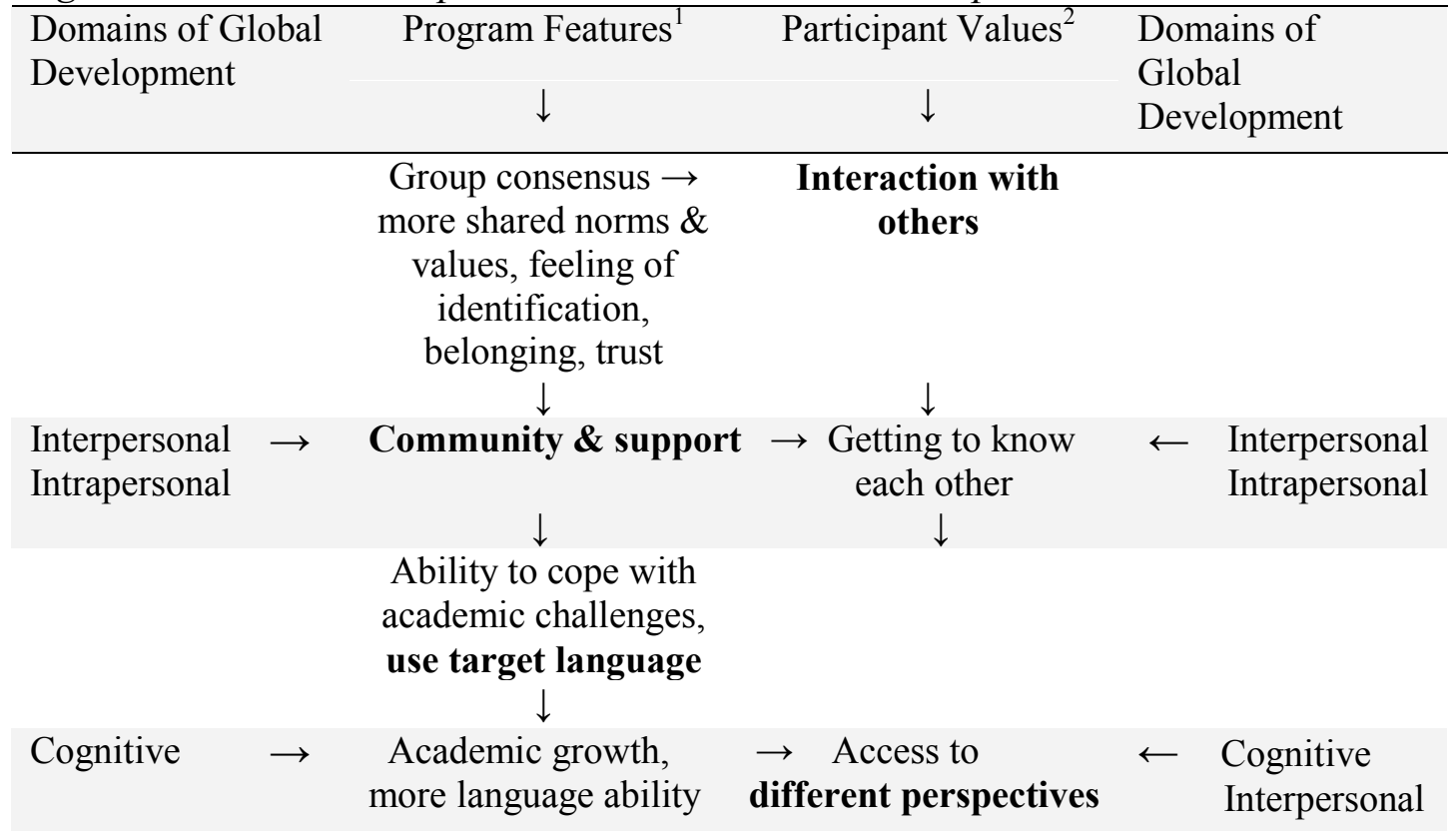

Note. Themes identified in the qualitative analysis are in bold.

${ }^{1}$ Intense contact to others, faculty, shared academic/out-of-class activities

${ }^{2}$ Learning German, other shared values

Table 8 illustrates the way in which program features and participant input in the form of shared values may have combined to influence growth across the three domains. Salient themes identified in the qualitative analysis of comments on memorable program experiences are shown in bold to highlight the role of these 
findings in perceived program influence on global development. In the DFLI environment, program features, such as the intense contact to other participants and faculty during in-class and outside-of-class activities, led to group consensus as the group found commonalities and individual participants began to identify with the group and develop trust. This created a supportive community that facilitated growth in both the interpersonal and intrapersonal domains. Participants and faculty lived in close quarters and the atmosphere these close quarters created was supportive and nonjudgmental. This community of learners supported participants' ability to cope with the commitment to speaking German and the challenging and varied academic experiences. Participants were encouraged to try out new activities and new modes of learning. This led to academic growth and increased language ability and fostered growth in the cognitive domain.

At the same time, participants brought with them a number of shared values, such as interest in learning German, and, among some participants, a personal interest in, for example, music, theater, or sports. The atmosphere encouraged communication by providing an array of opportunities for formal and informal exchange as well as a large amount of input on various topics. These commonalities together with the experiences at the DFLI program fostered interaction with others, led participants to get to know each other well, and facilitated growth in the cognitive domain as participants accessed and began to appreciate others' perspectives, and gained knowledge and skills that would allow them to better draw conclusions about global issues. At the same time, the intense interactions with others in the target language 
provided learning experiences that aided participants' search for self-knowledge as well as self-acceptance, thus facilitating growth in the intrapersonal domain. Additionally, these interactions between participants and faculty helped facilitate an interest in seeking out those who are different from themselves and supported growth in the interpersonal domain. .This characterization of the overlap of domains conforms to Braskamp et al.'s (2009) model of global development in that growth in one domain occurs simultaneously with growth in the other domains. At the same time, development in one area influences development in other areas.

However, this explanation of synergistic development across the three domains contradicts the finding in this study that the perceived influence of the program on social responsibility was lower than on the other scales. In spite of the fact that the atmosphere at the DFLI appeared to be conducive to community and support for fellow participants, there are other factors that have to do with the nature of the DFLI program as well as the particular countries where German is spoken that may explain the lower degree of perceived influence on Social Responsibility.

First of all, while the relatively isolated location of the program may be conducive to the language learning process, and while program participants form a close-knit community that fosters empathy and support for each other, the location provided little or no opportunity for participants to interact with those outside the program, much less witness situations that might have led participants to critically reflect on their own role in society and become aware of the import of their actions. Second, while there are study abroad programs with a service learning component that 
might cause participants to undergo a shift of perception of the effects of globalization, such as the service learning program Lewis and Niesenbaum (2005) investigated in Costa Rica, the DFLI program does not have a service learning component, nor would a service learning component be compatible with a German language immersion program in this country.

Finally, while it is possible for American students to work for charitable organizations in Germany, an experience that could help students develop social responsibility, such opportunities are rare, and most American students who study abroad in Germany or Austria do not have opportunity to witness poverty or other social ills that could lead them to question values and become more aware of the effects of their behaviors on the rest of the world. In addition, students who participate in study abroad programs in Germany tend to be placed in good homes or other adequate housing and have their needs well met while they are abroad. Students who have studied in Germany and subsequently attend the DFLI program tend not to have had study abroad experiences that would lead to development of social responsibility.

\section{Student Characteristics and Extent of Program Influence}

The DFLI program examined in this study draws participants from different backgrounds and ages, and for this reason, it was important to find out whether perceived program influence was moderated by any of these characteristics.

I surmised that for older students as well as more experienced graduate students, levels of maturation might result in diminished perceived program influence. Similarly, it was possible that for participants who had prior international or other 
intercultural experience, this exposure to an internationalized atmosphere might lead to less perceived influence than for participants who were inexperienced internationally and interculturally. It was also possible that participants with higher levels of language proficiency might perceive a different degree of program influence than other students. I surmised that students with more advanced language ability might also have more advanced levels of global development, and that for these participants, perceived program influence might be lower.

I also examined the effect of on-campus residence on perceived program influence. Applicants to the DFLI program are encouraged to live on campus rather than commute from home to be able to get the full immersion benefit. The program maintains that participants who live off campus and commute to campus may not achieve the same language proficiency gains, and I surmised that off-campus participants might achieve less progress in terms of global development. Similarly, I theorized that participants who attended only part time might not benefit in terms of global learning to the same degree as full-time students.

In addition, I examined the perceived influence of the program in terms of gender to determine whether gender-based ways of learning might lead to different perceived impacts. Finally, I included attendance in multiple years as opposed to attendance during a single summer in my analysis.

However, the results of the statistical analysis showed that none of these characteristics were associated with perceived program influence on global development. With regard to maturation, research has demonstrated that 
undergraduate students show development as they progress from freshmen to seniors (e.g., Perry, 1981) but it is possible that this development does not continue in the same fashion after the traditional college age of 24 or for students pursuing advanced degrees. Hadis (2005) obtained a similar result in his research on study abroad participants, although his older participants were younger than the older participants in this study.

A surprising finding was that for participants who had significant prior international or intercultural experience, there was no significant difference in perceived program influence. A possible explanation might be that international or intercultural experience gives participants the ability to tap into ranges of global development through subsequent exposure to DFLI that are not accessible to those with less experience. Rifkin (2005a) argues that only students who have advanced foreign language knowledge have the ability to understand the intricacies of cultural difference, and it is possible that this explanation is valid for those with significant international or intercultural experience as well. Hokanson's 2000 investigation of study-abroad students in Guatamala supports this explanation:

It was also surprising that off-campus and part-time participants perceived the same levels of program influence as those who lived on campus and those who attended full time. Perhaps it was sufficient for these participants to spend a portion of time in the immersion environment each day to realize global development benefits. Gladwell (2000) theorizes that in any event or situation there is a tipping point at which a trend or idea will take hold. Since a majority of DFLI participants lived on 
campus and maintained the intense character of the DFLI environment by speaking only in the target language, building a close community, and engaging in shared learning experiences, it is possible that this effect spilled over to participants who lived off campus or attended part time.

In a program that attracts participants with varying characteristics and also tries to accommodate varying participant needs, the fact that perceived program influence was not moderated by age, gender, on- or off-campus residence, times attended, degree level, full-time or part-time status, language level, or amount of international or intercultural experience is good news. This finding is an indication that the DFLI can be beneficial for students with varying characteristics. As university populations become more diverse, programs that are versatile enough to be beneficial to students with varying characteristics have a better change of success.

\section{Implications for Practice}

The DFLI program I investigated in this study exhibited several features that may have facilitated global development, including (a) plentiful and varied opportunities to interact with others, also those different from oneself, (b) a Germanonly requirement, and (c) a supportive community of learners and instructors. A significant finding was that none of the student characteristics included in the study were associated with perceived program influence.

There are arguments from the transformative learning camp that help explain the many positive participant comments on the program. According to Daloz (2000), the prerequisite for transformative learning is the existence of an empathic connection 
with another person. The DFLI program's promotion of interaction combined with the intensity of the immersion experience, the level of academic challenge, and the close proximation to fellow participants and faculty may have facilitated transformative learning that resulted in development of global competencies.

The findings of this study point to a number of ways to improve educational practices to facilitate global learning. Many of these ideas are not new but are worthy of reconsideration in light of the current interest of colleges and universities in global learning.

A second implication for practice is to provide opportunities for interaction with significant numbers of students and faculty with different backgrounds. Whereas the American Council on Education (1998) has long made the recommendation that institutions offer more opportunities for exchanges with citizens of other countries, the results of my study indicate that exchanges with people from different background in the U.S. can foster global learning. One type of program that offers such exchanges is "study away." Study away refers to the practice of studying away from home at an institution outside one's state or local area (Sobania \& Braskamp, 2009). Sobania and Braskamp recommend this type of program as an alternative for students for whom study abroad is not feasible for various reasons.

The findings of this study substantiate the importance of rich and varied opportunities for exchanges with others. In the field of foreign languages as well as in other educational settings, the opportunity to share a wide variety of activities with others who seek increased language proficiency or other educational goals gives 
students the opportunity to get to know each other and interact over many kinds of topics. This increased interaction helps students recognize and understand other cultural perspectives. In a foreign language setting, this could mean setting up sport clubs or activities and events that are related to the target language such as film evenings, cooking events or songfests. This study demonstrates that a variety of activities in a range of settings, including activities that are seemingly unrelated to program content, can have an impact on students' learning.

For foreign language programs, the target-language-only feature is one experience that can be duplicated on a smaller scale, for example in weekend programs or even "target-language-only days." Such programs exist at a number of colleges and universities. Many foreign language departments have courses that require use of the target language for communication in class. There are, however, obstacles that can make a target-language-only course less effective in terms of global learning than the target-language-only requirement in a DFLI program. For example, making use of the foreign language a grade requirement puts undue pressure on students and may be demotivating. As Rifkin (2005a) points out, DFLI students tend to be a highly self-motivated group. These students are motivated intrinsically by a desire to become proficient in the language and for the most part elect voluntarily to participate in DFLI. Foreign language classroom practices that motivate students to use the target language as a medium for communication may promote global development. 
There appears to be a renewed interest in so-called "language houses" in residence halls of universities that have target-language-only requirements for residents when they enter the residence hall. For example, the University of Oregon ("University of Oregon Global Scholars," 2013) has recently opened a new residence hall that offers immersion in several languages. One of the findings in my study was that students who lived off campus perceived the same program influence on global learning as those who lived on campus. This suggests that it may not be necessary to participate in a 24-hour immersion experience to reap the benefits of global learning.

Finally, another finding of this study points to desirability of creating communities of learners that can support and encourage each other. This is a difficult task in many university settings, particularly for older students who have family, work or other obligations. There is a general trend towards more diverse and older student populations (Olson et al., 2006), and finding ways to create community, such as through a DFLI program, is a worthwhile endeavor.

\section{Limitations}

Several limitations have been noted in previous research on the impacts of study abroad programs including lack of a control group, self-selection, and problems with self-report data. An attempt was made in the design of this study to address these limitations.

Dwyer (2004) notes that it is difficult to find a control group that is truly comparable with the experimental group because there are too many confounding variables such as socio-economic levels, academic choices, maturation, etc. In 
addition, there is little incentive for students to participate in a control group when they have no vested interest in the program. As noted by Rifkin (2005a), we can assume that students who choose to participate in a DFLI program are not representative of the entire undergraduate population of a university. After all, these immersion participants are students who have chosen to study German, a reputedly difficult language, and give up five weeks of their summer to participate in an intense and work-intensive summer program. Therefore, an appropriate control group should match this group in motivation to learn. While it was difficult to find such a control group, it was at least possible to control for maturation, a potentially significant external factor in this study (Hadis, 2005). Hadis notes that traditional-age college students undergo noticeable maturation, especially between the second and third year of college. This retrospective design allowed me to control for age by separating and comparing data collected from traditional-age and older students to determine impacts that were attributable to program participation and those that may have been associated with maturation.

Another limitation in this study was self-selection. Former students in the program self-elected to participate in this study, and it is possible that students who experienced the most impact from the program were more interested in completing the questionnaire than other students. Since application materials and other background documentation on these students were available, it was possible to compare students who participated in the study with those who did not to determine any significant 
differences. This allowed me to make meaningful inferences as to program impact on the group as a whole.

The disadvantage of self-report data collected in this study was that it was impossible to know whether the participants responded truthfully. However, the use of self-report data was also advantageous in several ways. It allowed direct insight into participants' perceptions of their experience and eliminated the necessity of inferring students' experience based on observation. As Wang (2010) argues, a study that investigates shifts in perspectives, such as those involved in global learning, cannot illuminate such changes through quantitative measures but must take into account students' perceptions of learning. One main problem with self-report data was social desirability bias, that is, a skewing of responses by participants choosing to portray themselves in a favorable light. However, about half of the survey items used in this study were taken from Braskamp et al.'s (2010) GPI. The items in the GPI have undergone several revisions to reduce the likelihood of social desirability bias.

A further limitation of this study was recall bias. Griner Hill and Betz (2005) point out that there is some degree of recall bias in all retrospective ratings. However, there is also evidence that salient events such as those queried in this study tend to be recalled more accurately (Beckett et al., 2001). It should also be pointed out that retrospective designs are not necessarily less accurate than pre- and posttest designs. Pre-and posttest designs may also be problematic due to response-shift bias when participants overestimate knowledge or attitudes on the pretest that may result in an 
underestimation of program impact. In addition, participants may experience repeatmeasure fatigue that can affect data collected.

Another limitation was the difficulty of collecting post-program experience on survey participants to be able to determine whether such experience had an effect on recall. However, I collected information on post-international or other intercultural experience and was able to include this in the regression analysis used to answer Research Question No. 3. This analysis indicated that post-international or other intercultural experience was not a predictor of perceived program influence. Other post-program data were not collected. I did not want to add additional length to the survey when it seemed impossible to collect enough post-program data to ensure that I had accounted for all post-program characteristics that might impact responses.

\section{Recommendations for Further Research}

This study was a first probe into the type and extent of impact DFLI programs can have on global learning outcomes. As such, findings from this study can only be used as indications of impacts to be expected from other DFLI programs. However, these findings are not generalizable to the whole population of DFLI participants. For this reason, an investigation of other DFLI programs might corroborate the findings from this study and provide a better understanding of the specific global learning impacts of such programs.

One surprising finding in this study was that on-campus or off-campus residence was not a significant predictor of perceived program influence. A replication of this study with other types of programs used to support global learning outcomes 
could help ascertain which specific program features are significant factors in promoting global development.

In order to limit the possibility of recall bias, a further study of global development impacts of DFLI programs could incorporate a true pretest-posttest design. The pretest could be administered a few weeks prior to the start of the program, for example, at the time of admission, to lessen the possibility of responseshift bias. The posttest could be completed within a few months after program participation to decrease the likelihood of recall deterioration. Such a study might provide a tighter picture of global learning outcomes of this type of program.

Data for this study were collected solely by means of an online survey. The use of a qualitative open-ended question about a memorable program experience helped in the interpretation of the quantitative findings. Unfortunately, some of the responses to this question were not specific enough to be useful in the interpretation of the quantitative data. In a new study, the addition of participant interviews to be conducted subsequent to the survey would allow the researcher to probe the qualitative responses and collect enough detail to better explain the quantitative findings.

Finally, I noted in the literature review that the only research on DFLI programs has been in the area of second language acquisition. On the other hand, none of the research on transformative learning in foreign language classes and very little of the research on global learning in the context of study abroad have included a linguistic component. Nevertheless, there is some evidence that higher levels of language proficiency are associated with global development (Hokanson, 2000). A 
study of the relationship between global learning and second language acquisition in DFLI or other foreign language programs could lead to better practices in foreign language programs.

\section{Conclusion}

The purpose of the study was to investigate the role of DFLI programs in fostering global learning outcomes. Students today need to have an understanding of global issues and the knowledge and skills to live successful and useful lives. Educators are more interested than ever in finding ways to provide global learning opportunities for students, as they recognize that the world is becoming more interconnected and interdependent. However, there is a disconnect between educators' intentions and the means with which to provide those learning opportunities, as impacts of programs are not always clear. Musil (2006) argues that colleges and universities need to design well-defined and multiple pathways for students to acquire global learning. To clearly establish those pathways, it is important to understand the impacts of the programs that make up those pathways.

DFLI is one program along the pathway to global learning. Unfortunately, a lack of research on the impacts of DFLI has made it difficult to include these programs in a meaningful way in the palette of university global learning programs. These programs are held in esteem by students and educators, but so far, there has only been indirect evidence from short-term study abroad and anecdotes that give clues to how these programs foster global learning. This study provided more tangible evidence of global program impact. 
Braskamp (1989) describes an effective institution as one that emphasizes both the individual and the institution. This study considered both of these emphases. Research on the global learning impacts of domestic foreign language supports university global learning goals and provides impetus to give more consideration to these programs as universities consolidate efforts to create global learning opportunities for the benefit of students as well as the institution. 


\section{List of References}

Akande, Y., \& Slawson, C. (2000). Exploring the long-term impact of study abroad: A case study of 50 years of study abroad alumni. International Educator, 9(3) $12-17$

American Council for the Teaching of Foreign Languages. (1985). ACTFL proficiency guidelines. Hastings-on-Hudson, NY: ACTFL Materials Center.

American Council for the Teaching of Foreign Languages. (n.d.). Oral proficiency interview. Retrieved from http://www.actfl.org/professional-development /certified-proficiency-testing-program/testing-proficiency?pageid=3348

American Council on Education. (1998). Educating for global competence: America's passport to the future. Retrieved from EBSCOhost. Retrieved from http://www.eric.ed.gov/ERICWebPortal/search/detailmini.jsp?_nfpb=true\&_\& ERICExtSearch_SearchValue_0=ED421940\&ERICExtSearch_SearchType_0 $=$ no\&accno $=$ ED421940

Anderson, J. L., Levis-Fitzgerald, M. R., \& Rhoads, R. A. (2003). Democratic learning and global citizenship: The contribution of one-unit seminars. Journal of General Education, 52, 84-107.

Astin, A.W. (1993). Assessment for excellence: The philosophy and practice of assessment and evaluation in higher education. Phoenix, AZ: Oryx.

Baxter Magolda, M.B. (1992). Knowing and reasoning in college: Gender-related patterns in students' intellectual development. San Francisco, CA: JosseyBass. 
Beckett, M., Da Vanzo, J., Sastry, N., Panis, \& Peterson, C. (2001). The quality of retrospective data: An examination of long-term recall in a developing country. The Journal of Human Resources, 36, 593-625.

Bhanji, Z. (2008). Transnational corporations in education: filling the governance gap through new social norms and market multilateralism? Globalisation, Societies \& Education, 6, 55-73.

Braskamp, L. (1989). So, what's the use? New Directions for Higher Education, 67, 43-50.

Braskamp, L., Braskamp D., \& Merrill, K. (2009). Assessing progress in global learning and development of students with education abroad experiences. Frontiers: The Interdisciplinary Journal of Study Abroad, 18, 101-118.

Braskamp, L., Braskamp, D., Merrill, K., \& Engberg, M. (2010). Global Perspective Inventory (GPI). Retrieved from https://gpi.central.edu

Brecht, R., Davidson, D., \& Ginsberg, R. (1993). Predictors of language gain in study abroad. Washington, DC: National Foreign Language Center.

Buttaro, L., \& King, K.P. (2001). Listening to our adult ESL learners: Hispanic women's seldom heard voices. Adult Basic Education: An Interdisciplinary Journal for Adult Literacy Educators, 11, 40-60.

Byram, K., \& Kramsch, C. (2008). Why is it so difficult to teach language as culture? The German Quarterly, 81, 20-34. 
Carter, D., Latz, G., \& Thornton, P. (2010). Through a new lense: Assessing international learning at Portland State University. The Journal of General Education, 59, 172-181.

Center for Applied Linguistics. (2006). Directory of foreign language immersion programs in U.S. schools. Retrieved from http://www.cal.org/resources /immersion/

Chieffo, L., \& Griffiths, L. (2004). Large-scale assessment of student attitudes after a short-term study abroad program. Frontiers: The Interdisciplinary Journal of Study Abroad, 10, 165-177.

Chickering, A., \& Braskamp, L. (2009). Developing a global perspective for personal and social responsibility. PeerReview, 11, 27-30.

Cowles, M., \& Wiedemann, L. (2008). The impact of target country vs. home country immersion programs on intermediate L2 learners. Connections, 2, 1-15.

Cranton, P. (2006). Fostering authentic relationships in the transformative classroom. In E. Taylor (Ed.), Teaching for change: Fostering transformative learning in the classroom, (pp. 5-14). San Francisco, CA: Jossey-Bass.

Creswell, J.W., \& Plano Clark, V.L. (2007). Designing and conducting mixed methods research. Thousand Oaks, CA: Sage.

Daloz, L. (2000). Transformative learning for the common good. In J. Mezirow, (Ed.), Learning as transformation (pp. 103-124). San Francisco, CA: JosseyBass. 
Davis-Manigaulte, J., Yorks L., \& Kasl, E. (2006). Expressive ways of knowing and transformative learning. In E. Taylor (Ed.), Teaching for change: Fostering transformative learning in the classroom (pp. 27-36). San Francisco, CA: Jossey-Bass.

Deardorff, C. (2009). Understanding the challenges of assessing global citizenship. In R. Lewin (Ed.), The handbook of practice and research in study abroad: Higher education and the quest for global citizenship (pp. 346-364). New York, NY: Routledge.

Die Deutsche Sommerschule am Pazifik. (n.d.).Retrieved from http://www.pdx.edu /wll/dsap

Dolby, N. (2008). Global citizenship and study abroad: A comparative study of American and Australian Undergraduates. Frontiers: The Interdisciplinary Journal of Study Abroad, 17, 51-67.

Donnelly-Smith, L. (2009). Global learning through short-term study abroad. PeerReview, 11, 12-15.

Dörnyei, Z. (2003). Questionnaires in second language research: Construction, administration, and processing. London, England: Lawrence Erlbaum.

Dwyer, M.M. (2004). More is better: The impact of study abroad duration. Frontiers: The Interdisciplinary Journal of Study Abroad, 10, 157-185.

Engle, L., \& Engle, J. (2003). Assessing language acquisition and intercultural sensitivity development in relation to study abroad program design. Frontiers: The Interdisciplinary Journal of Study Abroad, 10, 219-236. 
Foster, E. (1997). Transformative learning in adult second language learning. New Directions for Adult and Continuing Education, 74, 33-40.

Fowler, F.J. (1995). Improving survey questions: Design and evaluation. Thousand Oaks, CA: Sage.

Freedman, K. (1998). Culture in curriculum: Internationalizing learning by design. In J. Mestenhauser, B. Mestenhauser \& B. Ellingboe (Eds.), Reforming the higher education curriculum: Internationalizing the campus (pp. 40-52). Phoenix, AZ:Oryx Press.

Fry, G. W., \& Jon, J. (2009). Study abroad for global engagement: A study of longterm impact. Paper presented at the annual meeting of the 53rd Annual Conference of the Comparative and International Education Society, Charleston, SC.

Giddens, A. (1992). The consequences of modernity. Cambridge, MA: Polty Press. Gilligan, C. (1982). In a different voice. Cambridge, MA: Harvard University Press. Gladwell, M. (2000). The tipping point. New York, NY: Little Brown.

Goulah, J. (2007). Village voices, global visions: Digital video as a transformative foreign language learning tool. Foreign Language Annals, 40, 62-78.

Green, J.C., Caracelli, V.J., \& Graham, W.F. (1989). Toward a conceptual framework for mixed-method evaluation designs. Educational Evaluation and Policy Analysis, 11, 255-274.

Griner Hill, L., \& Betz, D.L. (2005) Revisiting the retrospective pretest. American Journal of Evaluation, 26, 501-516. 
Hadis, B. (2005). Gauging the impact of study abroad: How to overcome the limitations of a single-cell design. Assessment \& Evaluation in Higher Education, 30, 3-19.

Hamilton, H., Crane, C., \& Bartoshesky, A. (2007). Doing foreign language: Bringing Concordia Language Villages into language classrooms. Upper Saddle River, NJ: Pearson Education.

Hendershot, K. (2010). Transformative learning and global citizen identity development in undergraduates: A case study. Retrieved from ProQuest LLC (UMI No. 3389956)

Hokanson, S. (2000). Foreign language immersion homestays: Maximizing the accommodation of cognitive styles. Applied Language Learning, 11, 239-264.

Hovland, K. (2009). Global learning: What is it? Who is responsible for it? PeerReview, 11, 4-7.

Institute of International Education. (2006). Study abroad duration during select years. Retrieved from http://opendoors.iienetwork.org/?p=89222

Institute of International Education. (2006). Open doors report 2006. Retrieved from http://opendoors.iienetwork.org/

Institute of International Education. (2008). Open doors report 2008. Retrieved from http://opendoors.iienetwork.org/

Jiang, N. (1999). Lexical representation in immersion foreign language learners: Evidence from masked translation priming. Paper presented at Middlebury College, Middlebury, VT. 
Johnson, S., \& Nelson, B. (2010). Above and beyond the syllabus: Transformation in an adult, foreign language classroom. Language Awareness, 19, 35-50.

Kehl, K., \& Morris, J. (2007). Differences in global-mindedness between short-term and semester-long study abroad participants at selected private universities. Frontiers: The Interdisciplinary Journal of Study Abroad, 15, 67-79.

King, K. P. (2000). The adult ESL experience: Facilitating perspective transformation in the classroom. Adult Basic Education, 10, 69-89.

Lewis, T.L., \& Niesenbaum, R.A. (2005). The benefits of short-term study abroad programs. The Chronicle of Higher Education, 51/39. Retrieved from: http://find.galegroup.com.proxy.lib.pdx.edu/gtx.start.do? prodId= AONE\& userGroupName=s 1185784

Liskin-Gasparro, J. (1998). Linguistic development in an immersion context: How advanced learners of Spanish perceive SLA. The Modern Language Journal, $82,159-174$.

Maxwell, J.A. (2005). Qualitative research design: An interactive approach. Thousand Oaks, CA: Sage.

Medina-Lopez-Portillo, A. (2004). Intercultural learning assessment: The link between program duration and intercultural sensitivity. Frontiers: The Interdisciplinary Journal of Study Abroad, 10, 179-199.

Merriam, S., \& Cafarella, R. (1999). Learning in adulthood: A comprehensive guide. San Francisco, CA: Jossey-Bass.

Mezirow, J. (2000). Learning as transformation. San Francisco, CA: Jossey-Bass. 
Middlebury Language Schools. (2010). Retrieved from http://www.middlebury.edu /1s/approach/

Miles, M.B., \& Huberman, A.M. (1984). Qualitative data analysis. Beverly Hills, CA: Sage

Modern Language Association. (2007). Foreign languages and higher education: New structures for a changed world. Retrieved from http://www.mla.org/flreport

Mohajeri Norris, E., \& Gillespie, J. (2009). How study abroad shapes global careers: Evidence from the United States. Journal of Studies in International Education, 13, 382-397.

Musil, C. (2006). Assessing global learning: Matching good intentions with good practice. Washington, DC : Association of American Colleges and Universities.

Olson, C., Green, M.F., \& Hill, B.A. (2006). A handbook for advancing comprehensive internationalization: What institutions can do and what students should learn. Washington, DC: American Council on Education.

Oral Proficiency Interview. (n.d.). Retrieved from http://www.actfl.org/i4a/pages /index.cfm?pageid $=3348$

O'Sullivan, E. (1999). Transformative learning: Educational vision for the $21^{\text {st }}$ century. Toronto, Canada: University of Toronto Press.

Paige R.M., Cohen, A.D., Kappler, B., Chi, J. and Lassegard, J. (2006). Maximizing study abroad: A students' guide to strategies for language and culture learning 
and use. (2nd ed.). Minneapolis, MN: University of Minnesota, Center for Advanced Research on Language Acquisition (CARLA).

Parsons, R. (2010). The effects of an internationalized university experience on domestic students in the United States and Australia. Journal of Studies in International Education, 14, 313-334.

Perry, W.P., Jr. (1981). Cognitive and ethical growth: The making of meaning. In A.W. Chickering and Associates (Eds.), The modern American college, (pp. 76-116). San Francisco, CA: Jossey-Bass.

Pilling-Cormick, J. (1997). Transformative self-directed learning in practice. New Directions for Adult and Continuing Education, 1997(74), 69-77.

Postrel, V. (2006, March 23). The container that changed the world. The New York Times. Retrieved from http://www.nytimes.com/2006/03/23/business /23scene.html

Rifkin, B. (2005a). The ceiling effect in traditional-classroom foreign language learning. Modern Language Journal, 89, 3-18.

Rifkin, B. (2005b). Summer language study: Middlebury or study abroad. Retrieved from http://www.middlebury.edu/media/view/44861/original/Rifkin_On_ Language.pdf

Russo, G. A. (1997). A study of metaphorical competence of Anglophone learners of Italian at Middlebury College. (Unpublished doctoral dissertation). Dartmouth College, Hanover, NH. 
Saldana, J. (2009). The coding manual for qualitative researchers. Los Angeles, CA: Sage.

Shames, W., \& Alden, P. (2005). The impact of short-term study abroad on the identity development of college students with learning disabilities and/or AD/HD. Frontiers: The Interdisciplinary Journal of Study Abroad, 11, 1-31.

Small, S., \& Supple, A. (2001). Communities as systems: Is a community more than the sum of its parts? In A. Booth \& A.C. Crouter (Eds.), Does it take a village? Community effects on children, adolescents, and families (pp. 161-174). Mahwah, NJ: Erlbaum.

Smallman, S., \& Brown, K. (2011). Introduction to international and global studies. Chapel Hill, NC: University of North Carolina Press.

Sobania, N., \& Braskamp, L. (2009). Study abroad or study away: It's not merely semantics. PeerReview, 11, 23-26.

Spielmann, G., \& Radnofsky, M.L. (2001). Learning language under tension: New directions from a qualitative study. Modern Language Journal, 85, 259-278.

Steger, M. (2005). Ideologies of globalization. Journal of Political Ideologies, 10, 11 30.

Steger, M. (2009). Globalization: a very short introduction ( $2^{\text {nd }}$ ed.). Oxford, England: Oxford University Press.

Steinberg, M. (2007). The place of outcomes assessment in higher education today and the implications for education abroad. In M. C. Bolen (Ed.), A guide to 
outcomes assessment in education abroad (pp.7-22). Carlisle, PA: Forum on Education Abroad.

Taylor, E. (Ed.). (2006). Teaching for change: Fostering transformative learning in the classroom. San Francisco, CA: Jossey-Bass.

Teddlie, C., \& Tashakkori, A. (2003). Major issues and controversies in the use of mixed methods in the social and behavioral sciences. In A. Tashakkori \& C. Teddlie (Eds.), Handbook of mixed methods in social \& behavioral research (pp. 3-50). Thousand Oaks, CA: Sage.

United Nations Department of Economic and Social Affairs/Population Division. (2004). World population prospects: The 2004 revision, volume III: Analytical report. Retrieved from http://www.un.org/esa/population/publications /WPP2004/ WPP2004_Vol3_Final/Chapter5.pdf

University of Arizona International Affairs. (n.d.) Arizona study abroad in Leipzig. Retrieved from http://global.arizona.edu/study-abroad/program/arizonasummer-study-leipzig

University of Minnesota Study Abroad for Global Engagement. (2006). Retrieved from http://www.cehd.umn.edu/ projects/SAGE/

University of Oregon Global Scholars Hall. (2013). Retrieved from http://globalscholars. uoregon.edu/

Wang, C. (2010). Toward a second language socialization perspective: Issues in study abroad research. Foreign Language Annals, 43, 50-63. 


\section{Appendix A}

\section{DFLI Program: Global Learning Survey}

Q1 INSTRUCTIONS: As you think back to your experiences with the DFLI Program and your current perspective on the topics mentioned in the survey, please respond to the survey items below. There is no time limit, but try to respond to each statement as quickly as possible. There are no right or wrong answers, only responses that are right for you. Thank you for your cooperation!

Q2 When I notice cultural differences, my culture tends to have the better approach.

O Strongly Agree (1)

O Agree (2)

O Neutral (3)

O Disagree (4)

Strongly disagree (5)

Q3 My response to the above question was influenced by my participation in the DFLI Program:

To a strong degree (1)

To some degree (2)

Very little (3)

Not at all (4)

Q4 I can explain my personal values to people who are different from me.

O Strongly Agree (1)

O Agree (2)

O Neutral (3)

O Disagree (4)

Strongly disagree (5)

Q5 My response to the above question was influenced by my participation in the DFLI Program:

To a strong degree (1)

To some degree (2)

O Very little (3)

Not at all (4)

Q6 Most of my friends are from my own ethnic background.

O Strongly Agree (1)

Agree (2)

O Neutral (3) 
Disagree (4)

O Strongly Disagree (5)

Q7 My response to the above question was influenced by my participation in the DFLI Program:

To a strong degree (1)

To some degree (2)

O Very little (3)

O Not at all (4)

Q8 I think of my life in terms of giving back to society.

O Strongly Agree (1)

Agree (2)

O Neutral (3)

Disagree (4)

Strongly Agree (5)

Q9 My response to the above question was influenced by my participation in the DFLI Program:

To a strong degree (1)

To some degree (2)

O Very little (3)

Not at all (4)

Q10 Some people have a culture and others do not.

O Strongly Agree (1)

Agree (2)

O Neutral (3)

O Disagree (4)

Strongly Disagree (5)

Q11 My response to the above question was influenced by my participation in the DFLI Program:

To a strong degree (1)

To some degree (2)

O Very little (3)

O Not at all (4)

Q12 In different settings what is right and wrong is simple to determine.

O Strongly Agree (1)

O Agree (2)

O Neutral (3) 
Disagree (4)

Strongly Disagree (5)

Q13 My response to the above question was influenced by my participation in the DFLI Program:

To a strong degree (1)

To some degree (2)

O Very little (3)

O Not at all (4)

Q14 I am informed of current issues that impact international relations.

O Strongly Agree (1)

Agree (2)

O Neutral (3)

Disagree (4)

Strongly Disagree (5)

Q15 My response to the above question was influenced by my participation in the DFLI Program:

To a strong degree (1)

To some degree (2)

O Very little (3)

Not at all (4)

Q16 I know who I am as a person.

O Strongly Agree (1)

Agree (2)

O Neutral (3)

O Disagree (4)

Strongly Disagree (5)

Q17 My response to the above question was influenced by my participation in the DFLI Program:

To a strong degree (1)

To some degree (2)

O Very little (3)

Not at all (4)

Q18 I feel threatened around people from backgrounds very different from my own. O Strongly Agree (1)

Agree (2)

O Neutral (3) 
Disagree (4)

O Strongly Disagree (5)

Q19 My response to the above question was influenced by my participation in the DFLI Program:

To a strong degree (1)

O To some degree (2)

V Very little (3)

O Not at all (4)

Q20 I often get out of my comfort zone to better understand myself.

O Strongly Agree (1)

Agree (2)

O Neutral (3)

Disagree (4)

Strongly Disagree (5)

Q21 My response to the above question was influenced by my participation in the DFLI Program:

To a strong degree (1)

To some degree (2)

O Very little (3)

Not at all (4)

Q22 I am willing to defend my own views when they differ from others.

O Strongly Agree (1)

Agree (2)

O Neutral (3)

O Disagree (4)

Strongly Disagree (5)

Q23 My response to the above question was influenced by my participation in the DFLI Program:

To a strong degree (1)

To some degree (2)

O Very little (3)

O Not at all (4)

Q24 I understand the reasons and causes of conflict among nations of different cultures.

O Strongly Agree (1)

Agree (2)

O Neutral (3) 
Disagree (4)

Strongly Disagree (5)

Q25 My response to the above question was influenced by my participation in the DFLI Program:

To a strong degree (1)

O To some degree (2)

V Very little (3)

O Not at all (4)

Q26 I am confident that I can take care of myself in a completely new situation.

O Strongly Agree (1)

Agree (2)

O Neutral (3)

Disagree (4)

Strongly Disagree (5)

Q27 My response to the above question was influenced by my participation in the DFLI Program:

To a strong degree (1)

To some degree (2)

O Very little (3)

Not at all (4)

Q28 People from other cultures tell me that I am successful at navigating their cultures.

O Strongly Agree (1)

Agree (2)

O Neutral (3)

O Disagree (4)

Strongly Disagree (5)

Q29 My response to the above question was influenced by my participation in the DFLI Program:

O To a strong degree (1)

To some degree (2)

V Very little (3)

O Not at all (4)

Q30 I work for the rights of others.

O Strongly Agree (1)

O Agree (2)

O Neutral (3) 
Disagree (4)

O Strongly Disagree (5)

Q31 My response to the above question was influenced by my participation in the DFLI Program:

To a strong degree (1)

To some degree (2)

V Very little (3)

O Not at all (4)

Q32 I see myself as a global citizen.

O Strongly Agree (1)

Agree (2)

O Neutral (3)

Disagree (4)

Strongly Disagree (5)

Q33 My response to the above question was influenced by my participation in the DFLI Program:

To a strong degree (1)

To some degree (2)

O Very little (3)

Not at all (4)

Q34 I take into account different perspectives before drawing conclusions about the world around me.

Strongly Agree (1)

O Agree (2)

O Neutral (3)

Disagree (4)

O Strongly Disagree (5)

Q35 My response to the above question was influenced by my participation in the DFLI Program:

To a strong degree (1)

O To some degree (2)

V Very little (3)

O Not at all (4)

Q36 I understand how various cultures of this world interact socially.

O Strongly Agree (1)

Agree (2) 
O Neutral (3)

O Disagree (4)

Strongly Disagree (5)

Q37 My response to the above question was influenced by my participation in the DFLI Program:

To a strong degree (1)

To some degree (2)

V Very little (3)

O Not at all (4)

Q38 I get offended often by people who do not understand my point-of-view.

O Strongly Agree (1)

Agree (2)

O Neutral (3)

O Disagree (4)

O Strongly Disagree (5)

Q39 My response to the above question was influenced by my participation in the DFLI Program:

To a strong degree (1)

To some degree (2)

Very little (3)

Not at all (4)

Q40 I am able to take on various roles as appropriate in different cultural and ethnic settings.

Strongly Agree (1)

O Agree (2)

Neutral (3)

Disagree (4)

Strongly Disagree (5)

Q41 My response to the above question was influenced by my participation in the DFLI Program:

To a strong degree (1)

To some degree (2)

Very little (3)

Not at all (4)

Q42 I put my beliefs into action by standing up for my principles.

Strongly Agree (1) 
Agree (2)

O Neutral (3)

O Disagree (4)

O Strongly Disagree (5)

Q43 My response to the above question was influenced by my participation in the DFLI Program:

To a strong degree (1)

O To some degree (2)

Very little (3)

O Not at all (4)

Q44 I consider different cultural perspectives when evaluating global problems.

O Strongly Agree (1)

Agree (2)

O Neutral (3)

Disagree (4)

Strongly Disagree (5)

Q45 My response to the above question was influenced by my participation in the DFLI Program:

To a strong degree (1)

To some degree (2)

O Very little (3)

Not at all (4)

Q46 I rely primarily on authorities to determine what is true in the world.

O Strongly Agree (1)

Agree (2)

O Neutral (3)

O Disagree (4)

Strongly Disagree (5)

Q47 My response to the above question was influenced by my participation in the DFLI Program:

To a strong degree (1)

O To some degree (2)

O Very little (3)

Not at all (4)

Q48 I know how to analyze the basic characteristics of a culture.

O Strongly Agree (1) 
Agree (2)

O Neutral (3)

Disagree (4)

O Strongly Disagree (5)

Q49 My response to the above question was influenced by my participation in the DFLI Program:

To a strong degree (1)

To some degree (2)

Very little (3)

O Not at all (4)

Q50 I am sensitive to those who are discriminated against.

O Strongly Agree (1)

Agree (2)

O Neutral (3)

Disagree (4)

Strongly Disagree (5)

Q51 My response to the above question was influenced by my participation in the DFLI Program:

To a strong degree (1)

To some degree (2)

O Very little (3)

Not at all (4)

Q52 I do not feel threatened emotionally when presented with multiple perspectives.

O Strongly Agree (1)

Agree (2)

O Neutral (3)

O Disagree (4)

Strongly Disagree (5)

Q53 My response to the above question was influenced by my participation in the DFLI Program:

To a strong degree (1)

O To some degree (2)

O Very little (3)

Not at all (4)

Q54 I prefer to work with people who have different cultural values from me.

O Strongly Agree (1) 
Agree (2)

O Neutral (3)

Disagree (4)

O Strongly Disagree (5)

Q55 My response to the above question was influenced by my participation in the DFLI Program:

To a strong degree (1)

O To some degree (2)

Very little (3)

O Not at all (4)

Q56 I am accepting of people with different religious and spiritual traditions.

O Strongly Agree (1)

Agree (2)

O Neutral (3)

Disagree (4)

Strongly Disagree (5)

Q57 My response to the above question was influenced by my participation in the DFLI Program:

To a strong degree (1)

To some degree (2)

O Very little (3)

Not at all (4)

Q58 Cultural differences make me question what is really true.

O Strongly Agree (1)

Agree (2)

O Neutral (3)

O Disagree (4)

Strongly Disagree (5)

Q59 My response to the above question was influenced by my participation in the DFLI Program:

To a strong degree (1)

O To some degree (2)

O Very little (3)

Not at all (4)

Q60 I put the needs of others above my own personal wants.

O Strongly agree (1) 
Agree (2)

O Neutral (3)

O Disagree (4)

O Strongly Disagree (5)

Q61 My response to the above question was influenced by my participation in the DFLI Program:

To a strong degree (1)

To some degree (2)

Very little (3)

O Not at all (4)

Q62 I can discuss cultural differences from an informed perspective.

O Strongly Agree (1)

Agree (2)

O Neutral (3)

Disagree (4)

Strongly Disagree (5)

Q63 My response to the above question was influenced by my participation in the DFLI Program:

To a strong degree (1)

To some degree (2)

O Very little (3)

Not at all (4)

Q64 I am developing a meaningful philosophy of life.

O Strongly Agree (1)

Agree (2)

O Neutral (3)

O Disagree (4)

Strongly Disagree (5)

Q65 My response to the above question was influenced by my participation in the DFLI Program:

To a strong degree (1)

To some degree (2)

Very little (3)

Not at all (4)

Q66 I intentionally involve people from many cultural backgrounds in my life. O Strongly Agree (1) 
Agree (2)

O Neutral (3)

Disagree (4)

O Strongly Disagree (5)

Q67 My response to the above question was influenced by my participation in the DFLI Program:

To a strong degree (1)

O To some degree (2)

Very little (3)

O Not at all (4)

Q68 I rarely question what I have been taught about the world around me.

O Strongly Agree (1)

Agree (2)

O Neutral (3)

Disagree (4)

Strongly Disagree (5)

Q69 My response to the above question was influenced by my participation in the DFLI Program:

To a strong degree (1)

To some degree (2)

O Very little (3)

Not at all (4)

Q70 I constantly need affirmative confirmation about myself from others.

O Strongly Agree (1)

Agree (2)

O Neutral (3)

O Disagree (4)

Strongly Disagree (5)

Q71 My response to the above question was influenced by my participation in the DFLI Program:

To a strong degree (1)

O To some degree (2)

O Very little (3)

Not at all (4)

Q72 I enjoy when my friends from other cultures teach me about our cultural differences. O Strongly Agree (1) 
Agree (2)

O Neutral (3)

Disagree (4)

O Strongly Disagree (5)

Q73 My response to the above question was influenced by my participation in the DFLI Program:

To a strong degree (1)

O To some degree (2)

Very little (3)

Not at all (4)

Q74 I consciously behave in terms of making a difference.

O Strongly Agree (1)

Agree (2)

O Neutral (3)

Disagree (4)

Strongly Disagree (5)

Q75 My response to the above question was influenced by my participation in the DFLI Program:

To a strong degree (1)

To some degree (2)

O Very little (3)

Not at all (4)

Q76 I am open to people who strive to live lives very different from my own life style.

O Strongly Agree (1)

Agree (2)

Neutral (3)

O Disagree (4)

Strongly Disagree (5)

Q77 My response to the above question was influenced by my participation in the DFLI Program:

To a strong degree (1)

To some degree (2)

O Very little (3)

Not at all (4)

Q78 Volunteering is not an important priority in my life.

O Strongly Agree (1) 
Agree (2)

O Neutral (3)

Disagree (4)

O Strongly Disagree (5)

Q79 My response to the above question was influenced by my participation in the DFLI Program:

To a strong degree (1)

To some degree (2)

Very little (3)

O Not at all (4)

Q80 Please describe an experience you had in the DFLI Program that was memorable to you:

Q81 What is your current age?

O 16 to 19 (1)

O 20 to 24 (2)

O 25 to 34 (3)

O $35-44$ (4)

O $45-54(5)$

O 55-64 (6)

O 65 or over (7)

Q82 What is your gender?

O Male (1)

Female (2)

Q83 Are you an international student or foreign national?

Y Yes (1)

No (2)

Q84 Did you participate in a study abroad program with a foreign language component BEFORE your participation in the DFLI Program?

Y Yes (1)

No (2)

Q85 How long did you study abroad?

O Under 3 months (1)

O Between 3 and 6 months (2)

Over 6 months and under 12 months (3)

O 12 months or more (4) 
Q86 Did you live abroad BEFORE your participation in the DFLI Program?

O Yes (1)

No (2)

Q87 How long did you live abroad?

Between 3 and 6 months (1)

Over 6 months and under 12 months (2)

O 12 months to 24 months (3)

O Over 24 months (4)

Q88 Did you have other significant intercultural experience in the U.S. BEFORE your participation in the DFLI Program?

Y Yes (1)

No (2)

Q89 Please describe this experience briefly.

Q90 How long did this experience last?

O Under 3 months (1)

O 3 months to 6 months (2)

O Over 6 months to 12 months (3)

O Over 12 months (4)

Q91 Did you participate in a study abroad program with a language component AFTER your participation in the DFLI Program?

Yes (1)

No (2)

Q92 How long did you study abroad after your participation in the DFLI Program?

under 3 months (1)

$O$ between 3 and 6 months (2)

over 6 months and under 12 months (3)

O 12 months or more (4)

Q93 Did you live abroad AFTER your participation in the DFLI Program?

Y Yes (1)

No (2)

Q94 How long did you live abroad after your participation in the DFLI Program

O under 3 months (1)

between 3 and 6 months (2)

over 6 months and under 12 months (3) 
12 months or more (4)

Q95 Did you participate in an other significant intercultural experience AFTER your participation in the DFLI Program?

Y Yes (1)

No (2)

Q96 Please describe this experience briefly.

Q97 How long did this experience last?

O under 3 months (1)

between 3 and 6 months (2)

over 6 months and under 12 months (3)

O 12 months or more (4)

Thank you for your participation in this survey! 


\section{Appendix B}

\section{Advance Email}

You are receiving this email to let you know of an upcoming survey of DFLI alumni. You will receive an invitation to the survey at the beginning of 2012.

For some time now, we have been interested in determining the types of learning that take place at the DFLI, and we hope that you will be willing to participate in our survey project. The results of the survey should help us to improve the DFLI and also help us to better advocate for our program among external stakeholders.

If your contact information has changed, we would appreciate an update from you. Also, if you know of any other former DFLI students who would appreciate hearing from us, please pass this email on to them with the message to contact us.

Thanks for your continuing support of the Sommerschule.

Best wishes to you in your current endeavors! 


\section{Email Invitation}

\section{DFLI: Global Learning Survey}

Dear Former Student of the DFLI:

I am asking you to take fifteen minutes to complete a survey that will tell us your views and experiences and how your participation in the DFLI program influenced you. Your answers are crucial to our efforts to improve the DFLI program for students, therefore your participation in the survey is greatly appreciated.

Please be assured that your answers are completely confidential. Any information that is obtained in connection with this study that can be linked to you or identify you will be confidential. The answers you provide will be summarized along with the responses of other students so that your individual responses will never be identified in any report.

Your participation is entirely voluntary and you are free to stop responding at any time. Your willingness or unwillingness to participate will not affect decisions involving your relationship with Portland State University.

If you have concerns about your participation in this study, please contact the Chair of the Human Subjects Research Review Committee, Office of Research and Sponsored Projects, 600 Unitus Building, (503) 725-4288, hsrrc@pdx.edu. If you have questions about the study itself, please contact me at 503 725-5294 or at godfreyk@pdx.edu

Thank you for telling us about your experience with the DFLI program and helping us to improve the program.

Sincerely,

Assistant Director

DFLI

DFLI: Global Learning Survey

Follow this link to the Survey:

$\$\{1: / /$ SurveyLink?d=Take the Survey $\}$

Or copy and paste the URL below into your internet browser:

$\$\{1: / /$ SurveyURL $\}$

Follow the link to opt out of future emails:

$\$\{1: / / O p t O u t L i n k ? d=$ Click here to unsubscribe $\}$ 


\section{Follow-Up Reminder}

Dear Former Student of the DFLI:

A short time ago, I invited you to answer some questions to complete a survey that will tell us your perspectives and experiences and how these were influenced by your participation in the DFLI program. Your answers to these questions are crucial to our efforts to improve student experiences at the DFLI program, and I hope you will take the 15 minutes required to complete the survey.

Please be assured that your answers are completely confidential. Any information that is obtained in connection with this study that can be linked to you or identify you will be confidential. The answers you provide will be summarized along with the responses of other students so that your individual responses will never be identified in any report.

Although your participation is entirely voluntary, I hope you will complete the survey. Your willingness or unwillingness to participate will not affect decisions involving your relationship with Portland State University. You may choose not to participate and can withdraw at any time.

If you have concerns about your participation in this study, please contact the Chair of the Human Subjects Research Review Committee, Office of Research and Sponsored Projects, 600 Unitus Building, (503) 725-4288, hsrrc@pdx.edu. If you have questions about the study itself, please contact Kathie Godfrey at 503 725-5294 or at godfreyk@pdx.edu

Thank you for telling us about your experience with the DFLI program and helping us to improve the program.

Sincerely,

Assistant Director

DFLI

Follow this link to the Survey:

$\$\{1: / /$ SurveyLink?d=Take the Survey $\}$

Or copy and paste the URL below into your internet browser:

$\$\{1: / /$ SurveyURL $\}$

Follow the link to opt out of future emails:

$\$\{1: / /$ OptOutLink? $=$ Click here to unsubscribe $\}$ 